University of Rhode Island

DigitalCommons@URI

Open Access Master's Theses

2002

\title{
EFFECT OF CRYSTALLINE TO AMORPHOUS CONVERSIONS ON SOLUBILITY OF CEFUROXIME AXETIL
}

Tooba Murshedkav

University of Rhode Island

Follow this and additional works at: https://digitalcommons.uri.edu/theses

\section{Recommended Citation}

Murshedkav, Tooba, "EFFECT OF CRYSTALLINE TO AMORPHOUS CONVERSIONS ON SOLUBILITY OF CEFUROXIME AXETIL" (2002). Open Access Master's Theses. Paper 270.

https://digitalcommons.uri.edu/theses/270

This Thesis is brought to you for free and open access by DigitalCommons@URI. It has been accepted for inclusion in Open Access Master's Theses by an authorized administrator of DigitalCommons@URI. For more information, please contact digitalcommons-group@uri.edu. 
EFFECT OF CRYSTALLINE TO AMORPHOUS CONVERSIONS ON SOLUBILITY OF CEFUROXIME AXETIL

BY

TOOBA MURSHEDKAR

\begin{abstract}
A THESIS SUBMITTED IN PARTIAL FULFILLMENT OF THE REQUIREMENTS FOR THE DEGREE OF

MASTER OF SCIENCE

IN

PHARMACEUTICS
\end{abstract}

UNIVERSITY OF RHODE ISLAND

2002 
MASTER OF SCIENCE THESIS

OF

TOOBA MURSHEDKAR

APPROVED:

Thesis Committee

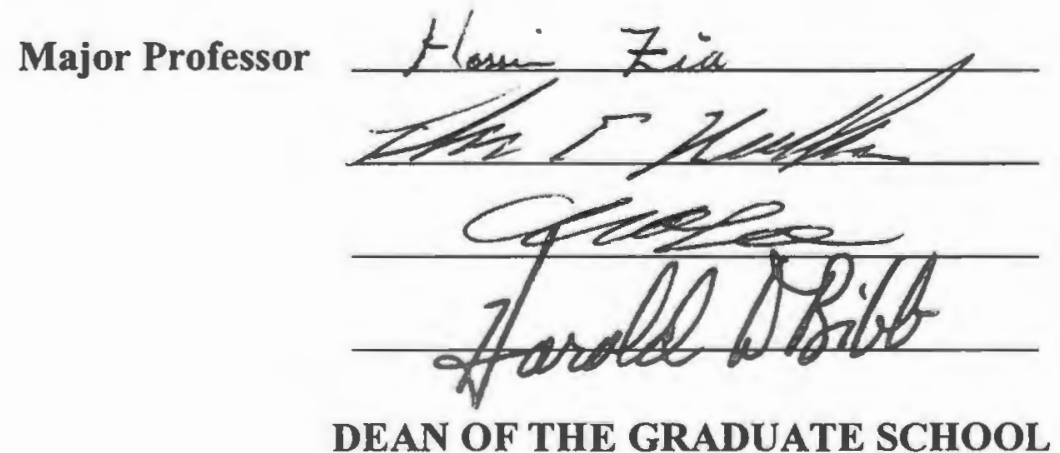

'UNIVERSITY OF RHODE ISLAND

2002 


\begin{abstract}
This study investigates a new method of converting a crystalline drug to its amorphous form and studying the effect this conversion has on the solubility of the drug. The physical form of the drug is of great importance in the process of taking a drug molecule from its discovery to its formulation into an acceptable dosage form. For oral solid dosage forms, the physical state of the drug molecule influences various important parameters including bioavailability and stability. Bioavailability in turn is governed by factors like dissolution and solubility, which can be altered to give desired results. A review of the various methods involved in solid state modifications is provided to enable the reader to comprehend the importance and extensive applications of these techniques in the field of preformulation and pharmaceutical dosage form development. This study uses a poorly water-soluble drug, cefuroxime axetil, and determines the effects the treatment processes have on its solubility. The processes differ in that one renders the drug totally amorphous while the other disrupts the crystalline structure to an extent where it is in a partially crystalline state. The varied purposes of polymers used in this study have also been investigated. Polymers have been used to enhance solubility, act as impurities in the crystal structure, and in solution as crystallization inhibitors. The results of this study show that appropriate processpolymer combinations can yield significant results for solubility enhancements.
\end{abstract}




\section{ACKNOWLEDGEMENTS}

I take this opportunity to express my sincere gratitude to my major advisor, Dr. Hossein Zia, whose inexhuastible energy has been a source of inspiration for me, throughout my years at URI. His support and efforts have made, what otherwise appeared to be a daunting task, an exciting process of learning. I thank him for being there whenever I needed him, for patiently answering every query, and for being that source of motivation I so earnestly needed. I have also to thank Dr. Thomas Needham, whose guidance through this entire project has been a valuable asset. His ideas and suggestions have helped refine the project and are an indispensible part of this work. I would also like to thank Dr. Chong Lee for his invaluable guidance, right from his course, through my project. Thank you for being a part of my committee. My sincere gratitude to Dr. Keykavous Parang for serving as Chair on my committee.

It is a pleasure for me to be able to thank my family-dad, mom, yusra, munnu and wadood, without your support I would not have been able to see myself as I do today. Daddy and Mummy - thank you for believing in me and for giving me this opportunity, that has helped me to learn and understand the value of every little thing you did for me. To Yusra - my sister and best friend, we are miles apart and yet so close. Some of my most cherished moments here were those that I shared with you, those hours long sisterly talk that we had and those advices that we always give each other. Munazzah and Wadood - the life of our family. Your crazy antics have always put a smile on our face and pulled us through some of 
the toughest times together. I want you all to know that I have always loved you and missed you every day that I have been here.

I would like to thank all my friends, Dipti, Rina, Sejal, Keyur, Niraj, Chandra, Vikas, Sekhar and Gautam, for making my stay here, like home away from home. Dipti-Keyur, Rina-Sekhar - I will always feel fortunate to have friends like you. Among other things, staying with you guys I learned to cook, which at one point in time, was unimaginable !!! Niraj - I don't know from where our friendship started, but it is something I will cherish for a long time to come. You helped me all those times when I didn't know what to do or what to say (and those were a lot of times). I owe you big time. Chandra, I have to thank you not only for helping me with my research, but for being a good friend. Your every honest opinion is appreciated. Vikas, thank you for providing those moments of relief that were so needed. I've enjoyed all the times we've spent together and all the smiles we've shared together. And then there was the time when I thought I would be all alone, and lo and behold - there was Sejal and Gautam. You've seen me through some of the hardest times, and all I can say is thank you. To all my friends - I enjoyed the times we spent together, the laughter and the tears we shared, the crazy trips that we planned together, and all the lovely food you guys treated me to!!!! Thank you for being there. 


\section{TABLE OF CONTENTS}

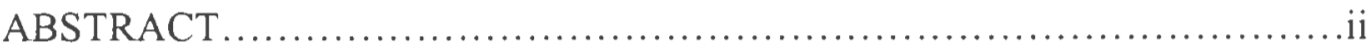

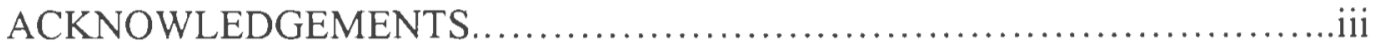

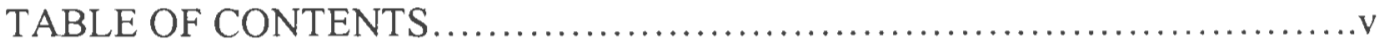

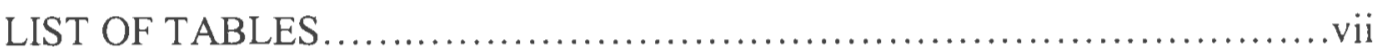

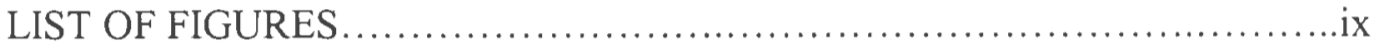

SECTION I: INTRODUCTION

1.1 Solid States....................................................

1.2 Characteristics and Significance of the Crystalline and Amorphous

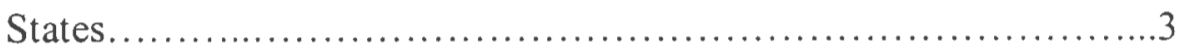

1.2.1 Crystalline Solids....................................4

1.2 .2 Amorphous Solids.........................................5

1.3 Solubilization by Solid-State Modification........................

1.3.1 Crystal Defects.........................................

1.3.2 Solid Dispersion and Solid Solutions.....................14

1.3.3 Polymoprhic Transformations.............................. 19

1.4 Solid-State Characterization...................................22

1.4.1 X-Ray Diffraction....................................22

1.4.2 Differential Scanning Calorimetry (DSC) .................23

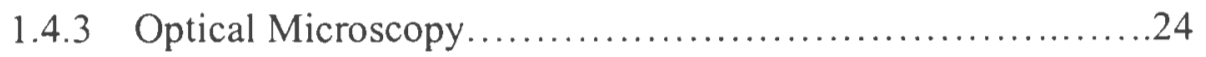

1.5 Cefuroxime Axetil.............................................

1.6 Objectives of the Study.....................................29 
1.7 References.

SECTION II: EXPERIMENTAL

2.1 Assay for Cefuroxime Axetil..................................42

2.2 Solubility Studies of Cefuroxime Axetil.........................49

2.3 Modification of Physical State...............................61

2.3.1 Selection of Polymers.............................61

2.3.2 Selection of Processes..............................63

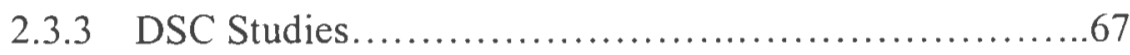

2.4 Results and Discussion.......................................67

2.4.1 Effect of crystalline to amorphous conversion on solubility of the drug in the absence of polymers..................75

2.4.2 Effect of crystalline to amorphous conversion on solubility of the drug in the presence of polymers................84

2.5 Statistical Analysis....................................... 100

2.6 Tablet Preparation and Dissolution Studies........................110

2.7 Results and Discussion.................................. 113

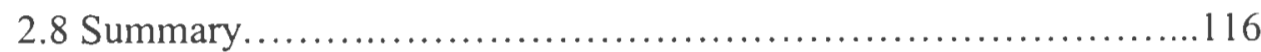

2.9 References................................................. 120

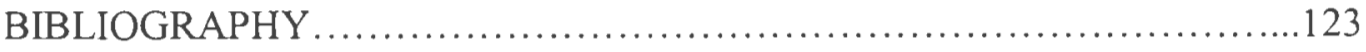




\section{LIST OF TABLES}

1. Approaches to improve the solubility or to increase the available surface area for dissolution.

2. Methods for the characterization of solid dispersions.

3. Data for calibration curve of cefuroxime axetil (USP reference standard).....46

4. Data for calibration curve of total concentration of cefuroxime axetil........50

5. Data for calibration curve of isomer A of the drug.........................51

6. Data for calibration curve of isomer B of the drug.......................52

7. Percentage of isomers $\mathrm{A}$ and $\mathrm{B}$ determined from the calibration data of total drug and the individual isomers....................................53

8. Reproducibility of cefuroxime axetil from standard solutions over 5 days of validation studies. 56

9. Determination of the percentage purity of cefuroxime axetil sample based on the USP refernce standard. .57

10. The combinations of drug-polymer-process that have been studied. .68

11. Heat of fusion $(\mathrm{J} / \mathrm{g})$ of isomer $A$ for the different process-polymer combinations (the remaining process-polymer combinations convert the isomer to its amorphous form).

12. Purity data of physical mixtures of cefuroxime axetil with polymers - PVP, Eudragit RD 100 and Eudragit EPO

13. Purity data of the microfluidized and recrystallized drug with the polymers PVP, Eudragit EPO and Eudragit RD 100. .92 
14. Yields for the different process-polymer combinations are shown (reported values are the average of three replicates)

15. List of factors and levels used in ANOVA analysis of effects on solubility 102

16. $3 \times 4$ (2-factor) full factorial design. 103

17. Data for each representative group of factors and response...... 104

18. ANOVA table summarizing the statistical analyses. 106

19. Formulations A and B for tablet preparation. 112

20. Data for the content uniformity of the tablets for formulations $A$ and B.....114

21. Data for the dissolution of tablets for formulations A and B... 118 


\section{LIST OF FIGURES}

1. Crystalline defects of various dimensionalities.

2. A schematic representation of the bioavailability enhancement of a poorly water-soluble drug by solid dispersion compared with conventional tablet or capsule..... 16

3. Phase diagram for a eutectic system................................... 16

4. Structural formulae of cefuroxime axetil and cefuroxime..................28

5. Chromatogram showing the peaks of isomers $\mathrm{B}$ and $\mathrm{A}$, eluting at $10.5 \mathrm{~min}$ and $11.6 \mathrm{~min}$

6. Representative calibration curve for cefuroxime axetil.

7. Representative calibration curves for the isomers $\mathrm{A}$ and $\mathrm{B}$ of cefuroxime axetil.

8. Representative calibration curve from the validation study for cefuroxime axetil. .54

9. Representative calibration curves for the isomers A and B from the validation study for cefuroxime axetil......................................... 55

10. Solubility profile of untreated cefuroxime axetil in water and $0.07 \mathrm{~N} \mathrm{HCl}$ (average of $n=3, \pm$ S.D.). .59

11. Solubility profile of cefuroxime axetil in water and $0.07 \mathrm{~N} \mathrm{HCl}$ (average of $\mathrm{n}=$ 3, \pm S.D.). .60

12. Picture of the M-110S Microfluidizer processor, Microfluidics Corp. 64 
13. Diagram showing the parts and dimensions of the M-110S Microfluidizer, Microfluidics Corp.................................................65

14. XRD scan of the USP reference standard of cefuroxime axetil...............70

15. XRD scan of the sample of cefuroxime axetil.............................71

16. DSC thermogram showing the presence of the two melting endotherms at 124 ${ }^{\circ} \mathrm{C}$ and $173^{\circ} \mathrm{C}$ (weight of sample $=10 \mathrm{mg}$, scanning rate $=10^{\circ} \mathrm{C} / \mathrm{min}$ ) $\ldots \ldots . .72$

17. The percentage of isomers $\mathrm{A}$ and $\mathrm{B}$, of the solid drug and the drug in solution [in $0.07 \mathrm{~N} \mathrm{HCl}(\mathrm{HCl})$ and water $(\mathrm{W})]$

18. The solubility profile of isomers $\mathrm{A}$ and $\mathrm{B}$ in water and $0.07 \mathrm{~N} \mathrm{HCl}$ .74

19. Solubility profile of untreated, microfluidized and recrystallized cefuroxime axetil (average of $n=3, \pm$ S.D.) .76

20. Percentage of cefuroxime axetil isomers A and B in solution for untreated, microfluidized and recrystallized drug (W:water, $\mathrm{HCl}: 0.07 \mathrm{~N} \mathrm{HCl}) \ldots \ldots \ldots . .78$

21. XRD scan of the untreated, microfluidized and recrystallized cefuroxime axetil (without polymers)

22. Optical microscopic image of cefuroxime axetil showing needle shaped crystals 82

23. Optical microscopic image of treated cefuroxime axetil showing loss of needle shaped crystals. 83

24. Solubility profile of cefuroxime axetil and its physical mixtures with PVP, Eudragit EPO and Eudragit RD100, in $0.07 \mathrm{~N} \mathrm{HCl}$. .85

25. Solubility profile of cefuroxime axetil and its physical mixtures with PVP, Eudragit EPO and Eudragit RD100, in water. .86 
26. XRD scan of the untreated drug and physical mixtures of the drug with polymers (A:untreated, B: CA + PVP, C: CA + Eudragit RD100, D: CA + Eudragit EPO).

27. Solubility profile of untreated and microfluidized cefuroxime axetil - with PVP, Eudragit EPO and Eudragit RD100 (average of $n=3, \pm$ S.D.)

28. Solubility profile of untreated and recrystallized cefuroxime axetil - with PVP, Eudragit EPO and Eudragit RD100 (average of $n=3, \pm$ S.D.)

29. Chromatogram showing the peaks of isomers B and A, eluting at $10.5 \mathrm{~min}$ and $11.6 \mathrm{~min}$ and the complex at $12.4 \mathrm{~min}$.

30. Solubility profile of the untreated drug and the physical mixture, microfluidized and recrystallized drug with PVP (average of $n=3, \pm$ S.D.)...94

31. Solubility profile of the untreated drug and the physical mixture, microfluidized and recrystallized drug with Eudragit EPO (average of $n=3$, \pm S.D.) .95

32. Solubility profile of the untreated drug and the physical mixture, microfluidized and recrystallized drug with Eudragit RD100 (average of $n=3$, \pm S.D.) 96

33. XRD scan of the untreated and recrystallized cefuroxime axetil with the polymers (A: untreated, B: CA + PVP, C: CA + Eudragit RD100, D: CA + Eudragit EPO)

34. XRD scan of the untreated and microfluidized cefuroxime axetil with the polymers (A: untreated, B: CA + PVP, C: CA + Eudragit RD100, D: CA + Eudragit EPO) 
35. Main effects plot for polymer and process

36. Interaction plot showing the effect of various process-polymer combinations on solubility. 108

37. Normal probability plot following an almost normal or linear distribution. 109

38. Dissolution profiles (in terms of concentration of cefuroxime axetil) of the tablets prepared from the untreated drug (Formulation A), drug-PVP mixture (Formulation B) and the marketed formulation (Ceftin). 115

39. Dissolution profiles (in terms of $\%$ dissolved of cefuroxime) of the tablets prepared from the untreated drug (Formulation A), drug-PVP mixture (Formulation B) and the marketed formulation (Ceftin).... 
SECTION I 


\section{Introduction}

\subsection{Solid States}

The existence of drugs and excipients in multiple physical forms (e.g. polymorphs, isomers) provides pharmaceutical scientists with an opportunity to select the preferred form(s) of the materials to be used in a formulation. This is very useful since critical properties, such as particle morphology and solubility, frequently vary between the different physical forms of a given active pharmaceutical ingredient (API) ${ }^{\prime}$. The amorphous form of pharmacologically active materials has received considerable attention because, in theory, this form represents the most energetic solid state of a material, and thus it should provide the biggest advantage in terms of solubility and bioavailability ${ }^{2}$. Differences in the physical properties of various solid forms have an important effect on the processing of API's into drug products ${ }^{3}$, while differences in solubility may have implications on the absorption of the active drug from its dosage form ${ }^{4}$, by affecting dissolution rate and possibly the mass transport of the molecules.

The most significant physical property of the solid state is the high degree of order in which substances (e.g. metals, minerals) usually exist. The structure may be crystalline and lattice-like or non-crystalline, such as in plastic, glass or gels, which are not lattice-like or only partly so. These latter materials do have, however, much more order than liquids and gases. These materials also have, in varying degrees, some plastic and elastic properties wherein some resistance to applied stresses exists, but when the stress reaches certain intensity, either flow or fracture ensues. Although different classifications exist, four major types of 
bonds hold solids together; the strong bonds impart higher melting points to drug substances. In order of decreasing strength, the bond types are metallic, ionic (salts), valence (diamond) and molecular (many organic compounds). Thus, in some solids, the atoms or molecules or ions may be arranged in a regularly repeating pattern (crystalline state), whereas other solids are considered noncrystalline or amorphous if they do not have this characteristic of regularity ${ }^{5}$.

\subsection{Characteristics and Significance of the Crystalline and Amorphous States}

During the final stage of developing a new drug entity, a great deal of emphasis is placed on obtaining material of high purity and reproducibility in terms of its physical, chemical, and biological properties. Every effort is made to ensure a high degree of crystallinity, wherein the molecules have regular and well-defined molecular packing, and emphasis is also placed on whether or not the compound can exist in polymorphic or solvated crystal forms ${ }^{6}$. These forms can have different thermodynamic properties (e.g., melting temperature, vapor pressure, solubility), and knowledge of their existence is required to anticipate spontaneous changes in the properties of the solid during storage and/or handling of the material. It is also possible that upon isolation the material will be obtained in a fully or partially amorphous state ${ }^{7}$.

Many compounds, especially complex organic molecules, will naturally occur or are capable of being manipulated to exist in more than one form as solids. Some of these forms are crystalline phases while others are meta-stable states where the compound is in a noncrystalline or molecularly dispersed form. Pharmaceutical 
scientists have been making use of the differences in the physical chemical properties that exist between these various solid states to optimize drug delivery ${ }^{8}$.

\subsubsection{Crystalline Solids}

The crystalline state is thermodynamically favored for solids. It is characterized by the three-dimensional order of the molecules within its crystal lattice. The molecules are arranged in a pattern that minimizes the total energy of the crystal, both kinetic and potential. This usually results in a minimum amount of void space between the molecules, as there is a maximization of intermolecular contact (bonding). The packing arrangement for a compound will be a function of both its molecular shape and the chemical groups in the molecule involved in directional intermolecular bonding, e.g., hydrogen bonding, charge transfer interaction, and dipole-dipole interactions ${ }^{8}$. The structural units of crystalline solids, such as ice, sodium chloride, and menthol, are arranged in fixed geometric patterns or lattices. Crystalline solids, unlike liquids and gases, have definite shapes and an orderly arrangement of units. Gases are easily compressed, whereas solids, like liquids, are practically incompressible. Crystalline solids show definite melting points, passing rather sharply from the solid to the liquid state. The units that constitute the crystal structure can be atoms, molecules, or ions. The sodium chloride crystal consists of a cubic lattice of sodium ions interpenetrated by a lattice of chloride ions, the binding force of the crystal being the electrostatic attraction of the oppositely charged ions. In diamond and graphite, the lattice units consist of atoms held together by covalent bonds. Solid 
carbon dioxide, and naphthalene form crystals composed of molecules as the building units. In organic compounds, the molecules are held together by Van der Waals forces, consisting of Keesam and London forces, which account for the various melting points of these crystals. Ionic and atomic crystals in general are hard and brittle and have high melting points 9 .

\subsubsection{Amorphous Solids}

The three-dimensional long-range order that normally exists in a crystalline material does not exist in the amorphous state, and the position of molecules relative to one another is more random as in the liquid state ${ }^{2}$. These materials are referred to as glasses, noncrystalline, amorphous, and vitreous solids. Typically amorphous solids exhibit short-range order over a few molecular dimensions and have physical properties quite different from those of their corresponding crystalline states. The noncrystalline state is thermodynamically unstable and there will be a tendency to entropically drive these solids to a stable crystalline state. However, since the diffusional process is slow in the solid state, it is in many instances possible to isolate and make use of these materials in dosage forms. The free energy of these noncrystalline solids is much higher than that of their corresponding crystalline forms. As a result of its higher internal energy, the amorphous state should have enhanced thermodynamic properties relative to the crystalline state (e.g., solubility, vapor pressure) and greater molecular motion. The high internal energy and specific volume can lead to enhanced dissolution and bioavailability ${ }^{10}$, but can also create the possibility that during processing or 
storage the amorphous state may spontaneously convert back to the crystalline state $^{11}$.

Amorphous solids may be considered as supercooled liquids in which the molecules are arranged in a random manner similar to the liquid state. They differ from crystalline solids in that they tend to flow when subjected to sufficient pressure over a period of time, and they do not have definite melting points. An amorphous solid can also be defined with reference to a crystalline solid: similar to a crystalline solid, an amorphous solid may have short-range molecular order (i.e. in relationship to neighboring molecules); but unlike a crystalline solid, an amorphous solid has no long-range order of molecular packing or well-defined molecular conformation if the constituent molecules are conformationally flexible. Amorphous solids exist in many industrially important products, such as polymers, ceramics, metals, optical materials (glasses and fibers), foods and pharmaceuticals. In the case of pharmaceutical materials, the importance of amorphous solids stems from ${ }^{12}$ :

1. Useful properties. Amorphous solids have higher solubility, higher dissolution rate, and sometimes better compression characteristics than corresponding crystals.

2. Instability. Amorphous solids are generally less stable physically and chemically than corresponding crystals.

3. Common occurrence. Amorphous solids can be produced by standard pharmaceutical processes and are the common form of certain materials (e.g. proteins, peptides, some sugars and polymers). 
Amorphous solids may co-exist with and have the potential to convert to crystalline solids. The amorphous substances, however, cannot achieve their maximum theoretical solubility under practical experimental conditions because of the strong driving force for crystallization in the presence of the dissolution media'. Studies have been done where this problem has been avoided by adding crystallization inhibitors to the dissolution media ${ }^{13,14}$, however, the use of such crystallization poisons is likely to alter the equilibrium solubility of the crystallized and/or amorphous forms. Amorphous solids exist widely in and impart special properties to pharmaceutical products. Given their instability, general strategies for stabilizing amorphous solids against crystallization and structural relaxation would be desirable ${ }^{12}$.

Research aimed at stabilizing amorphous solids is multi-faceted, including: (i) the stabilization of labile biomolecules (e.g. proteins and peptides) through $\operatorname{additives}^{15,16,17,18}$, (ii) the prevention of crystallization of excipients that must remain amorphous for their intended functions ${ }^{19,20,21}$, (iii) the specification of appropriate storage temperatures to achieve acceptable shelf-life ${ }^{2,11,22}$, and (iv) the prevention of chemical degradation and microbial growth through antioxidant, $\mathrm{pH}$ buffer, preservatives, etc.

\subsection{Solubilization by Solid-State Modification}

The solubility behavior of drugs remains one of the most challenging aspects in formulation development. With the advent of combinatorial chemistry and high 
throughput screening, the number of poorly water-soluble compounds has dramatically increased and the formulation of poorly soluble compounds for oral delivery now presents one of the most frequent and greatest challenges to formulation scientists in the pharmaceutical industry ${ }^{23}$.

Together with permeability, the solubility behavior of a drug is a key determinant of its oral bioavailability. Consideration of the modified Noyes-Whitney equation $^{24}$ provides some hints as to how the dissolution rate of even very poorly soluble compounds might be improved so that the limitations to oral availability can be minimized:

$$
\frac{d C}{d t} \equiv \frac{A D\left(C_{s}-C\right)}{h}
$$

where, $d C / d t$ is the rate of dissolution, $A$ is the surface area available for dissolution, $D$ is the diffusion coefficient of the compound, $C_{s}$ is the solubility of the compound in the dissolution medium, $C$ is the concentration of the drug in the medium at time $\boldsymbol{t}$ and $\boldsymbol{h}$ is the thickness of the diffusion boundary layer adjacent to the surface of the dissolving compound. The main possibilities for improving dissolution according to this analysis are to increase the surface area available for dissolution by decreasing the particle size of the solid compound and/or by optimizing the wetting characteristics of the compound surface, to decrease the boundary layer thickness, to ensure sink conditions for dissolution and last but not the least, to improve the apparent solubility of the drug under physiologically relevant conditions. Of these possibilities, the most attractive option for 
increasing the release rate is the improvement of the solubility through formulation approaches. Table 1 summarizes the various formulation and chemical approaches that can be taken to improve the solubility or to increase the available surface area for dissolution.

Of the physical approaches, the use of polymorphs ${ }^{25}$, the amorphous form of the $\mathrm{drug}^{2}$, and complexation ${ }^{26,27}$ have been widely reviewed. Decreasing the particle size of the compound by milling the drug powder theoretically results in an increase in the available area for dissolution, but in some cases the micronized powder tends to agglomerate, thereby at least partly negating the milling procedure. Presenting the compound as a molecular dispersion, on the other hand, combines the benefits of a local increase in the solubility and maximizing the surface area of the compound that comes in contact with the dissolution medium as the carrier dissolves.

\subsubsection{Crystal Defects}

The crystal lattice is generally regarded as a highly ordered structure that repeats itself in three dimensions. Guest molecules (impurities or additives), together with some crystallization solvent, are often incorporated into the host crystals during crystallization from solution. The guest molecules may be incorporated either in solid solution or in liquid inclusions, or by both mechanisms ${ }^{28}$. Upon crystallization of crystals (the host) from the solution, impurities or additives (the guest molecules) in the crystallization medium are often found in the crystals at 


\section{Physical modifications}

Particle size

Micronization

Nanosuspensions

Modifications of the crystal habit

Polymorphs

Pseudopolymorphs (including solvates)

Complexation/solubilization

Use of surfactants

Use of acceptable cyclodextrins

Drug dispersion in carriers

Eutectic mixtures

Solid dispersions (non-molecular)

Solid solutions

\section{Chemical modifications}

Soluble prodrugs

Salts

Table 1: Approaches to improve the solubility or to increase the available surface area for dissolution 
various levels. The location of the guest molecule depends on the nature of the system, the treatment of the crystals upon harvesting, and the crystallization conditions, including concentrations of both the host and the guest in the crystallization medium, supersaturation of the host, and the degree of agitation ${ }^{29,}$ $30,31,32$. This phenomenon may be termed 'doping' of the 'host' crystals by the 'guest' molecules. Structurally, the guest may be closely related to the host, e.g. synthetic impurities ${ }^{29,33}$ or chiral isomers ${ }^{34,35,36}$, or may significantly differ from the host, e.g. a macromolecular surfactant ${ }^{37}$ or the solvent itself ${ }^{38,39}$. However, even the most carefully prepared and grown crystals, such as those of many drug substances, inevitably contain defects, i.e. imperfections and residual impurities ${ }^{40}$. Crystal defects can broadly be classified into point and lattice defects (see Figure 1). Point defects are localized imperfections and are, in general, thermodynamically stable. They include vacancies (vacant sites in the crystal lattice caused by absence of atoms) and extra atoms (foreign or of same species) occupying interstitial or substitutional positions in the crystal lattice. Lattice defects include line defects or dislocations and grain boundaries, which are arrays of dislocations ${ }^{41}$. Dislocations are regions within the solid where the regularly repeating lattice array shows a discontinuity or distortion from the ideal alignment of units within the crystal. The atoms in this region are therefore not properly surrounded by neighbors. Since the imperfection is contained within a few atomic diameters of a line, it is called a line defect or dislocation ${ }^{42}$. The nature and concentration of crystal defects are altered as a result of the stress prevailing during many pharmaceutical processing operations, such as drying, milling and 

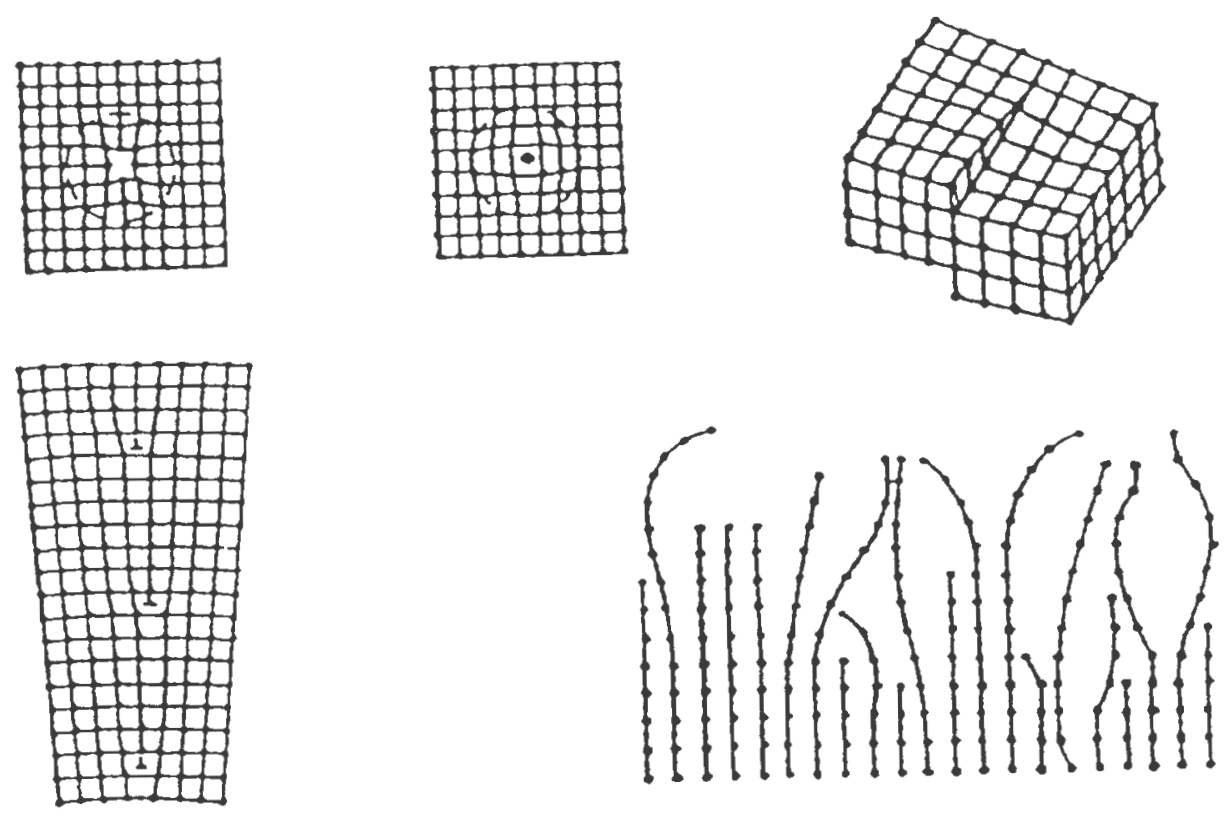

Figure 1: Crystalline defects of various dimensionalities 
compression $^{43}$. The imperfections may develop, wander, change their nature and/or disappear in the crystal lattice during processing ${ }^{10,44}$. Virtually all crystalline drug substances contain impurities which are incorporated into the crystal lattice during crystallization, or which are taken up by the crystal from the vapor phase, e.g. water. The impurity, a guest molecule, by the virtue of its different shape and electronic structure, interacts with the neighboring host molecules in a way, which is different from the interaction between a host molecule and the surrounding host molecules. Thus, the host molecules surrounding a guest molecule possess energies and occupy positions which are different from those of the host molecules surrounding another host molecule in a normal host lattice, to extents which depend on the difference between the shape and electronic structure of the impurity molecule and the host molecule ${ }^{40}$. Thus, the incorporation of the impurity leads to a decrease in the overall symmetry of the crystal ${ }^{45}$ which has been demonstrated in organic solids by Weissinger Lewin et $\mathrm{al}^{46}$.

Even in a crystal of $99.9 \%$ purity, one molecule in ten in any given direction is likely to be an impurity molecule ${ }^{40}$, perturbing the crystalline order of the lattice and increasing the lattice strain. As a result of the incorporation of an impurity, the increase in enthalpy of the solid itself due to the increased lattice strain may be partially offset by an increase in entropy, corresponding to the accompanying disorder, so that the corresponding increase in Gibbs free energy may not be large. However, because equilibrium properties such as solubility and solid 
reaction rates are exponential functions of Gibbs free energy, and because crystal disruption can arise relatively easily from the incorporation of impurity molecules and from the development of crystal imperfections, major effects on the physicochemical properties of solids may result ${ }^{43}$.

Crystals are always imperfect in some sense and these imperfections or defects can confer some important chemical and mechanical properties on crystalline materials ${ }^{4 !}$. Crystal lattice imperfections, e.g. point defects and dislocations, develop during crystallization ${ }^{47}$ and have been found to exert major effects in pharmaceutical formulation and processing ${ }^{10}$. Crystal imperfections have also been shown to influence chemical reactivity ${ }^{6}, 48$ and dissolution rate $^{41}$. Consequently the bioavailability of a solid may be significantly increased by the presence of a high density of lattice imperfections. The process-induced changes in the solid-state properties often result in the batch-to-batch or lot-to-lot variations in the performance of pharmaceutical solid dosage forms, such as tablets and capsules. Digoxin represents a classical example of a drug whose dissolution rate and bioavailability can vary between wide limits if its crystal properties are not controlled ${ }^{49,50,51}$.

\subsubsection{Solid Dispersions and Solid Solutions}

In 1961, a unique approach of solid dispersion to reduce the particle size and increase rates of dissolution and absorption was first demonstrated by Sekiguchi and $\mathrm{Obi}^{52}$. They proposed the formation of a eutectic mixture of a poorly soluble drug with a physiologically inert, easily soluble carrier. The eutectic mixture was 
prepared by melting the physical mixture of the drug and the carrier, followed by a rapid solidification process. Upon exposure to aqueous fluids, the active drug was expected to be released into the fluids as fine, dispersed particles because of the fine dispersion of the drug in the solid eutectic mixture and rapid dissolution of the soluble matrix. The advantage of solid dispersion, compared with conventional capsule and tablet formulations, is shown schematically in Figure $2^{53}$.

The term 'solid dispersion' can be defined as a dispersion of one or more active ingredients in an inert carrier or matrix at solid state, prepared by the melting (fusion), solvent or melting-solvent method. The dispersion of a drug or drugs in a solid diluent or diluents by traditional mechanical mixing is not included in this category. The solid dispersions may also be called solid-state dispersions ${ }^{54}$. Since the dissolution rate of a component from a surface is affected by the second component in a multiple component mixture, the selection of the carrier has an ultimate influence on the dissolution characteristics of the dispersed drug. Therefore, a water-soluble carrier results in a fast release of the drug from the matrix, and a poorly soluble or insoluble carrier leads to a slower release of the drug from the matrix. A simple 'eutectic mixture' consists of two compounds which are completely miscible in the liquid state but only to a very limited extent in the solid state (see Figure 3). When a mixture of $\mathrm{A}$ and $\mathrm{B}$ of composition $\mathrm{E}$ is cooled, A and B crystallize out simultaneously, whereas when other compositions are cooled, one of the components starts to crystallize out before the other. Solid 


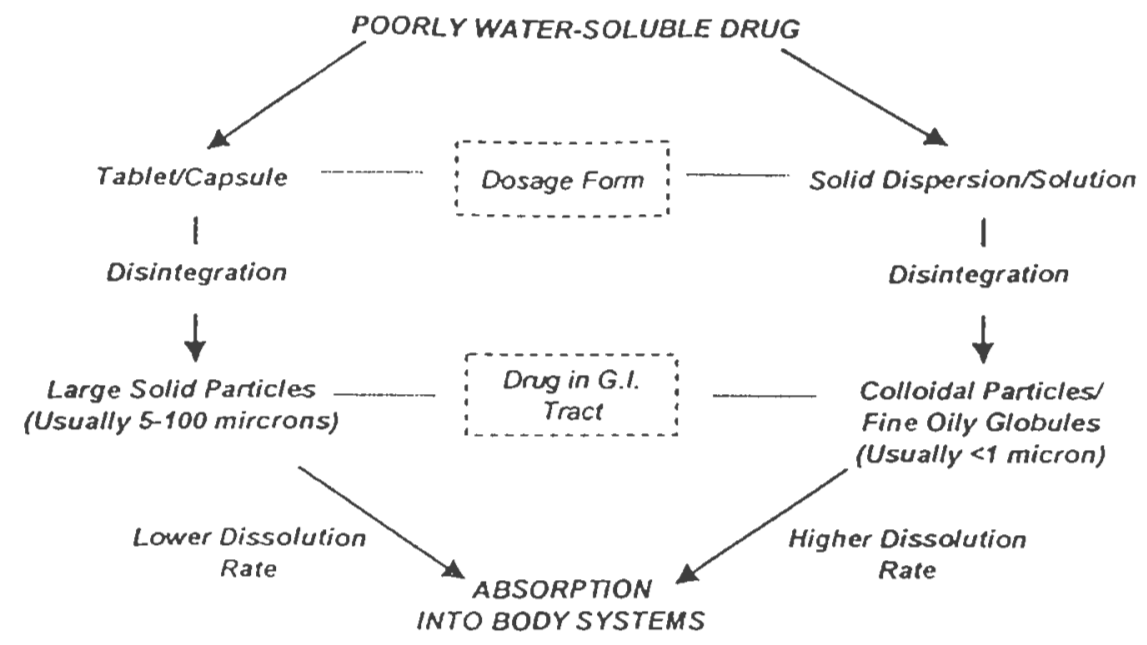

Figure 2: A schematic representation of the bioavailability enhancement of a poorly water-soluble drug by solid dispersion compared with conventional tablet or capsule

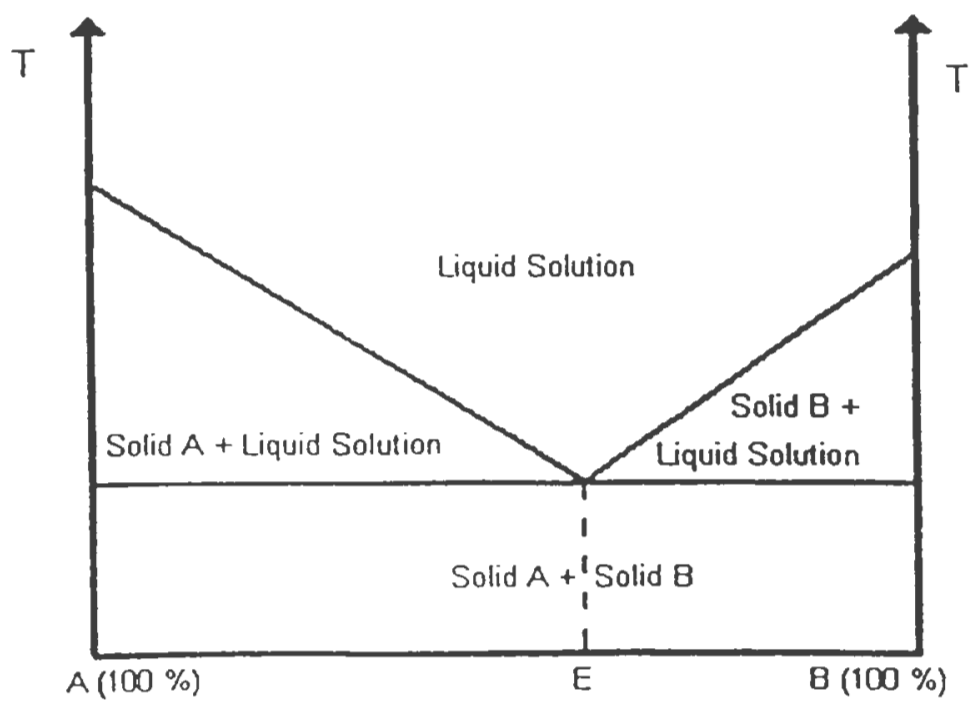

Figure 3: Phase diagram for a eutectic system 
eutectic mixtures are usually prepared by rapid cooling of a melt of the two compounds in order to obtain a physical mixture of very fine crystals of the two components. When a mixture of composition $\mathrm{E}$, consisting of a slightly soluble drug and an inert, highly water-soluble carrier, is dissolved in an aqueous medium, the carrier will dissolve rapidly, releasing very fine crystals of the drug ${ }^{52}$ 55. The large surface area of the resulting suspension should result in an enhanced dissolution rate and thereby improved bioavailability ${ }^{23}$.

'Solid solutions' are comparable to liquid solutions, consisting of just one phase irrespective of the number of components, and are made up of a solid solute dissolved in a solid solvent. It is often called a mixed crystal because the two components crystallize together in a homogenous one-phase system ${ }^{56}$. Solid solutions containing a poorly water soluble drug dissolved in a carrier with relatively good aqueous solubility achieve a faster dissolution rate than a eutectic mixture because the particle size of the drug in the solid solution is reduced to a minimum state, i.e., its molecular size, and the dissolution rate is determined by the dissolution rate of the carrier ${ }^{57}$. By judicious selection of a carrier, the dissolution rate of the drug can be increased by up to several orders of magnitude. In addition to the reduction of the crystalline size, the following factors may contribute to the faster dissolution rate of a drug dispersed in these systems ${ }^{54}$,

a) An increase in drug solubility may occur if the majority of its solid crystallites are extremely small ${ }^{9}$. 
b) A solubilization effect by the carrier may operate in the microenvironment (diffusion layer) immediately surrouding the drug particle in the early stages of dissolution since the carrier completely dissolves in a short time. This was demonstrated by the faster dissolution rate of acetaminophen from its physical mixture with urea than that of the pure compound with comparable particle size $\mathrm{e}^{58}$.

c) The absence of aggregation and agglomeration between fine crystallites of the pure hydrophobic drug may play a far more important role in increasing rates of dissolution and absorption than is presently recognized. Serious drawbacks of aggregation and agglomeration and lumping in the dissolution medium between pure drug particles are, however, rarely present in most solid dispersion systems because the individually dispersed particles are surrounded in a matrix of carrier particles. It must be emphasized that the aggregation and agglomeration of the solid dispersion powders may not significantly affect the dissolution of the drug, which can still disintegrate quickly due to the more rapid dissolution of the soluble carrier. This advantage of solid dispersion systems was demonstrated in the in vivo absorption ${ }^{59}$ of griseofulvin when dispersed in polyethylene glycol $6000(10 \% \mathrm{w} / \mathrm{w})$ and compressed into a hard tablet. The dissolution rate of the dispersed drug was found to be 25 times that of the pure drug.

d) Excellent wettability and dispersibility of a drug from these systems, prepared with a water-soluble matrix result in an increased dissolution rate 
of the drug in aqueous media. This is due to the fact that each single crystallite of the drug is very intimately encircled by the soluble carrier which can readily dissolve and cause the water to contact and wet the drug particle. As a consequence, a fine homogenous suspension of a drug can be easily obtained with minimum stirring ${ }^{52}$.

The methods that have been used to characterize solid dispersions are summarized in Table 2. Among these, the most important methods are thermoanalytical, Xray diffraction, infrared spectroscopy and measurement of the release rate of the drug. In addition to characterizing the solid dispersion, these methods can be used to differentiate between solid solutions (molecularly dispersed drug), solid dispersions in which the drug is only partly molecularly dispersed and physical mixtures of the drug and carrier ${ }^{23}$.

\subsubsection{Polymorphic Transformations}

Many drug substances can exist in more than one crystalline form with different space lattice arrangements. This property is known as polymorphism. The different crystal forms are called polymorphs. Crystalline polymorphs have the same chemical composition but different internal crystal structures and, therefore, possess different physicochemical properties. The different crystal structures in polymorphs arise when the drug substance crystallizes in different crystal packing arrangements and/or different conformations. The occurrence of polymorphism is quite common among organic molecules, and a large number of polymorphic drug 
Dissolution testing

Thermoanalytical methods: differential thermoanalysis and hot stage microscopy

Calorimetric analysis of the solution or melting enthalpy for calculation of entropy change

$\mathrm{X}$-Ray diffraction

Spectroscopic methods, e.g. IR spectroscopy

Microscopic methods including polarization microscopy and scanning electron microscopy

Table 2: Methods for the characterization of solid dispersions 
compounds have been noted and catalogued ${ }^{60,61,62,63}$. Occasionally, a solid crystallizes, entrapping solvent molecules in a specific lattice position and in a fixed stoichiometry, resulting in a solvate or pseudopolymorph. If the incorporated solvent is water, the solvate is termed as a hydrate. Many solids may be prepared in a particular polymorphic form via appropriate manipulation of conditions of crystallization. These conditions include nature of the solvent, temperature, rate of cooling, and other factors. Because different crystalline polymorphs and solvates differ in crystal packing, and/or molecular conformation as well as in lattice energy and entropy, there are usually significant differences in their physical properties, such as density, hardness, tabletability, refractive index, melting point, enthalpy of fusion, vapor pressure, solubility, dissolution rate, other thermodynamic and kinetic properties and even color ${ }^{64}$. The physical stability of any crystalline polymorph is dictated by its free energy. The most stable form under a given set of conditions is the form with the lowest free energy. All other solid-state modifications would in time transform to that particular crystalline phase $^{8}$. The transformation rate of one polymorph to another, however, depends on the mobility of the molecules in the solid, the type of structural change that takes place, and environmental factors. If the transformation involves only a small degree of alteration in the intermolecular bonding, one could find a rapid conversion of a metastable form to the stable form. On the other hand, when a substantial difference in the packing arrangement exists between the two forms, the transformation can be extremely slow ${ }^{65}$. Polymorphism has achieved significance in recent years owing to the fact that different polymorphs exhibit 
different solubilities. In the case of slightly soluble drugs, this may affect the rate of dissolution. As a result, one polymorph may be more active therapeutically than another polymorph of the same drug. The polymorphic state of chloramphenicol palmitate has been shown to have a significant effect on the biological availability of the drug. It is essential, therefore to define and monitor the solid state of a drug substance. Occasionally, it may be necessary to search for a different polymorphic form to overcome stability, bioavailability, or processing problems. Differences in the dissolution rates and solubilities of different polymorphic forms of a given drug are used when absorption of the drug is dissolution rate limited ${ }^{66}$. In such cases, a more soluble and faster dissolving form may be utilized to improve the rate and extent of bioavailability.

\subsection{Solid-State Characterization}

Many methods are available that can contribute information regarding the nature of a solid system. In many instances, a combination of two or more methods is required to study its complete picture. The analytical techniques used in this study will be discussed briefly in the following section.

\subsubsection{X-Ray Diffraction}

In 1912, Max Von Laue pointed out that if the wavelength of electromagnetic radiation became as small as the distance between atoms in the crystals, a diffraction pattern should result. Later it was found that the X-ray region has the right wavelength and a definite diffraction pattern was obtained for copper sulfate 
crystals. In essence, the crystal diffracts X-rays similar to a diffraction grating, whose plane diffracts ordinary light. The three-dimensional crystal functions like a series of plane gratings stacked one above the other ${ }^{5}$. For a single crystal the diffracted X-rays consist of a few lines; with powder, due to a random distribution of crystals, the diffraction pattern consists of a series of concentric cones with a common apex on the sample. The atoms in a crystal possess the power of diffracting the X-ray beam. Each substance scatters the beam in a particular diffracting pattern, producing a fingerprint for each atomic crystal or molecule. Powder X-ray diffraction analysis is employed for characterization of crystalline structure. It has been used to determine the existence of polymoprhic forms of many substances. It is a very important and efficient tool in studying the physical nature of solids.

\subsubsection{Differential Scanning Calorimetry (DSC)}

Thermal analysis is a technique in which a physical property of a substance is monitored as a function of controlled temperature increase. Modern thermal analytical methods can measure weight loss on heating, melting points, heat and energy of transitions and changes in form, in dimensions or in the viscoelastic properties of the substance. They find wide application in material characterization, purity of medicinal substances, study of relative heat stabilities and dymamic properties of new compounds, as well as in crystallography, chemical kinetics and generation of phase diagrams ${ }^{5}$. Most thermodynamic events are accompanied by a loss of heat or require addition of heat from an 
external source in order to proceed. Each of these occurrences can be followed thermodynamically by noting either change of temperature of the sample under study or energy changes of the sample with respect to time. Thermal analyses include thermogravimetry (thermogravimetric analysis, TGA), differential thermal analysis (DTA) and differential scanning calorimetry (DSC). DSC is very closely related to TGA, but differs only in that the sample and reference containers are not contiguous, but are heated separately by individual coils that are heated (or cooled) at the same rate. Platinum resistance thermometers monitor the temperature of the sample and reference holders and electronically maintain the temperature of the two holders constant. If a thermodynamic event occurs which is either endothermic or exothermic, the power requirements for the coils maintaining a constant temperature will differ. This power difference is plotted as a function of the temperature recorded by the programming device. Unlike DTA, in DSC the amount of heat put into the system is exactly equivalent to the amount of heat absorbed or liberated during a specifc transition (transition energy).

\subsubsection{Optical Microscopy}

The past decade has witnessed an enormous growth in the application of optical microscopy for micron and sub-micron level investigations in a wide variety of disciplines. Microscopy

has been used quite often to study the morphology of solids, alone, in mixtures or dispersions, and in polymorphism. The properties of the particles in a powder can influence profoundly the pharmaceutical performance of the solid, such as the 
processing, compaction, stability, and/or release rate of the active constituent. Optical microscopy can be used to study the crystal habit (shape and roughness) of crystalline substances.

The physical characterization of amorphous solids utilizes a wide range of techniques and offers several types of information ${ }^{12}$ :

1. Structure. Amorphous solids are not random at the molecular level, but may possess short-range order, residual crystallinity, polymorphic states and regions of different density.

2. Thermodynamics. Amorphous solids have higher energy, entropy and free energy than the corresponding crystals. The excess properties are parameters in some theoretical models of crystallization and structural relaxation.

3. Changes. Amorphous solids can crystallize or undergo structural relaxation owing to the instability with respect to the corresponding crystals and "equilibrium" glasses.

4. Multi-component systems. Many pharmaceutical formulations are multicomponent, with water being a ubiquitous ingredient. It is desirable to predict properties of multi-component systems from those of individual components. 


\subsection{Cefuroxime Axetil}

Cefuroxime axetil (CA), an acetoxyethyl ester prodrug of cefuroxime, was the first oral cephalosporin of the second generation to be commercially available as tablets in $1989^{67}$. Cefuroxime has a broad spectrum of in vitro antibacterial activity which encompasses methicillin-sensitive staphylococci and the common respiratory pathogens Streptococcus pneumoniae, Haemophilus influeza, Moraxella (Branhamella) catarrhalis and group A $\beta$-heamolytic streptococci ${ }^{68}$. It has broad spectrum activity against the $\beta$-lactamase positive respiratory pathigens H. influenzae and $M$. catarrhalis; it shows activity against penicillin-susceptible and-intermediate strains of $S$. pneumoniae. Cefuroxime axetil is indicated for the treatment of patients with mild to moderate infections caused by susceptible strains of the designated microorganisms in the following conditions - pharyngitis / tonsillitis (caused by Streptococcus pyogenes), acute baterial otitis media (caused by $S$. pneumoniae, $H$. influenzae, $M$ catarrhalis or $S$. pyogenes), acute bacterial maxillary sinusitis (caused by $S$. pneumoniae or $H$. influenzae), acute bacterial exacerbations of chronic bronchitis and secondary bacterial infections of acute bronchitis (caused by $S$. pneumoniae, H. influenzae, or H. parainfluenzae), uncomplicated skin and skin structure infections (caused by Staphylococcus

aureus or $S$. pyogenes), uncomplicated urinary tract infections (caused by Escherichia coli or Klebsiella pneumoniae), uncomplicated gonorrhea (caused by Neisseria gonorrhoeae), and early Lyme disease (caused by Borrelia burgdorferi). Since cefuroxime is not absorbed orally, its use for outpatient treatment of community acquired infections is limited. Cefuroxime axetil, the 
orally absorbed prodrug, is formed by esterification of the parent cefuroxime molecule. The 1-(acetyloxy) ethyl ester group enhances lipid solubility and gastric stability and facilitates oral absorption ${ }^{69}$. It exists as a 50:50 mixture of diastereomers A and B. After oral administration, $\mathrm{CA}$ is absorbed from the GIT and rapidly hydrolyzed (within 3-4 minutes) by non-specific esterases in the intestinal mucosa and blood to yield the active parent compound, cefuroxime (see Figure 4), which is subsequently distributed throughout the extracellular fluids. The in vivo bactericidal activity of cefuroxime axetil is due to cefuroxime's binding to essential target proteins and the resultant inhibition of cell-wall synthesis ${ }^{70}$. Peak plasma cefuroxime concentrations of approximately 4.1 to 4.8 $\mathrm{mg} / \mathrm{L}$ are attained 2 to 2.5 hours after a single oral dose of cefuroxime axetil 250 $\mathrm{mg}$ (tablet formulation). The absorption of cefuroxime axetil is significantly increased by the presence of food. In one study, the bioavailability of cefuroxime increased from $36 \%$ in fasted individuals to $52 \%$ when the drug was administered with food. The volume of distribution of cefuroxime is 0.25 to $0.3 \mathrm{~L} / \mathrm{kg}$ and the drug is approximately $33 \%$ plasma protein bound. Distribution of cefuroxime into body tissues and fluids is variable, but the drug penetrates well (35 to $90 \%$ ) into tonsil tissue, sinus tissue and bronchial mucosa; mean tissue concentrations of cefuroxime ranged from 1.4 to $3.8 \mathrm{mg} / \mathrm{kg}$. After administration of single doses of cefuroxime axetil (250 to $1000 \mathrm{mg}$ ), the plasma elimination half-life of the drug ranged from 1.1 to 1.5 hours in healthy volunteers with normal renal function, but was significantly increased by moderate to severe renal impairment. Cefuroxime is not significantly metabolized and is eliminated by the kidneys as unchanged 


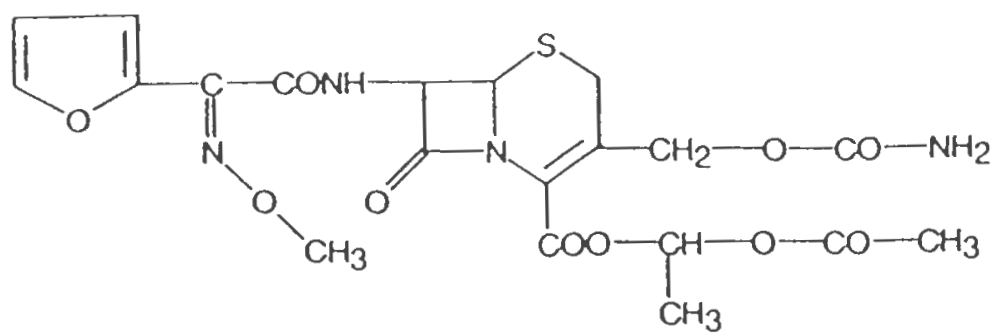

Cefuroxime axetil

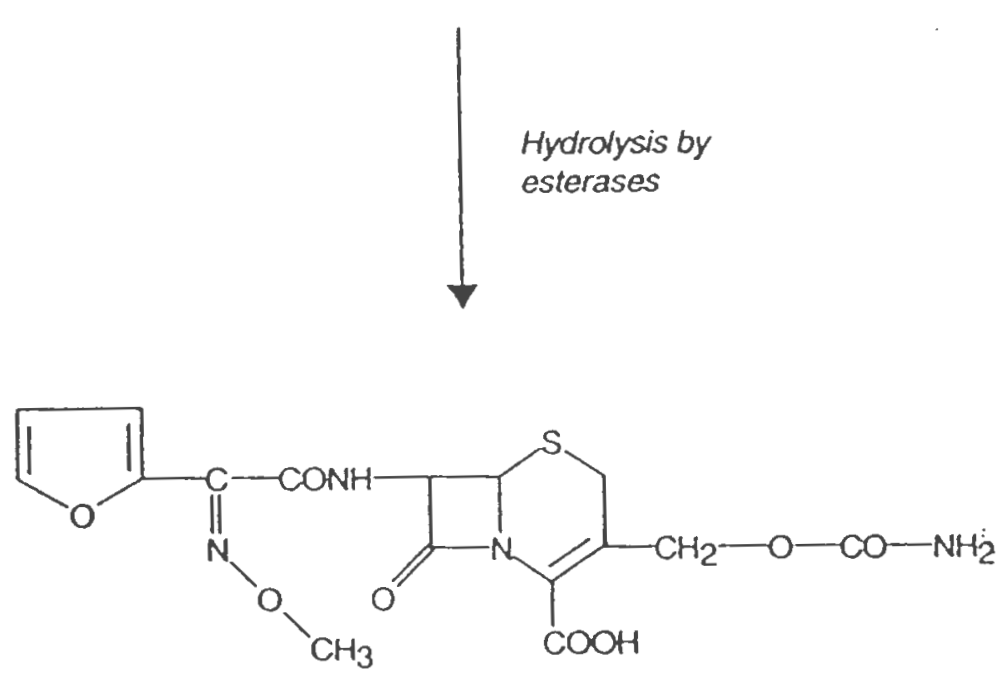

Cefuroxime

Figure 4: Structural formulae of cefuroxime axetil and cefuroxime 
drug, resulting in high urinary concentrations of cefuroxime. Cefuroxime axetil is associated with a low incidence of adverse events, with gastrointestinal disturbances being the most frequently observed. Thus it is an effective and convenient treatment for a wide range of infections, and may be considered a therapeutic option when empirical treatment of community-acquired infections is required.

\subsection{Objectives of the Study}

The crystalline nature of a drug has a direct effect on its solubility, and may be a limiting factor for its dissolution and bioavailability. A reduction in the crystallinity of the drug or its conversion to the zero - crystalline (amorphous) state, would be a means of enhancing the bioavailability of the drug. However, the unstable nature of the amorphous state, accelerated by external factors (e.g. moisture), limits its wider and more frequent application.

This study primarily investigates the effect of crystal modification on the solubility of CA and its individual isomers. Techniques used have been employed with the aim of altering the crystal structure. A comparative study between the processes has also been used to determine the varied effect on the solid-state of the drug. Polymers have also been used, in conjunction with the processes; to investigate any positive effect on the ability of the drug to retain its modified state (of improved solubility). Use of polymers has been considered as they not only assist in improving solubility; but can also act as impurity (in small quantities), to destabilize the rigid crystal structure. Since the drug exists as a mixture of 
diastereoisomers, we can expect a difference in the effects of the processes and polymers on the individual isomers. Diastereoisomers have different solubilities and melting points, and hence will show differences in the degree of conversion from crystalline to partially crystalline to amorphous states. 


\section{References:}

1) Hancock BC, Parks M. What is the true solubility advantage for amorphous pharmaceuticals? Pharmaceutical Research 2000, 17 (4), 397 404.

2) Hancock BC, Zografi G. Characteristics and significance of the amorphous state in pharmaceutical systems. Journal of Pharmaceutical Sciences 1997, 86 (1), 1-12.

3) Haleblian JK, McCrone WC. Pharmaceutical applications of polymorphism. Journal of Pharmaceutical Sciences 1969, 58, 911-929.

4) Higuchi WI, Lau PK, Higuchi T, Shell JW. Polymorphism and drug availability. Solubility relations in the methylprednisolone system. Journal of Pharmaceutical Sciences 1963, 52, 150-153.

5) Gennaro AR. Remington's Pharmaceutical Sciences. Mack Publishing Company, Pennsylvania, 1990.

6) Byrn SR. Solid State Chemistry of Drugs. Academic Press, New York, 1982.

7) Roy RJ. Non Crystalline Solids 1970, 3, 33-40.

8) Yalkowsky SH. Techniques of Solubilization of Drugs (Drugs and the Pharmaceutical Sciences) 1981, Volume 12, Marcel Dekker Inc.

9) Martin A. Physical Pharmacy 1993, $4^{\text {th }}$ Edition, Lea and Febiger.

10) Huttenrauch R. Molecular pharmaceutics as a basis for modern drug formulation. Acta Pharmaceutica Technology Supplement 1978, 6, 55 127. 
11) Yoshioka M, Hancock BC, Zografi G. Crystallization of indomethacin from the amorphous state below and above its glass transition temperature. Journal of Pharmaceutical Sciences 1994, 83(12), 1700-5.

12) Lian Y. Amorphous pharmaceutical solids: preparation, characterization and stabilization. Advanced Drug Delivery Reviews 2001, 48, 27-42.

13) Sato T, Okada A, Sekiguchi K, Tsuda Y. Difference in physicopharmaceutical properties between crystalline and non-crystalline $9,3^{\prime \prime}-$ diacetylmidecamycin. Chemical and Pharmaceutical Bulletin 1981, 29, 2675-2682.

14) Corrigan OI, Holohan EM, Sabra K. Amorphous forms of thiazide diuretics prepared by spray-drying. International Journal of Pharmaceutics 1984, 18, 195-200.

15) Pikal M. Freeze drying of proteins: process, formulation and stability. Formulation and Delivery of Proteins and Peptides ACS, Washington DC, 1994, pp 20-133.

16) Carpenter JF. Interactions of stabilizers with proteins during freezing and drying. Formulation and Delivery of Proteins and Peptides ACS, Washington DC, 1994, pp 134-147.

17) Crowe JH, Carpenter JF, Crowe LM. The role of vitrification in anhydrobiosis. Annual Review of Physiology 1998, 60, 73-103.

18) Sun WQ, Davidson P, Chan HSO. Protein stability in the amorphous carbohydrate matrix: relevance to anhydrobiosis. Biochimica et Biophysica Acta 1998, 1425, 245-254. 
19) Kim AI, Akers MJ, Nail SL. The physical state of mannitol after freezedrying: effects of mannitol concentration, freezing rate, and a noncrystalline cosolute. Journal of Pharmaceutical Sciences 1998, 87, 931935.

20) Izutsu K, Yoshioka S, Terao T. Effect of mannitol crystallinity on the stabilization of enzymes during freeze-drying. Chemical and Pharmaceutical Bulletin 1994, 42, 5-8.

21) Shalaev EY, Lu Q, Shalaeva M, Zografi G. Acid-catalyzed inversion of sucrose in the amorphous state at very low levels of residual water. Pharmaceutical Research 2000, 17, 366-370.

22) Hatley RHM. Glass fragility and the stability of pharmaceutical preparations - excipients selection. Pharmaceutical Development and Technology 1997, 2, 257-264.

23) Leuner C, Dressman J. Improving drug solubility for oral delivery using solid dispersion. European Journal of Pharmaceutics and Biopharmaceutics 2000, 50, 47-60.

24) Noyes AA, Whitney WR. The rate of solution of solid substances in their own solutions. Journal of the American Chemical Society 1897, 19, 930934.

25) Vippagunta SR, Brittain HG, Grant DJW. Crystalline solids. Advanced Drug Delivery Reviews 2001, 48, 3-26. 
26) Hoerter D, Dressman JB. Influence of physicochemical properties on dissolution of drugs in the gastrointestinal tract. Advanced Drug Delivery Reviews 1997, 25, 3-14.

27) Loftsson T, Brewster ME. Pharmaceutical application of cyclodextrins. I. Drug solubilization and stabilization. Journal of Pharmaceutical Sciences $1996,85,1017-1025$.

28) Zhang GGZ, Grant DJW. Incorporation mechanism of guest molecules in crystals: solid solution or inclusion? International Journal of Pharmaceutics 1999, 181, 61-70.

29) Chow KY, Go J, Mehdizadeh M, Grant DJW. Modification of adipic acid crystals: influence of growth in the presence of fatty acid additives on crystal properties. International Journal of Pharmaceutics 1984, 20, 3-24.

30) Chow AHL, Grant DJW. Modification of acetaminophen crystals. II. Influence of stirring rate during solution-phase growth on crystal properties in the presence and absence of p-acetoxyacetanilide. International Journal of Pharmaceutics 1988, 41, 29-39.

31) Chow AHL, Grant DJW. Modification of acetaminophen crystals. III. Influence of initial supersaturation during solution-phase growth on crystal properties in the presence and absence of p-acetoxyacetanilide. International Journal of Pharmaceutics 1988, 42, 123-133.

32) Chow AHL, Grant DJW. Influence of crystallization conditions on the physical properties of acetaminophen crystals: evaluation by multiple 
linear regression. International Journal of Pharmaceutics 1989, 51, 115127.

33) Chow AHL, Chow PKK, Zhongshan W, Grant DJW. Modification of acetaminophen crystals: influence of growth in aqueous solutions containing $\mathrm{p}$-acetoxyacetanilide on crystal properties. International Journal of Pharmaceutics 1985, 24, 239-258.

34) Duddu SP, Fung FKY, Grant DJW. Effect of the opposite enantiomer on the physicochemical properties of (-)-ephedrinium 2-naphthalenesulfonate crystals. International Journal of Pharmaceutics 1993, 94, 171-179.

35) Duddu SP, Fung FKY, Grant DJW. Effect of crystallization in the presence of the opposite enantiomer on the crystal properties of (SS)-(+)pseudoephedrinium salicylate. International Journal of Pharmaceutics $1996,127,53-63$.

36) Li ZJ, Grant DJW. Effects of excess enantiomer on the crystal properties of a racemic compound: ephedrinium 2-naphthalenesulfonate. International Journal of Pharmaceutics 1996, 137, 21-31.

37) Al-Meshal M, York P, Grant DJW. Disruptant effects of surfactant molecules incorporated into phenylbutazone crystals. The Journal of Pharmacy and Pharmacology 1985, 37, 58.

38) Law D, El-Said Y, Grant DJW. Influence of the crystallization medium on liquid inclusions in adipic acid crystals. Agglomeration and size enlargement: a symposium in the First International Particle Technology 
Forum of the AIChE, Denver, CO. American Institute of Chemical Engineers, 1994, pp 389-399.

39) El-Said Y. Effect of cosolvents on water content and physical properties of acetaminophen crystallized from aqueous solutions. Journal of Pharmaceutical Sciences 1995, 5, 232-237.

40) Wright JD. Molecular Crystals 1987, Cambridge University Press, Cambridge, pp 1-9, 45-59, 70.

41) Burt HM, Mitchell AG. Crystal defects and dissolution. International Journal of Pharmaceutics 1981, 9, 137-152.

42) Read WT. Dislocations in Crystals 1953, McGraw Hill, New York.

43) Duddu SP, Grant DJW. The use of thermal analysis in the assessment of crystal disruption. Thermochimica Acta 1995, 248, 131-145.

44) York P, Grant DJW. A disruption index for quantifying the solid state disorder induced by additives or impurities. I. Definition and evaluation from heat of fusion. International Journal of Pharmaceutics, 1985, 25, $57-72$.

45) Weissbuch I, Addadi L, Berkovitch-Yellin Z, Gati E, Weinstein S, Lahav M, Leiserowitz L. Centrosymmetric crystals for the direct assignment of the absolute configuration of chiral molecules. Application to the $\alpha$-amino acids by their effect on glycine crystals. Journal of the American Chemical Society 1983, 105, 6615-6621.

46) Weisinger-Lewin Y, Frolow F, McMullan RK, Koetzle TF, Lahav M, Leiserowitz L. Reduction in crystal symmetry of a solid solution: A 
neutron diffraction study at $15 \mathrm{~K}$ of the host/guest system asparagine/aspartic acid. Journal of the American Chemical Society 1989, $111,1035-1040$.

47) Mullin JW. Crystallization 1993, $3^{\text {rd }}$ Edition, Butterworth Heinemann, Oxford, pp 24-27, 248-257.

48) Boldyrev VV, Bulens M, Delmon B. The Control of the Reactivity of Solids, Studies in Surface Science and Catalysis 1979, Volume 2, Elsevier, Amsterdam.

49) Fairbrother JE, Grant DJW. Crystal engineering studies with an excipient material (adipic acid). Journal of Pharmacy and Pharmacology 1979, 31, $27 \mathrm{P}$

50) Black DB, Lovering EG. Estimation of the degree of crystallinity in digoxin by X-ray and infrared methods. Journal of Pharmacy and Pharmacology 1977, 29 (11), 684-7.

51) Chiou WL, Kyle LE. Differential thermal, solubility, and aging studies on various sources of digoxin and digitoxin powder: biopharmaceutical implications. Journal of Pharmaceutical Sciences 1979, 68(10), 12241229.

52) Sekiguchi K, Obi N. Studies on absorption of eutectic mixture. I. A comparison of the behavior of eutectic mixture of sulfathiazole and that of ordinary sulfathiazole in man. Chemical and Pharmaceutical Bulletin $1961,9,866-872$. 
53) Serajuddin ATM. Solid dispersion of poorly water-soluble drugs: early promises, subsequent problems, and recent breakthroughs. Journal of Pharmaceutical Sciences 1999, 88, 1058-1066.

54) Chiou WL, Riegelman S. Pharmaceutical applications of solid dispersion systems. Journal of Pharmaceutical Sciences 1971, 60 (9), 1281-1302.

55) Goldberg AH, Gibaldi M, Kanig JL. Increasing dissolution rates and gastrointestinal absorption of drugs via solid solutions and eutectic mixtures II - experimental evaluation of a eutectic mixture: ureaacetaminophen system. Journal of Pharmaceutical Sciences 1966, 55, $482-487$.

56) Findlay A. The Phase Rule $1951,5^{\text {th }}$ Edition, Dover, New York, p 477.

57) Goldberg AH, Gibaldi M, Kanig JL. Increasing dissolution rates and gastrointestinal absorption of drugs via solid solutions and eutectic mixtures I - theoretical considerations and discussion of the literature. Journal of Pharmaceutical Sciences 1965, 54, 1145-1148.

58) Goldberg AH, Gibaldi M, Kanig JL, Mayersohn M. Increasing dissolution rates and gastrointestinal absorption of drugs via solid solutions and eutectic mixtures. IV. Chloramphenicol--urea system. Journal of Pharmaceutical Sciences 1966, 55 (6), 581-583.

59) Chiou WL, Riegelman S. 1970, presented to the APhA, Academy of Pharmaceutical Sciences, Washington DC.

60) Kuhnert-Brandstatter M. Thermomicroscopy in the Analysis of Pharmaceuticals 1971, Pergamon, Oxford. 
61) Borka L, Haleblian JK. Crystal polymorphism of pharmaceuticals. Acta Pharmaceutica Jugosl 1990, 40, 71-94.

62) Borka L. Review on crystal polymorphism of substances in the European Pharmacopoeia. Pharmaceutica Acta Helvetia 1991, 66, 16-22.

63) Giron D. Thermal analysis and calorimetric methods in the characterization of polymorphs and solvates. Thermochimica Acta 1995, $248,1-59$.

64) Grant DJW. Theory and origin of polymorphism, in: Brittain HG. Polymorphism in Pharmaceutical Solids 1999, Vol. 95, Marcel Dekker, New York.

65) Verma AR, Krisha P. Polymorphism and Polytypism in Crystals 1966, Wiley, New York.

66) Aguiar AJ, Kro J, Kinkle AW, Samyn J. Effect of polymorphism on the absorption of chloramphenicol from chloramphenicol palmitate. Journal of Pharmaceutical Sciences 1967, 56 (7), 847-53.

67) Fabre H, Ibork H, Lemer DA. Photoisomerization kinetics of cefuroxime axetil and related compounds. Journal of Pharmaceutical Sciences 1994, $83(4), 553-558$.

68) Perry CM, Brogden RN. Cefuroxime axetil - A review of its antibacterial activity, pharmacokinetic properties and therapeutic efficacy. Drug Evaluation 1996, 52 (1), 125-158.

69) Oszczapowicz I., Malafiej E., Malafiej A. H., Szelachowska M., Kuklewicz C., Sieranska E. Esters of cephalosporins. Part III. Separation 
and properties of the $\mathrm{R}$ and $\mathrm{S}$ isomers of the 1-acetoxyethylester of cefuroxime. Acta Poloniae Pharmaceutica-Drug Research 1995, 52, $471-476$

70) Glaxo Wellcome Inc. Cefuroxime axetil. Product information data sheet. 2000, Research Triangle Park, North Carolina, USA. 
SECTION II: EXPERIMENTAL 
The solid state of a drug affects its solubility, and in turn its dissolution and bioavailability from the dosage form. The existence of the drug in the crystalline or amorphous form needs to be adequately characterized. Crystalline to partially crystalline or amorphous conversions have been studied in this project. The primary aim of this study was to determine the effect of processes and polymers on the crystalline to amorphous conversions and their effect on the aqueous solubility of the drug. Solubility is one of the parameters used to monitor these conversions. In addition, analytical techniques like DSC (Differential Scanning Calorimetry), XRD (X-Ray Diffraction), and optical microscopy were used to characterize these conversions.

\subsection{Assay for Cefuroxime Axetil (CA)}

\subsection{Equipments / Reagents:}

Equipments

Mettler AE 240 Weighing balance

Ultrasonifier (Fisher Scientific)

HPLC System consisting of:

Automated Gradient Controller (Waters ${ }^{\circledR}$ )

HPLC Pumps (Waters ${ }^{\circledR}$ Model 515)

Auto Sampler (Waters ${ }^{\circledR}$ Model 717 plus)

LC Spectrophotometer (Waters ${ }^{\circledR}$ Model 480)

Data Module (Waters ${ }^{\circledR}$ Model 746)

L-13 column (YMC $®)$

Column Temperature Controller (Fiatron Systems Inc, Model TC-50) 
Reagents

Cefuroxime Axetil (Hanmi Pharmaceuticals, Batch \# CFA - L99003)

Cefuroxime Axetil (USP Reference Standard)

Ammonium Phosphate Monobasic (HPLC Grade, Fisher Scientific)

Methanol (HPLC Grade, Fisher Scientific)

Deionized water.

\subsubsection{Standard Procedure:}

1) Mobile phase used in this study is a mixture of $0.2 \mathrm{M}$ monobasic ammonium phosphate and methanol (620:380).

2) Stock solution $(1 \mathrm{mg} / \mathrm{ml})$ of cefuroxime axetil in methanol is used for the preparation of the standard solutions.

3) Standards are made by serial dilutions of the stock solution with the mobile phase, to give concentrations of $10 \mu \mathrm{g} / \mathrm{ml}, 20 \mu \mathrm{g} / \mathrm{ml}, 40 \mu \mathrm{g} / \mathrm{ml}$, $60 \mu \mathrm{g} / \mathrm{ml}, 80 \mu \mathrm{g} / \mathrm{ml}, 100 \mu \mathrm{g} / \mathrm{ml}$ and $200 \mu \mathrm{g} / \mathrm{ml}$.

4) The HPLC system was prepared by setting the following parameters,

a) The column thermostat temperature should be set to $32{ }^{\circ} \mathrm{C}$.

b) The absorbance of the spectrophotometer should be set to 278 nm.

c) The flow rate should be set to $1 \mathrm{ml} /$ minute.

d) The run time should be set to 15 minutes.

e) Injection volume should be set to $10 \mu \mathrm{l}$.

f) Number of injections from each vial should be set to 2 . 
5) The assay for the USP reference standard and the sample of cefuroxime axetil were identical, performed using the standard procedure above.

6) The calibration curve is constructed by plotting the area under the curve (AUC) against their concentrations.

7) Since the drug exists as a mixture of diastereoisomers, the total concentration is given by the sum total of the concentration of the individual isomers.

8) Separate calibration curves for the individual isomers as well as the total drug have been constructed, which can be used to determine the unknown concentration of the samples.

9) Validation of the assay for cefuroxime axetil was performed over five days to ensure reproducibility.

The drug exists as a mixture of diastereoisomers A and B that elute separately. Isomer $\mathrm{B}(\sim 10.5 \mathrm{~min})$ elutes first followed by isomer $\mathrm{A}(\sim 11.5 \mathrm{~min})$ with a difference of approximately 1 minute between them (see Figure 5).

Table 3 shows the data for the calibration curve of the USP reference standard. From the tables we see that the ratio of the isomers, B (0.48) to A $(0.52)$, lie within the USP limits of 0.48 to 0.55 . Figures 6 and 7 illustrate the complete as well as linear portion of the calibration curve of the USP reference standard and its individual isomers, respectively. 


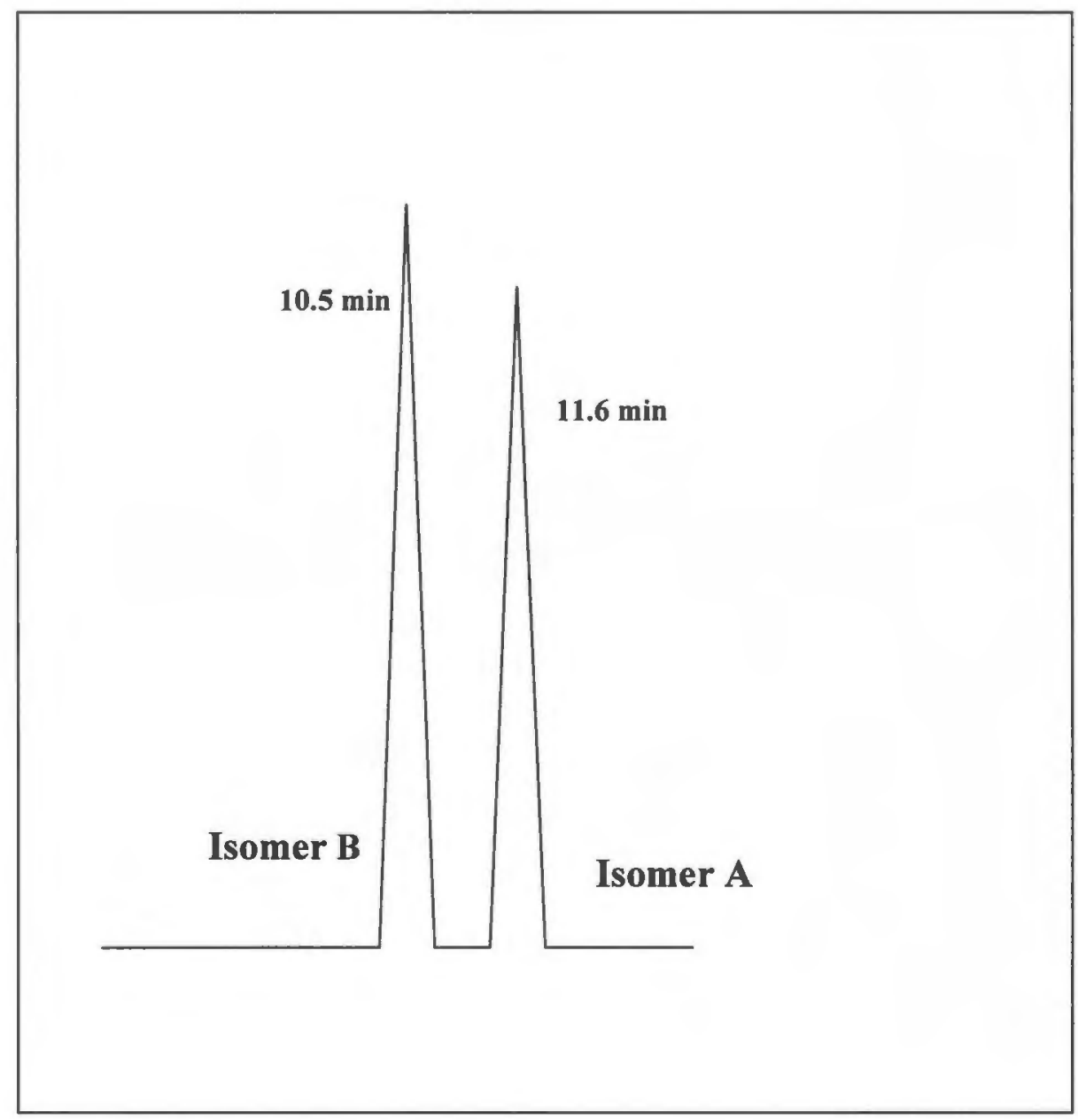

Figure 5: Chromatogram showing the peaks of isomers B and A, eluting at $10.5 \mathrm{~min}$ and $11.6 \mathrm{~min}$ 


\begin{tabular}{|c|c|c|c|c|c|c|c|}
\hline $\begin{array}{c}\text { Concentration } \\
(u g / \mathrm{ml})\end{array}$ & $\begin{array}{c}\text { AUC } \\
\text { Isomer B }\end{array}$ & $\begin{array}{c}\text { AUC } \\
\text { Isomer A }\end{array}$ & Total AUC & $\begin{array}{c}\text { Conc. (Isomer B) } \\
(\mu \mathrm{g} / \mathrm{ml})\end{array}$ & $\begin{array}{c}\text { Conc. (Isomer A) } \\
(\mu \mathrm{g} / \mathrm{ml})\end{array}$ & $\begin{array}{c}\text { Isomer B } \\
(\%)\end{array}$ & $\begin{array}{c}\text { Isomer A } \\
(\%)\end{array}$ \\
\hline $\begin{array}{c}0 \\
10.08 \\
20.16 \\
40.32 \\
60.48 \\
80.64 \\
100.8 \\
201.6\end{array}$ & $\begin{array}{c}0 \\
139424 \\
302160 \\
625688 \\
950409 \\
1328578 \\
1609064 \\
3182848\end{array}$ & $\begin{array}{c}0 \\
149775 \\
323067 \\
669151 \\
1007543 \\
1411506 \\
1697853 \\
3368529\end{array}$ & $\begin{array}{c}0 \\
289199 \\
625227 \\
1294839 \\
1957952 \\
2740084 \\
3306917 \\
6551377\end{array}$ & $\begin{array}{c}0 \\
4.86 \\
9.75 \\
19.48 \\
29.36 \\
39.09 \\
49.05 \\
97.94\end{array}$ & $\begin{array}{c}0 \\
5.22 \\
10.42 \\
20.84 \\
31.12 \\
41.54 \\
51.75 \\
103.66\end{array}$ & $\begin{array}{c}0 \\
48.21 \\
48.33 \\
48.32 \\
48.54 \\
48.49 \\
48.66 \\
48.58\end{array}$ & $\begin{array}{c}0 \\
51.79 \\
51.67 \\
51.68 \\
51.46 \\
51.51 \\
51.34 \\
51.42\end{array}$ \\
\hline
\end{tabular}

Table 3: Data for calibration curve of cefuroxime axetil 


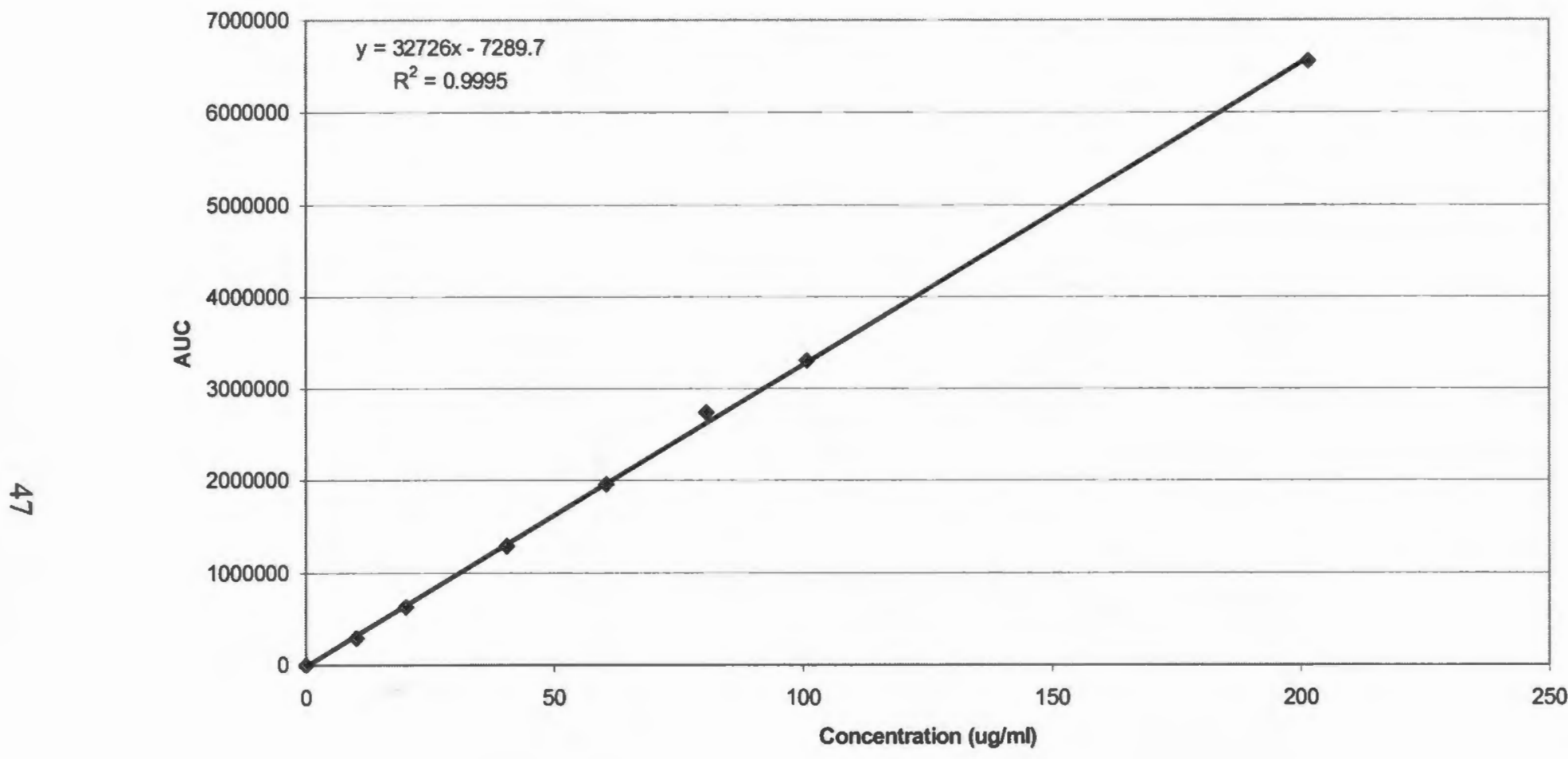

Figure 6: Representative calibration curve for cefuroxime axetil 


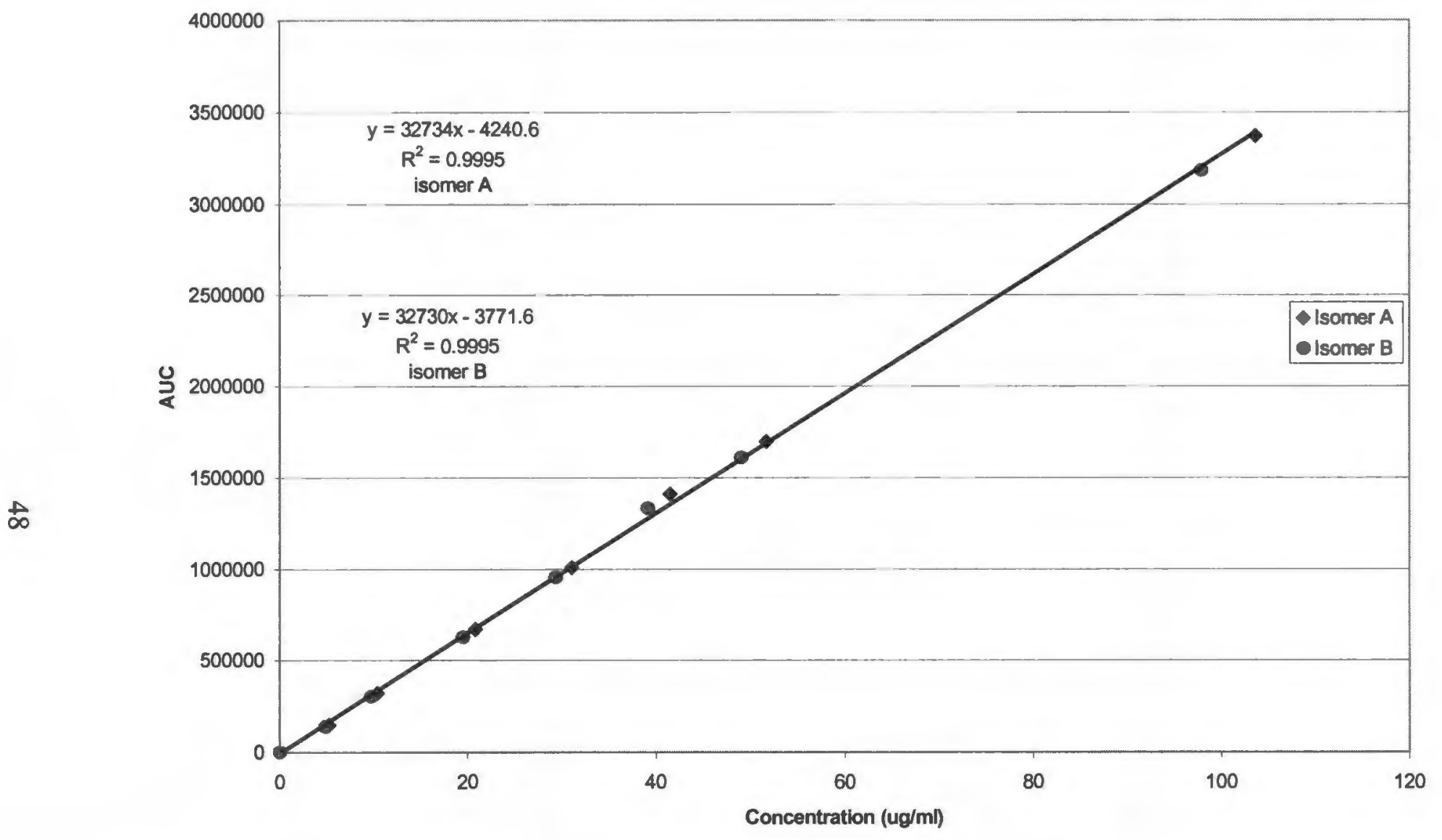

Figure 7: Representative calibration curves for the isomers $\mathrm{A}$ and $\mathrm{B}$ of cefuroxime axetil 
Table 4 shows the data for the calibration curve of cefuroxime axetil. Tables 5 and 6 show the data in terms of the individual isomers $\mathrm{A}$ and $\mathrm{B}$. Table 7 shows the percentage of isomers $\mathrm{A}$ and $\mathrm{B}$ in the cefuroxime axetil sample, and it can be seen that the ratio of the isomers lie within the USP limits. Figures 8 and 9 illustrate the linear portion of the calibration curve for the sample and its individual isomers, respectively. The correlation coefficient was found to be 0.9995 and 1.0 for cefuroxime axetil (USP) and the cefuroxime axetil sample respectively.

Table 8 shows the mean values of the data generated out of five days of replication studies for seven separate and distinct samples for series of cefuroxime axetil concentrations ranging from 10 to $200 \mu \mathrm{g} / \mathrm{ml}$.

The purity of the sample of cefuroxime axetil was determined as shown in Table 9. The average percentage purity was found to be $103.85 \%$ with a standard deviation of 4.462, when compared to the USP reference standard.

\subsection{Solubility Studies of Cefuroxime Axetil}

Solubility studies of the drug were carried out in water and $0.07 \mathrm{~N} \mathrm{HCl}$, for a period of 24 hours with samples withdrawn and analyzed at seven time intervals. The 24-hour time duration was selected to allow the drug to reach its equilibrium solubility. The USP dissolution test for cefuroxime axetil tablets uses $0.07 \mathrm{~N} \mathrm{HCl}$ as the dissolution medium in order to simulate gastric conditions; hence it has been selected as one of the media for solubility studies. 


\begin{tabular}{|c|c|c|c|c|c|c|c|}
\hline $\begin{array}{c}\text { Concentration } \\
(\mu \mathrm{g} / \mathrm{ml})\end{array}$ & $\begin{array}{c}\text { Av. AUC } \\
{[1]}\end{array}$ & $\begin{array}{c}\text { Av. AUC } \\
{[2]}\end{array}$ & $\begin{array}{c}\text { Av. AUC } \\
{[3]}\end{array}$ & $\begin{array}{c}\text { Av. AUC } \\
{[4]}\end{array}$ & $\begin{array}{c}\text { Av. AUC } \\
{[5]}\end{array}$ & Av. AUC & Std. Dev. \\
\hline 10 & 312426 & 314608 & 332367 & 319419 & 331576 & 322079 & 8391.76 \\
20 & 643677 & 637731 & 631992 & 685701 & 675389 & 654898 & 21512.76 \\
40 & 1286830 & 1277833 & 1297919 & 1392295 & 1391674 & 1329310 & 51567.87 \\
60 & 1918719 & 1911772 & 1938960 & 2171403 & 2167442 & 2021659 & 120984.89 \\
100 & 2594779 & 2545924 & 2556001 & 2803400 & 2792579 & 2658536 & 115076.64 \\
200 & 6464686 & 6347863 & 6411309 & 7092098 & 7013097 & 6665810 & 318948.92 \\
& & & & & & & \\
\hline
\end{tabular}

Table 4: Data for calibration curve of total concentration of cefuroxime axetil 


\begin{tabular}{|c|c|c|c|c|c|c|c|}
\hline $\begin{array}{c}\text { Concentration } \\
(\mu \mathrm{g} / \mathrm{ml})\end{array}$ & $\begin{array}{c}\text { Av. AUC } \\
{[1]}\end{array}$ & $\begin{array}{c}\text { Av. AUC } \\
{[2]}\end{array}$ & $\begin{array}{c}\text { Av. AUC } \\
{[3]}\end{array}$ & $\begin{array}{c}\text { Av. AUC } \\
{[4]}\end{array}$ & $\begin{array}{c}\text { Av. AUC } \\
{[5]}\end{array}$ & Av. AUC & Std. Dev. \\
\hline 10 & 160575 & 162050 & 170916 & 163362 & 168946 & 165170 & 4034.41 \\
20 & 331119 & 327530 & 323917 & 351588 & 345187 & 335868 & 10666.32 \\
40 & 660897 & 652037 & 664676 & 712155 & 711938 & 680340 & 26210.80 \\
60 & 982291 & 975823 & 992157 & 1113526 & 1114671 & 1035693 & 64229.22 \\
80 & 1328460 & 1297967 & 1306663 & 1431649 & 1433550 & 1359657 & 60382.51 \\
100 & 1656111 & 1645014 & 1635584 & 1786412 & 1794267 & 1703477 & 71262.75 \\
200 & 3328511 & 3258313 & 3294722 & 3651349 & 3601925 & 3426964 & 165277.89 \\
\hline
\end{tabular}

Table 5: Data for calibration curve of isomer A of the drug 


\begin{tabular}{|c|c|c|c|c|c|c|c|}
\hline $\begin{array}{c}\text { Concentration } \\
(\mu \mathrm{g} / \mathrm{ml})\end{array}$ & $\begin{array}{c}\text { Av. AUC } \\
{[1]}\end{array}$ & $\begin{array}{c}\text { Av. AUC } \\
{[2]}\end{array}$ & $\begin{array}{c}\text { Av. AUC } \\
{[3]}\end{array}$ & $\begin{array}{c}\text { Av. AUC } \\
{[4]}\end{array}$ & $\begin{array}{c}\text { Av. AUC } \\
{[5]}\end{array}$ & Av. AUC & Std. Dev. \\
\hline 10 & 151850 & 152557 & 161451 & 156056 & 162630 & 156909 & 4440.95 \\
20 & 312558 & 310201 & 308075 & 334113 & 330202 & 319030 & 10882.69 \\
40 & 625933 & 625795 & 633243 & 680140 & 679736 & 648969 & 25429.3 \\
60 & 936428 & 935949 & 946803 & 1057877 & 1052771 & 985965 & 56786.6 \\
80 & 1266319 & 1247956 & 1249338 & 1371751 & 1359029 & 1298879 & 54837.97 \\
100 & 1573644 & 1552513 & 1552704 & 1698657 & 1696908 & 1614885 & 68122.07 \\
200 & 3136174 & 3089549 & 3116586 & 3440749 & 3411172 & 3238846 & 153778.6 \\
& & & & & & & \\
\hline
\end{tabular}

Table 6: Data for calibration curve of isomer B of the drug 


\begin{tabular}{|c|c|c|c|c|c|c|c|}
\hline $\begin{array}{c}\text { Concentration } \\
(\mu \mathrm{g} / \mathrm{ml})\end{array}$ & $\begin{array}{c}\text { Av. AUC } \\
\text { (total) }\end{array}$ & $\begin{array}{c}\text { Av. AUC } \\
\text { (isomer A) }\end{array}$ & $\begin{array}{l}\text { Av. AUC } \\
\text { (isomer B) }\end{array}$ & $\begin{array}{c}\text { Concentration } \\
\text { (isomer A) } \\
(\mu \mathrm{g} / \mathrm{ml})\end{array}$ & $\begin{array}{c}\text { Concentration } \\
\text { (isomer B) } \\
(\mu \mathrm{g} / \mathrm{ml})\end{array}$ & $\%$ isomer $\mathrm{A}$ & $\%$ isomer $\mathrm{B}$ \\
\hline 10 & 322079 & 165170 & 156909 & 5.13 & 4.87 & 51.28 & 48.72 \\
\hline 20 & 654898 & 335868 & 319030 & 10.26 & 9.74 & 51.29 & 48.71 \\
\hline 40 & 1329310 & 680340 & 648969 & 20.47 & 19.53 & 51.18 & 48.82 \\
\hline 60 & 2021659 & 1035694 & 985965 & 30.74 & 29.26 & 51.23 & 48.77 \\
\hline 80 & 2658536 & 1359658 & 1298879 & 40.92 & 39.09 & 51.14 & 48.86 \\
\hline 100 & 3318363 & 1703478 & 1614885 & 51.33 & 48.67 & 51.34 & 48.67 \\
\hline 200 & 6665810 & 3426964 & 3238846 . & 102.82 & 97.18 & 51.411 & 48.59 \\
\hline
\end{tabular}

Table 7: Percentage of isomers A and B determined from the calibration data of total drug and the individual isomers 


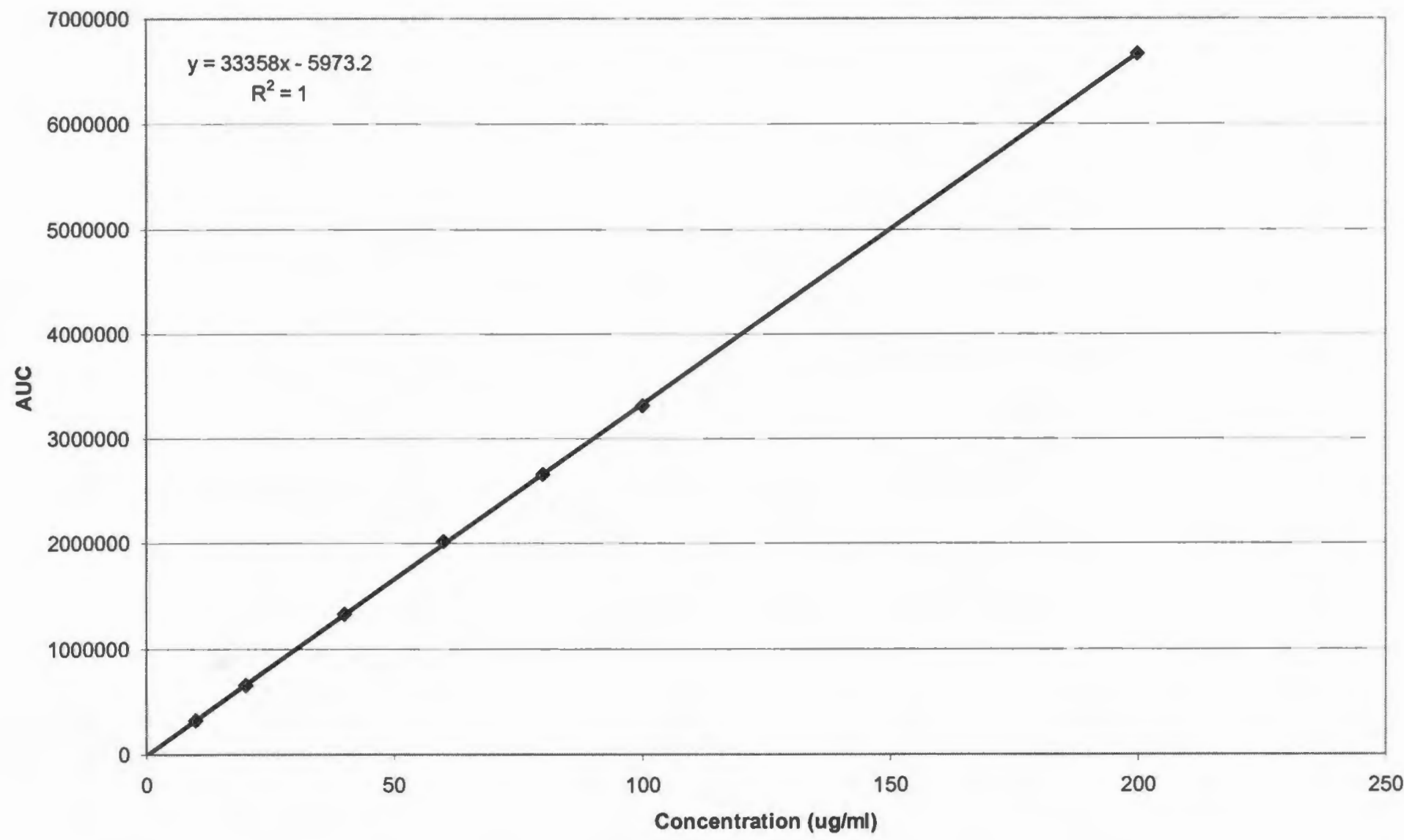

Figure 8: Representative calibration curve from the replication study for cefuroxime axetil 


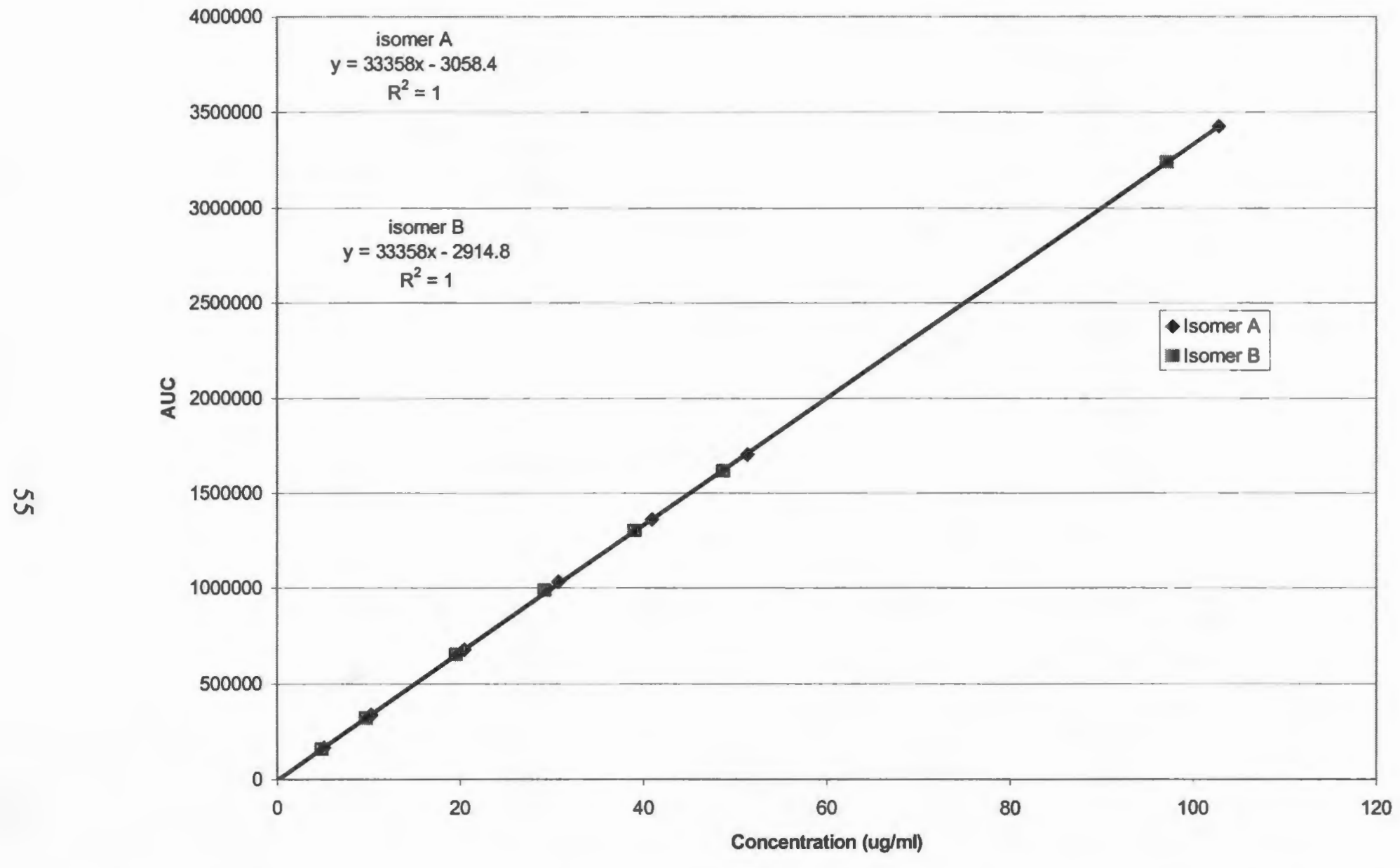

Figure 9: Representative calibration curve for isomers A and B from the replication study for cefuroxime axetil 


\begin{tabular}{|c|c|c|c|c|c|c|c|c|c|}
\hline \multirow{2}{*}{$\begin{array}{c}\text { Concentration } \\
(\text { ug/ml })\end{array}$} & \multicolumn{3}{|c|}{ Isomer A } & \multicolumn{3}{c|}{ Isomer B } & \multicolumn{3}{c|}{ Total } \\
\cline { 2 - 9 } & Av. AUC & Std. Dev. & $\%$ CV & Av. AUC & Std. Dev. & $\%$ CV & Av. AUC & Std. Dev. & $\%$ CV \\
\hline 10 & 165170 & 4034.41 & 2.44 & 156909 & 4440.95 & 2.83 & 322079 & 8391.75 & 2.61 \\
20 & 335868 & 10666.32 & 3.17 & 319030 & 10882.69 & 3.41 & 654898 & 21512.75 & 3.28 \\
40 & 680341 & 26210.8 & 3.85 & 648970 & 25429.3 & 3.92 & 1329310 & 51567.86 & 3.87 \\
60 & 1035694 & 64229.22 & 6.2 & 985966 & 56786.59 & 5.76 & 2021660 & 120984.89 & 5.98 \\
80 & 1359658 & 60382.51 & 4.44 & 1298879 & 54837.97 & 4.22 & 2658537 & 115076.63 & 4.32 \\
100 & 1703478 & 71262.75 & 4.18 & 1614886 & 68122.07 & 4.21 & 3318363 & 139303.25 & 4.19 \\
200 & 3426964 & 165277.89 & 4.82 & 3238846 & 153778.63 & 4.75 & 6665811 & 318948.91 & 4.78 \\
\hline
\end{tabular}

Table 8: Reproducibility of cefuroxime axetil from standard solutions over 5 days of replication studies 


\begin{tabular}{|c|c|c|c|c|c|}
\hline \multicolumn{2}{|c|}{ Cefuroxime Axetil (USP Std.) } & \multicolumn{4}{|c|}{ Cefuroxime Axetil (sample) } \\
\hline $\begin{array}{c}\text { Concentration } \\
(\mu \mathrm{g} / \mathrm{ml})\end{array}$ & Total AUC & $\begin{array}{c}\text { Theoretical } \\
\text { Concentration } \\
(\mu \mathrm{g} / \mathrm{ml})\end{array}$ & Total AUC & $\begin{array}{c}\text { Experimental } \\
\text { Concentration } \\
(\mu \mathrm{g} / \mathrm{ml})\end{array}$ & $\%$ Purity \\
\hline 10.08 & 289199 & 10 & 322079.2 & 11.23 & 112.26 \\
20.16 & 625227 & 20 & 654898.3 & 21.12 & 105.58 \\
40.32 & 1294839 & 40 & 1329310.4 & 41.39 & 103.48 \\
60.48 & 1957952 & 60 & 2021659.6 & 62.45 & 104.08 \\
80.64 & 2740084 & 80 & 2658536.9 & 78.24 & 97.80 \\
100.8 & 3306917 & 100 & 3318363.4 & 101.15 & 101.15 \\
201.6 & 6551377 & 200 & 6665810.7 & 205.12 & 102.56 \\
\cline { 5 - 7 } & & & & $\begin{array}{c}\text { Average } \\
\text { Std. Dev. }\end{array}$ & 103.85 \\
& & & & & 4.46 \\
\hline
\end{tabular}

Table 9: Determination of the percentage purity of the cefuroxime axetil sample based on the USP reference standard 
As observed from the solubility profile of the drug (Figure 10), CA reaches its equilibrium solubility by 4 hours and remains at equilibrium for over 10 hours. An excess amount of the drug in the medium ensured equilibrium and also accounted for any degradation that may have taken place during the 24 hour time period. The studies were conducted at room temperature $\left(25^{\circ} \mathrm{C}\right)$. Previous studies have shown that CA undergoes hydrolytic degradation in solution ${ }^{1}$. The first-order hydrolysis kinetics of $\mathrm{CA}$ was investigated as a function of $\mathrm{pH}$, temperature, buffers, and ionic strength. Chromatographically identified hydrolysis products were cefuroxime, $\Delta^{2}$-cefuroxime axetil, and $\alpha, \beta$-sulfoxides. Experimental Design: For these studies, excess amount of the sample $(\sim 30-40$ $\mathrm{mg}$ ) was weighed and transferred to a glass vial. After addition of $4 \mathrm{ml}$ of the medium, the vials were allowed to equilibrate on a rotary mixer for 24 hours. Samples were withdrawn at intervals of $10 \mathrm{~min}, 30 \mathrm{~min}, 45 \mathrm{~min}, 1 \mathrm{hr}, 2 \mathrm{hr}, 4 \mathrm{hr}$, $8 \mathrm{hr}$ and $24 \mathrm{hr}$. The solution was filtered, diluted with mobile phase and analyzed by HPLC. The solubility determination of each sample was done in triplicate. The concentration of the drug in solution was determined using the standard curves.

The solubility of the USP reference standard was determined in water and 0.07 $\mathrm{N} \mathrm{HCl}$ (see Figure 11). The untreated cefuroxime axetil sample was first tested to determine its solubility profile. The drug was then treated with a combination of processes and polymers. The solubility of these processed mixtures was then determined by the above procedure. The purity of the drug after treatment (with 


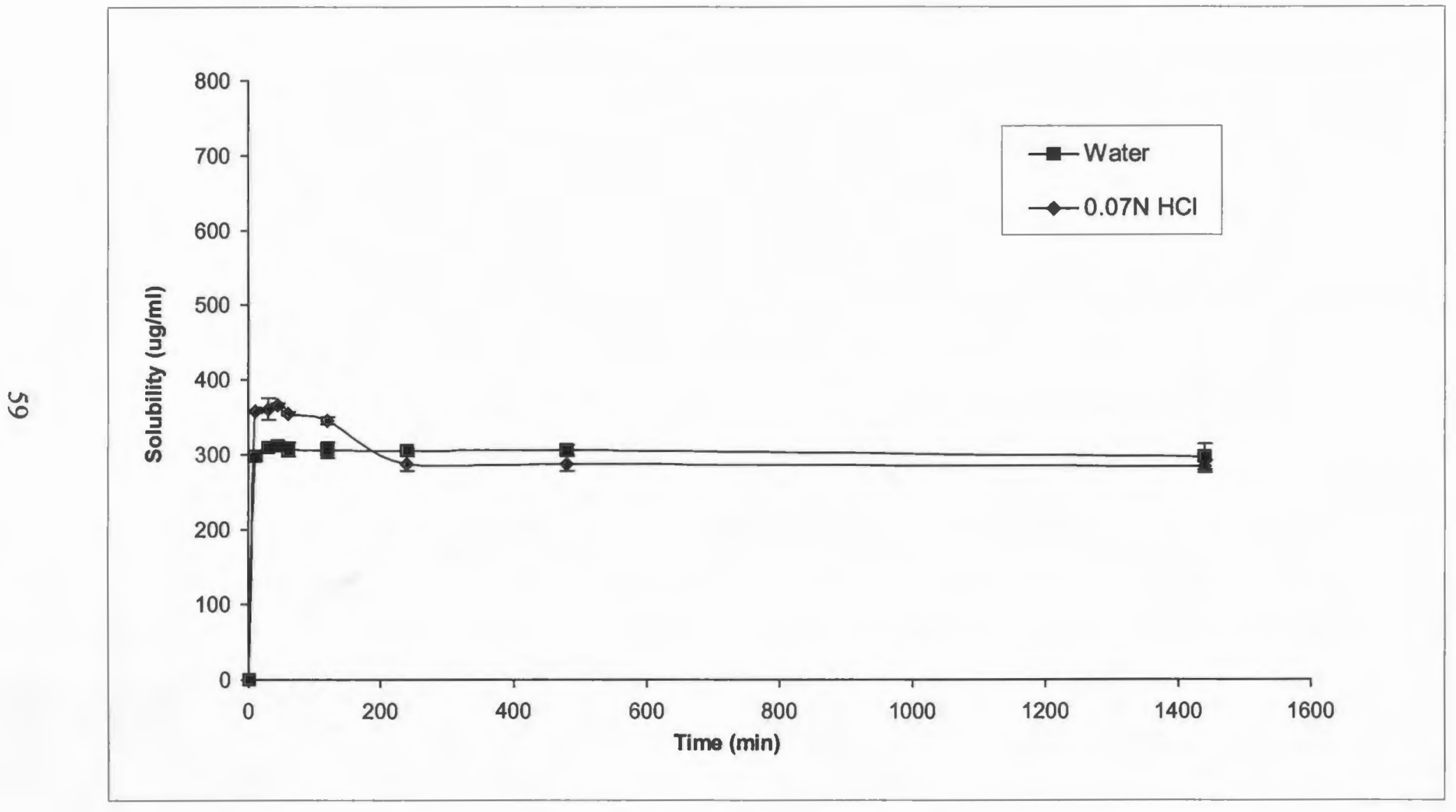

Figure 10: Solubility profile of untreated cefuroxime axetil in water and $0.07 \mathrm{~N} \mathrm{HCl}$ (average of $n=3$, \pm S.D.) 


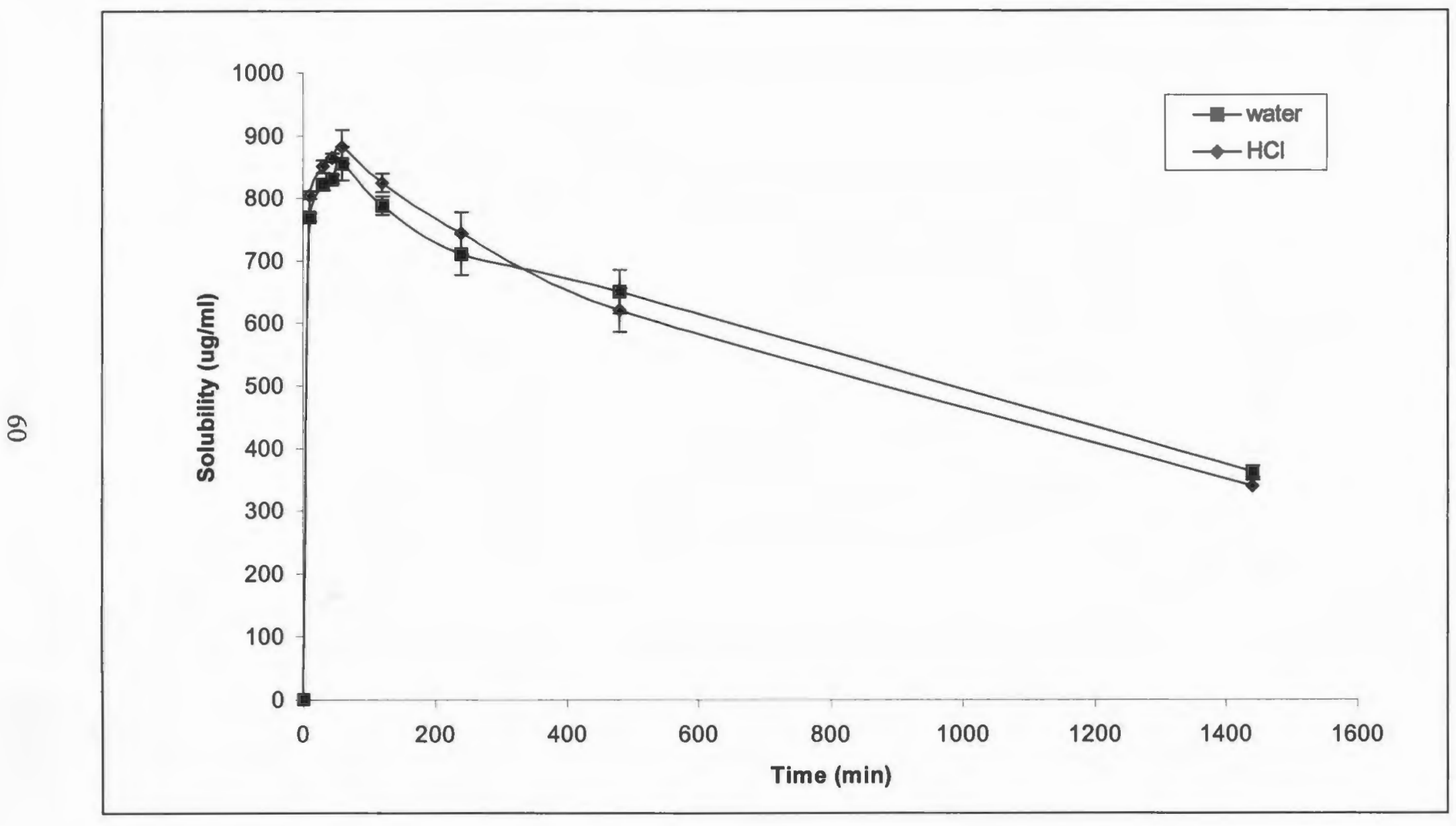

Figure 11: Solubility profile of cefuroxime axetil in water and $0.07 \mathrm{~N} \mathrm{HCl}$ (average of $n=3, \pm$ S.D.) 
process and/or polymer), was also determined to rule out any interactions /loss /degradation of the drug.

\subsection{Modification of Physical State}

This section deals with the various processes and polymers that were employed to bring about a modification in the solid state of the drug. Each factor is dealt with individually in a separate sub-section.

\subsubsection{Selection of Polymers}

The use of a polymer serves three purposes; enhances solubility, acts as an impurity to destabilize the rigid crystal structure ${ }^{2,3,4}$, and in the amorphous state, assists in preventing the re-conversion of the unstable amorphous state to its stable crystalline state ${ }^{5}$. This approach was adopted as the unstable nature of the amorphous state was recognized and known to limit its wider application. Amorphous substances cannot achieve their maximum theoretical solubility under practical experimental conditions because of the strong driving force for crystallization in the presence of the dissolution media ${ }^{6}$. Several previous workers have tried to avoid this problem by adding crystallization inhibitors to their dissolution media ${ }^{7}$.

The polymers selected were Eudragit EPO, Eudragit RD 100 and Polyvinylpyrrolidine (PVP C15). 
Eudragit $\Theta E P O$ supplied by Rohm America, in the powder form and is a cationic polymer with a dimethyl-aminoethyl ammonium functional group. It is a $\mathrm{pH}$ dependent polymer and is soluble in gastric fluid up to $\mathrm{pH} 5.0$, and swellable and permeable above $\mathrm{pH}$ 5.0. It has taste masking and odor masking properties ${ }^{8}$.

Eudragit $\Theta R D 100$ supplied by Rohm America, as powder and is based on Eudragit RL 100 (copolymer of acrylate and methacrylates with quaternary ammonium group as a functional group) and $\mathrm{Na}-\mathrm{CMC}$. It forms rapidly disintegrating films that are independent of $\mathrm{pH}^{8}$.

Both the Eudragits are used for immediate release coatings.

PVP C15 provided by ISP Technologies Inc., in the powder form and is a synthetic water-soluble polymer. It has a K-value of $16-18$, a molecular weight of 8,000 and a typical viscosity of $1.5 \mathrm{mPa}$.s. The $\mathrm{K}$-value is calculated from the kinematic viscosity of a $1 \%$ aqueous solution and hence is related to the average molecular weight of the polymer. It is also soluble in a wide range of organic solvents enabling its use in water sensitive pharmaceutical dosage forms. The viscosity of PVP in aqueous solution is unaffected by $\mathrm{pH}$ and salt concentration 9 . 


\subsubsection{Selection of Processes}

In this study, the process of microfluidization has been used to assist in converting the drug from its crystalline to amorphous form. Microfluidization is a widely used technique for the homogenization of emulsions and dispersions, liposomes and cell disruption. The M-110S Microfluidizer ${ }^{\circledR}$ Processor (Microfluidics Corporation, Newton, MA) shown in Figure 12, contains an airpowered intensifier pump designed to supply the desired pressure at a constant level to the product stream ${ }^{10}$. As the pump travels through its pressure stroke, it drives the product at a constant pressure through precisely defined fixedgeometry microchannels within the interaction chamber (Figure 13). As a result, the product stream accelerates to high velocities, creating shear rates within the product streams that are orders of magnitude greater than any other conventional means. All of the product experiences identical processing conditions, producing the desired results, including uniform particle size, and droplet size reduction (often submicron), deagglomeration, and high yield cell disruption. This study uses an existing technique for a new application, the modification of the crystal structure. A solution of the drug and/or polymer in an appropriate solvent system was prepared, and then passed through the microfluidizer under a defined set of conditions. The solvents were removed, and the treated drug characterized by solubility, DSC, XRD and microscopy. A system of drug/polymer in similar solvents was also prepared by solvent evaporation to study effects of solvent, if any. A physical mixture of the drug and polymer was also studied to determine any effects of polymer in the absence 


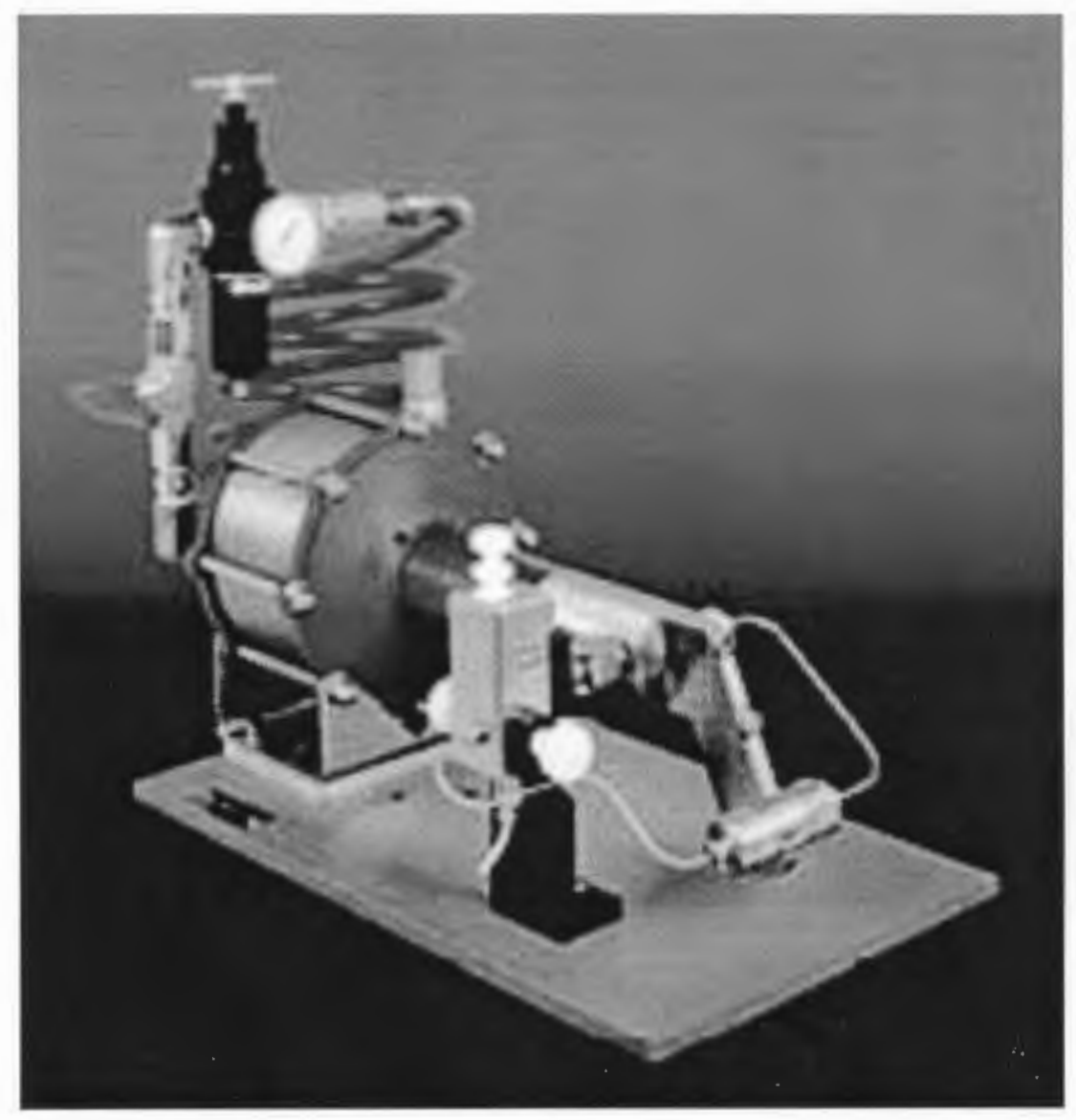

Figure 12: Picture of the M-110S Microfluidizer processor, Microfluidics Corp. 


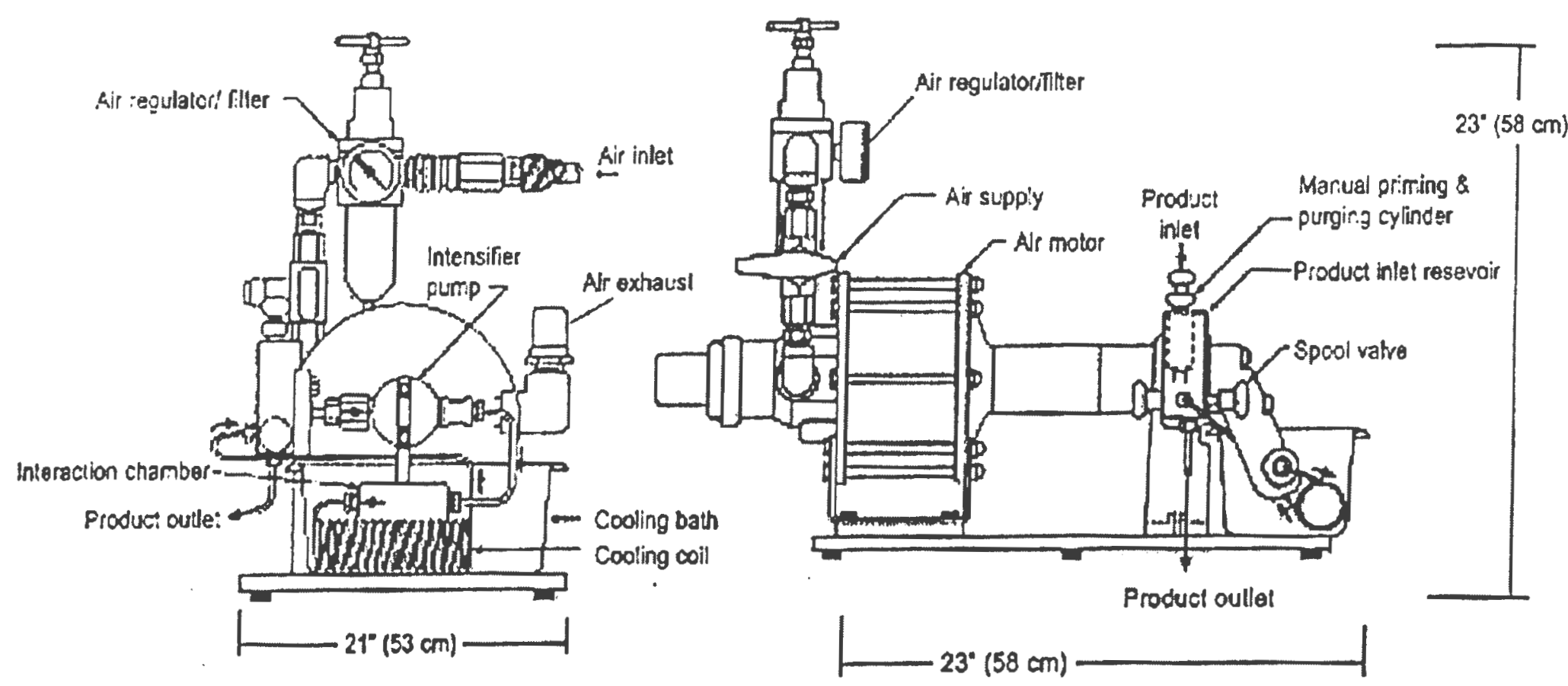

Figure 13: Diagram showing the parts and dimensions of the M-1 10S Microfluidizer, Microfluidics Corp. 
of the processes. The ratio of polymer in the drug-polymer mixture has been kept at a minimum. Throughout the studies the ratio of drug:polymer has been kept constant at 9:1. Low amounts of polymer can act as impurities in the destabilization of the crystal structure.

Experimental Design I: The drug and/or polymer were weighed out $(900 \mathrm{mg}$ drug $+100 \mathrm{mg}$ polymer) and dissolved by sonication in $20 \mathrm{ml}$ of a 1:1:2 mixture of acetone, methanol and ethanol. The pressure gauge of the microfluidizer was set at 40 psi. The solution was then passed through the equipment for 10 strokes of the pump and collected from the outlet. The solution was decolorized with charcoal to adsorb any impurities and to ensure a product with an acceptable color (white to pale yellow), and filtered under vacuum. The filtered solution was transferred to a glass evaporating dish that was placed under the vacuum hood, and the solvents were allowed to evaporate at room temperature. After the complete evaporation of the solvents, the sample was dried under vacuum in a dessicator for 24 hours or until no further loss in weight was observed. The sample was collected, percent yield determined and then stored in glass vials in a dessicator placed in a refrigerator, for further use.

Experimental Design II: The drug and/or polymer were weighed out (900 $\mathrm{mg}$ drug $+100 \mathrm{mg}$ polymer) and dissolved by sonication in $10 \mathrm{ml}$ of a $1: 1$ mixture of acetone and methanol. The solution was decolorized with charcoal, filtered under vacuum and then transferred to an evaporating dish. The solvents were allowed to evaporate at room temperature under the vacuum hood, and then the 
samples were transferred to a dessicator in which they were further dried for 24 hours or until no further loss in weight occurred. The samples obtained were weighed to determine the percent yield and were henceforth stored under vacuum in a refrigerator.

Experimental Design III: The drug and/or polymer were weighed out $(900 \mathrm{mg}$ drug $+100 \mathrm{mg}$ polymer) and transferred to a glass vial. The vial was placed on the rotary mixer for 10 min to ensure proper mixing of the drug and the polymer. This physical mixture of the drug and polymer was then used for solubility determinations and other characterizations.

Table 10 lists all the drug-polymer-process combinations that have been studied in this project.

\subsubsection{DSC Studies}

DSC analysis was carried out using Perkin Elmer DSC7 (Perkin Elmer, Wellesley, MA). Samples were weighed (approximately $10 \mathrm{mg}$ ), sealed in aluminum pans and loaded into the pan holder. An empty pan was used as blank. The scanning rate was set to $10^{\circ} \mathrm{C} / \mathrm{min}$. Three separate samples were tested for the drug and each of the processed mixtures.

\subsection{Results and Discussion}

The solubility profiles of the USP reference standard (Figure 11) and the sample (Figure 10) were determined. The USP reference standard was found to be in the amorphous form, as confirmed by the XRD data which showed an absence 


\begin{tabular}{|c|c|c|c|}
\hline No. & Drug & Polymer & Process \\
\hline & & & \\
1 & CA & - & - \\
2 & CA & - & Microfluidization \\
3 & CA & - & Solvent Evaporation \\
4 & CA & PVP & - \\
5 & CA & Eud EPO & - \\
6 & CA & Eud RD 100 & - \\
7 & CA & PVP & Microfluidization \\
8 & CA & Eud EPO & Microfluidization \\
9 & CA & Eud RD 100 & Microfluidization \\
10 & CA & PVP & Solvent Evaporation \\
11 & CA & Eud EPO & Solvent Evaporation \\
12 & CA & Eud RD 100 & Solvent Evaporation \\
& & & \\
\hline
\end{tabular}

Table 10: The combinations of drug-polymer-process that have been studied 
of peaks (see Figure 14). Over the duration of the solubility experiments, the amorphous starting material begins converting to its stable crystalline form, as evident from the solubility profile of the USP reference standard (Figure 11). The commercial sample exhibited multiple peaks in the XRD (Figure 15) indicating the presence of the crystalline form. The DSC data for the commercial sample (Figure 16) shows the presence of two melting endotherms, at $123{ }^{\circ} \mathrm{C}$ and at $173{ }^{\circ} \mathrm{C}$, for the two isomers $\mathrm{B}$ and $\mathrm{A}$, respectively. The drug degrades (at $\sim 175^{\circ} \mathrm{C}$ ) after the melting of the second isomer, as observed from the loss of the straight nature of the baseline. Also, visual examination shows browning and charring of the drug after $\sim 176^{\circ} \mathrm{C}$ when examined on the melting point apparatus. The drug in the solid form exists as a 1:1 mixture of the two isomers, A and B. However, in solution, isomer B is in greater concentration than isomer A due to its significantly greater solubility. In aqueous solution, the ratio of the solubilized isomers is 9:1 (B:A) (see Figure 17). This is also true for the solubility determinations made in $0.07 \mathrm{~N} \mathrm{HCl}$. The solubility of isomer $\mathrm{B}$ is $\sim 5$ times the solubility of isomer A (Figure 18).

Solubility determinations, using excess amounts of drug, follow a zero-order kinetics, in which the concentration in solution depends on the drug's solubility. Excess drug replaces any drug lost due to degradation in solution, whereby more drug is released from the suspended particles so that the amount of dissolved drug remains constant. This concentration is the drug's equilibrium solubility in a particular solvent at a particular temperature ${ }^{\mathrm{ll}}$. It is important to note that the amount of drug in solution remains constant despite its decomposition with time. 


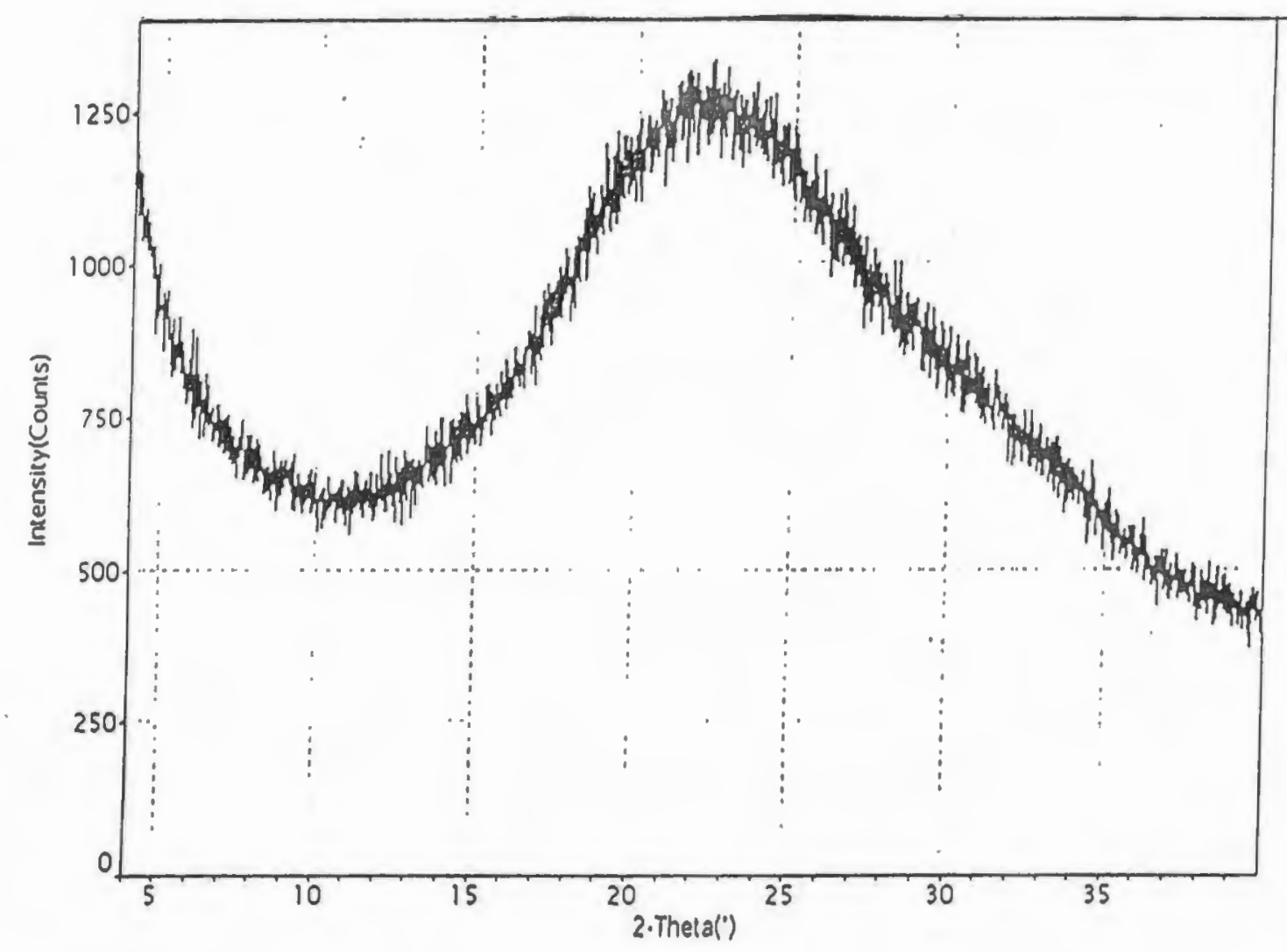

Figure 14: XRD scan of the USP reference standard of cefuroxime axetil 


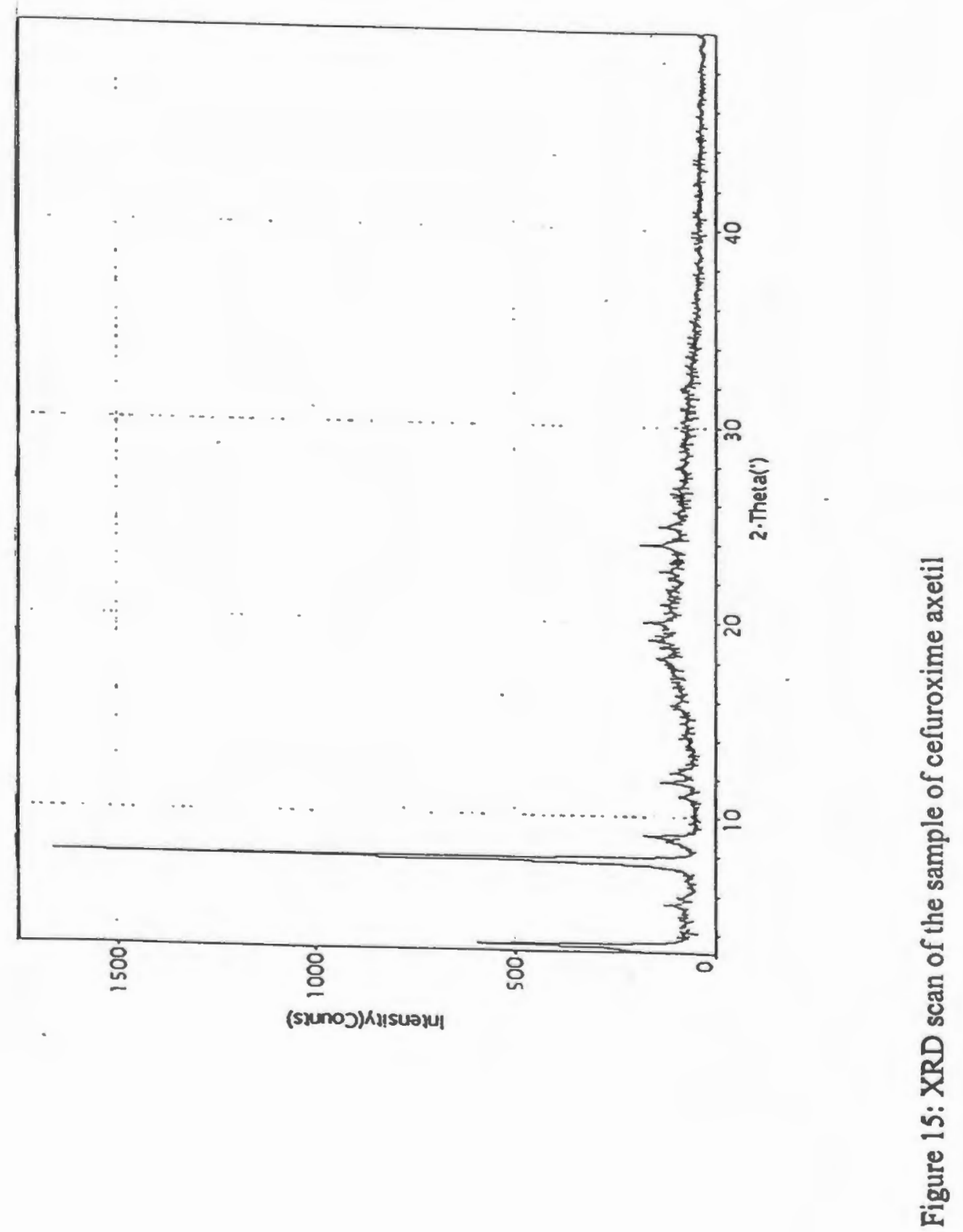




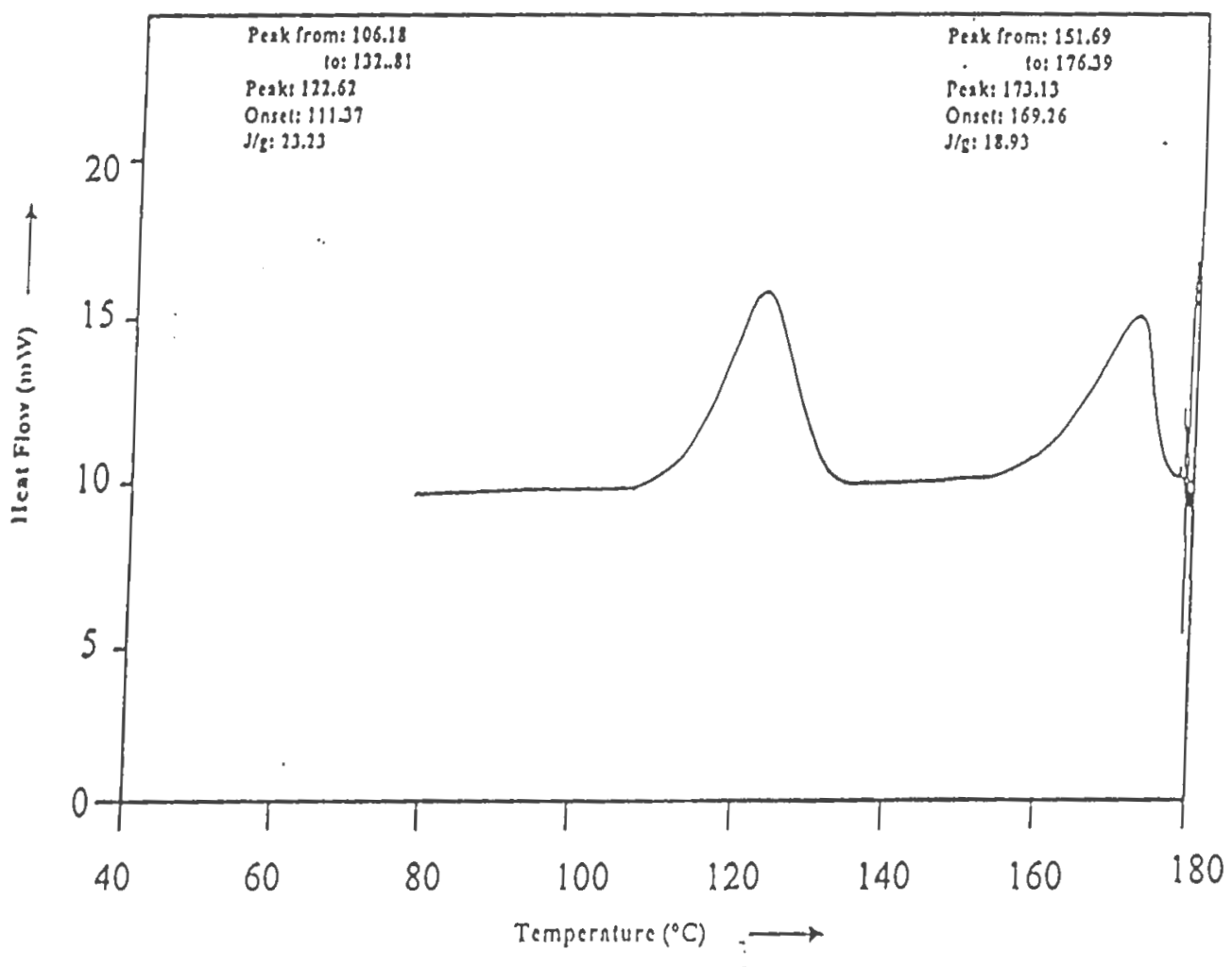
Figure 16: DSC thermogram for the commercial sample showing the presence of the two melting edotherms at $124^{\circ} \mathrm{C}$
and $173^{\circ} \mathrm{C}$ (weight of sample $=10 \mathrm{mg}$, scanning ratc $=10^{\circ} \mathrm{C} / \mathrm{min}$ ) 


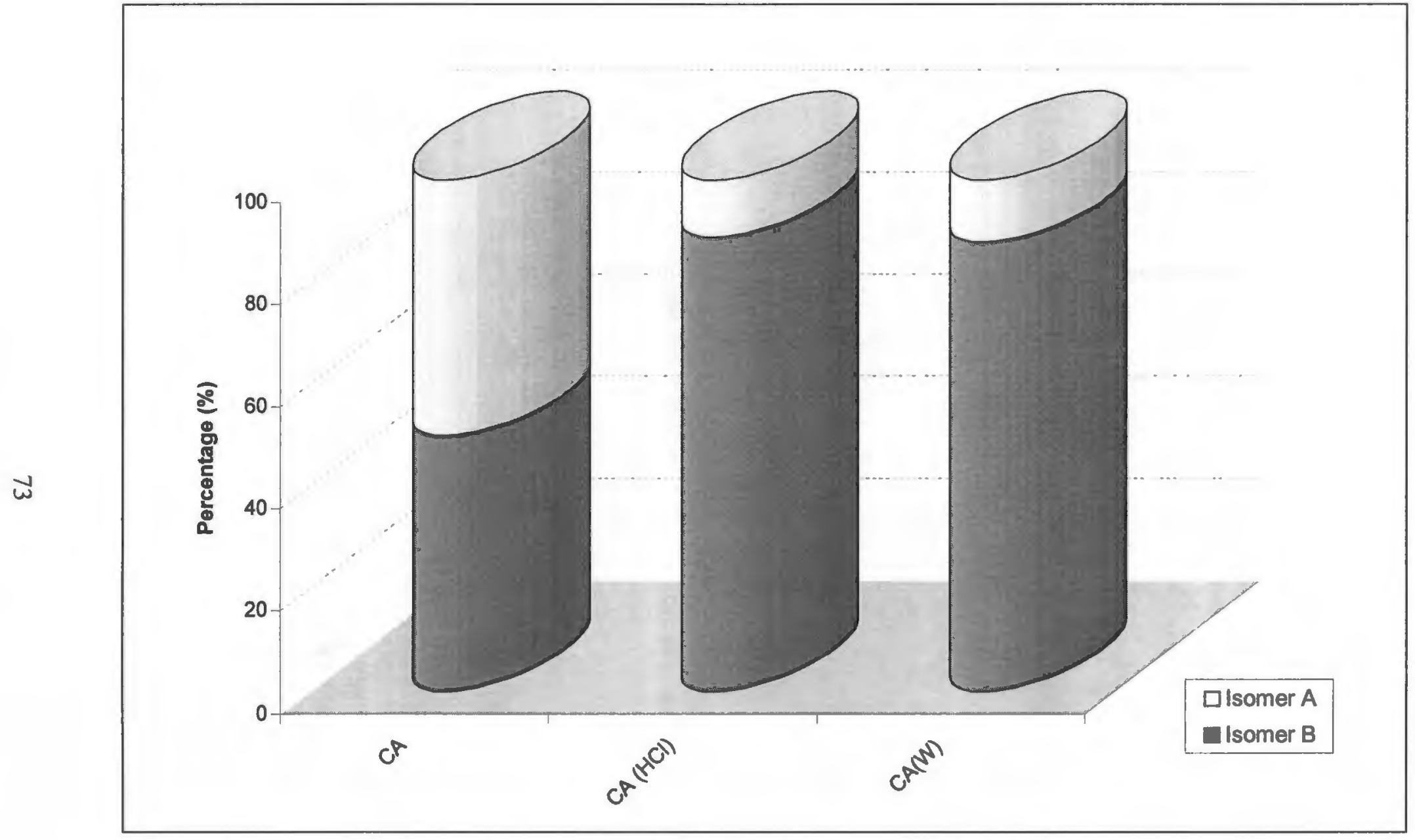

Figure 17: The percentage of isomers $\mathrm{A}$ and $\mathrm{B}$, of the solid drug (cefuroxime axetil) and the drug in solution [in $0.07 \mathrm{~N} \mathrm{HCl}$ $(\mathrm{HCl})$ and water $(\mathrm{W})]$ 


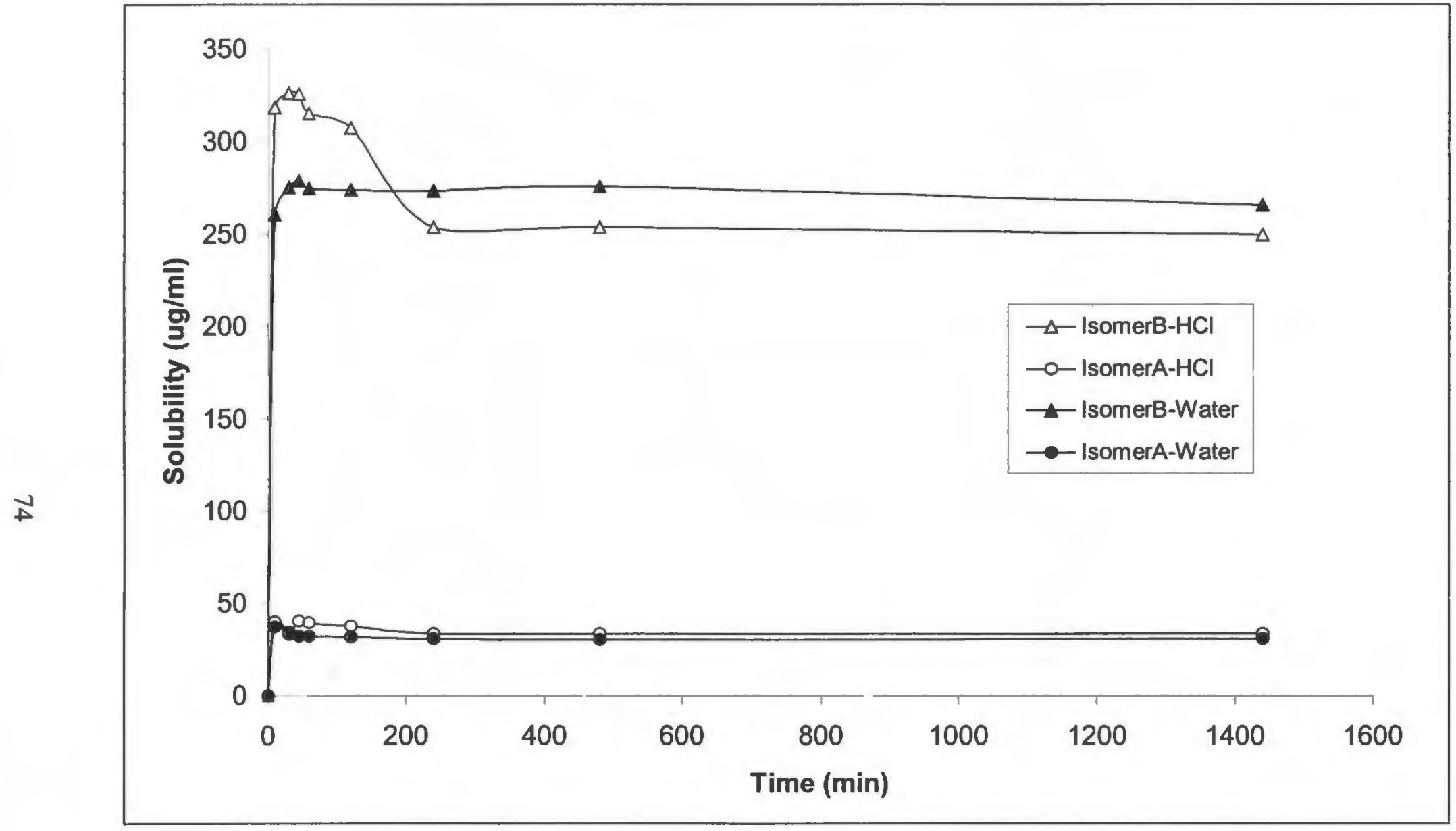

Figure 18: The solubility profile of isomers $\mathrm{A}$ and $\mathrm{B}$ in water and $0.07 \mathrm{~N} \mathrm{HCl}$ 
Degradation of CA was observed from the appearance of multiple peaks on the chromatograms in addition to the isomer peaks. The initial rate of solubilization of the drug varies hyperbolically with time. During the initial time period, the drug goes into solution continuously, increasing the concentration of the drug linearly. This approximates first-order kinetics in that the rate of dissolution is proportional to time. As the time increases, more and more drug goes into solution, until the solution is saturated with the drug, and zero-order or saturation kinetics is observed.

In the following section, the effect on solubility of the drug has been compared in the absence and in the presence of the selected polymers.

2.4.1 Effect of crystalline to amorphous conversion on solubility of the drug in the absence of polymers

The solubility profiles of the untreated drug, its microfluidized form and its recrystallized form were examined. As seen in Figure 19 both the processes bring about an increase in the solubility of CA. However, the recrystallized drug shows a dramatic decrease in solubility after the first two hours, reducing the amount of drug dissolved to the solubility of untreated CA after 24 hours. This indicates conversion of the amorphous (high solubility) form to its crystalline (low solubility) form. Similar observations of amorphous to crystalline conversion during solubility studies have been made for drugs like indomethacin and griseofulvin ${ }^{6}$. The microfluidized drug shows a very gradual decrease in solubility and would eventually reach the equilibrium solubility of 


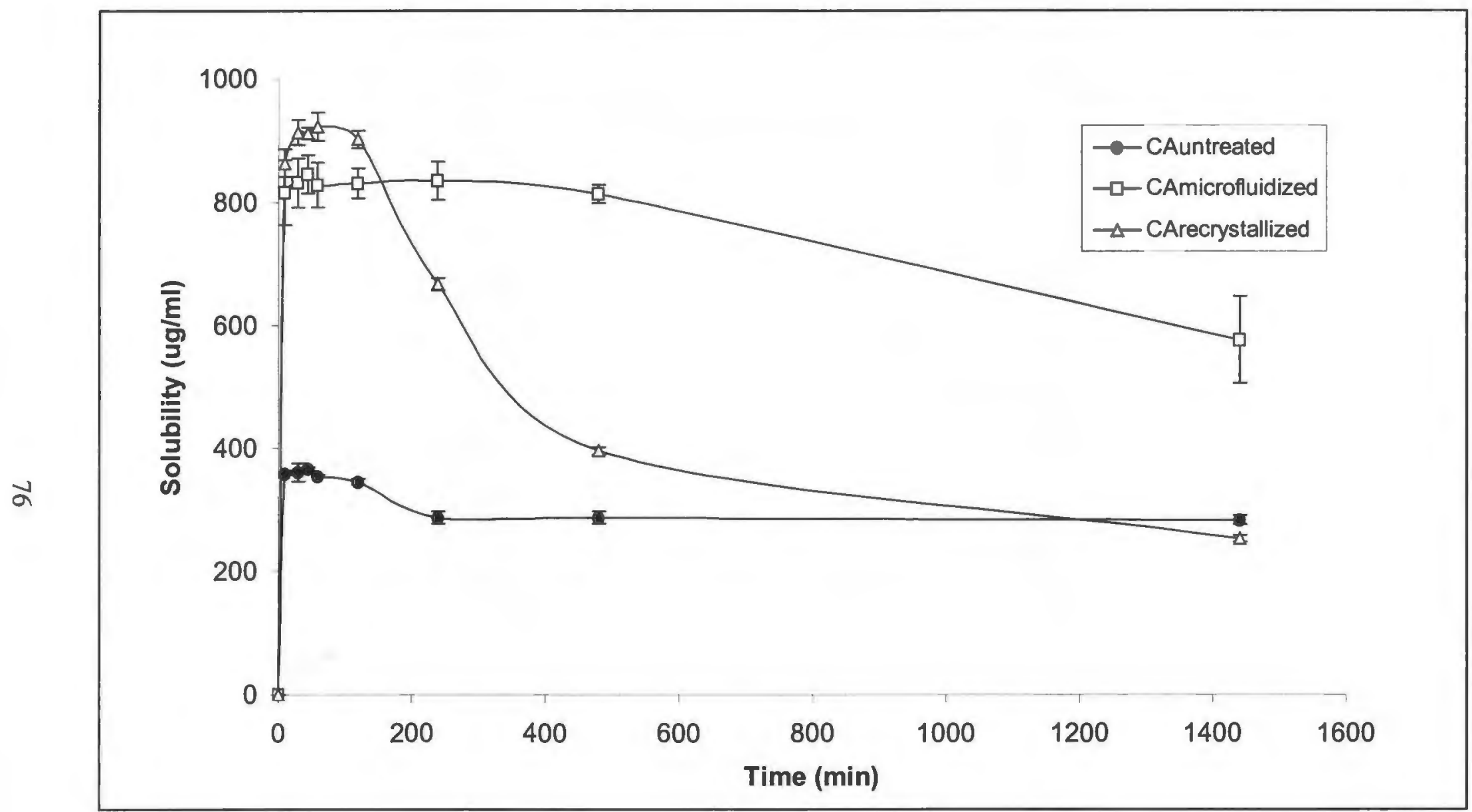

Figure 19: Solubility profile of untreated, microfluidized and recrystallized cefuroxime axetil in $0.07 \mathrm{~N} \mathrm{HCl}$ (average of $\mathrm{n}=3$, \pm S.D.) 
untreated CA. However, the solubility after 24 hours is still twice the solubility of the untreated and recrystallized CA.

Further examination of the solubility profile, in terms of the individual isomers of the drug, provides a better understanding of the effect of the treatment processes. The untreated solid drug is a 1:1 mixture of the two isomers, however, in solution, the composition of the mixture is 1:9 (A:B). The microfluidized sample, on the other hand, shows a change in this composition from 1:9 to $2: 3$, and more or less maintains that composition for the entire 24 hours over which the sample was tested (see Figure 20). As for the recrystallized sample, the composition changes gradually over the period of time. During the initial 2 hours the composition of the isomers in solution is $3: 7$ (A:B) which changes to $2: 3$ at the end of the 24 hours; while the total solubility of the drug falls from $\sim 3$ times the original, at 2 hours, to the original, at the end of the 24 hours. Thermal analysis of CA shows the presence of two melting endotherms. Isomer $\mathrm{B}$ melts at $123{ }^{\circ} \mathrm{C}$ while isomer $\mathrm{A}$ melts at a higher temperature of $173{ }^{\circ} \mathrm{C}$ (Figure 16). The lower melting isomer shows a greater solubility. The DSC scans for the recrystallized mixture show the presence of the melting endotherm at $173{ }^{\circ} \mathrm{C}$ which indicates the presence of isomer $\mathrm{A}$, while the endotherm for isomer B is not present. However, the heat of fusion of the recrystallized isomer $\mathrm{A}$ is lower than that of the pure isomer $\mathrm{A}$ (Table 11). Thus isomer A retains its crystalline form, albeit with defects to the crystal structure, indicated by a lower heat of fusion. The microfluidized CA shows an absence of both the endotherms. Thus, the microfluidized CA is in the 


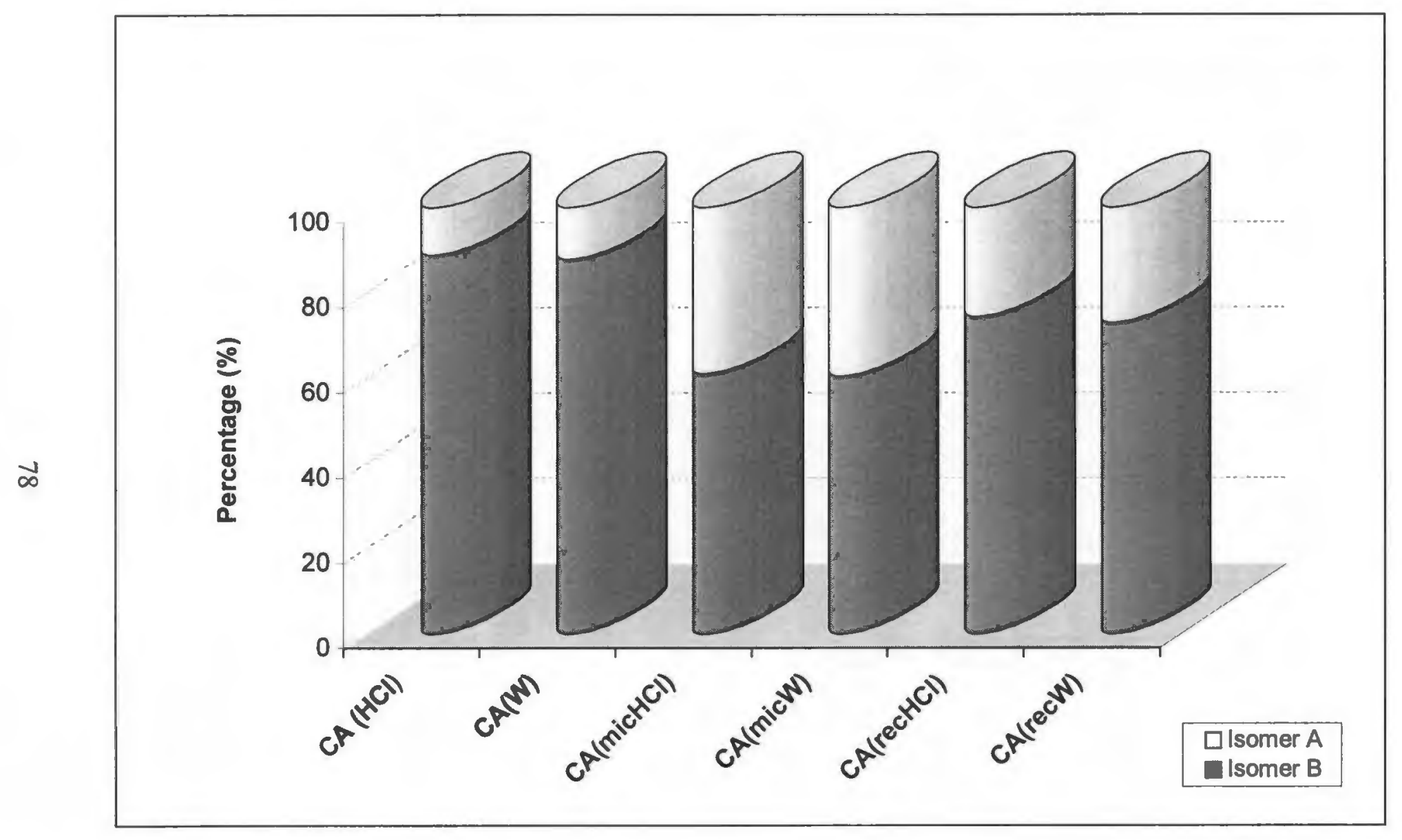

Figure 20: Percentage of cefuroxime axetil isomers A and B in solution (at 2 hours) for untreated, microfluidized and recrystallized drug $(\mathrm{W}$ : water, $\mathrm{HCl}: 0.07 \mathrm{~N} \mathrm{HCl})$ 


\begin{tabular}{|l|c|}
\hline \multicolumn{1}{|c|}{ Isomer A } & $\begin{array}{c}\text { Heat of Fusion } \\
(\mathrm{J} / \mathrm{g})\end{array}$ \\
\hline \multirow{4}{*}{ CA (untreated) } & 18.93 \\
CA (recrystallized) & 11.55 \\
CA + PVP (recrystallized) & 8.67 \\
CA + Eudragit RD100 (recrystallized) & 10.78 \\
& \\
\hline
\end{tabular}

Table 11: Heat of fusion (J/g) of isomer A for the different process-polymer combinations (the remaining process-polymer combinations convert the isomers to its amorphous form) 
amorphous form while the recrystallized drug is in a partially crystalline state. This is also confirmed by the comparison of the XRD data shown in Figure 21. The solubility and DSC data indicate that the higher solubility, lower melting isomer (B) is affected by both the processes and is converted to its amorphous form. In the case of the recrystallized sample, isomer (B) loses its amorphous form on prolonged exposure to the medium, as indicated by the downward slope of the solubility curve (Figure 19). However, the microfluidized drug shows only a gradual decrease in the solubility indicating a greater resistance to conversion to its original form. The use of microfluidization for these conversions has not been studied previously and is a new phenomenon. The drug is subjected to high pressure and velocities causing complete disruption of the crystal structure. Pharmaceutical solids, as we know them, rarely exist as $100 \%$ crystalline or $100 \%$ amorphous phases ${ }^{12}$. The presence of domains of one phase in another can act as a focal point for spontaneous phase transitions such as crystallization ${ }^{13,14,15}$. The process of microfluidization is likely to have reduced drastically the number of such domains, thereby decreasing initiation sites for crystallization and preventing rapid reconversion to the crystalline form. Microscopic analysis shows CA to be in a crystalline state with needle shaped crystals. The microfluidized and recrystallized samples show a loss of the needle shaped structure to give a more irregular appearance (Figures 22 and 23). 


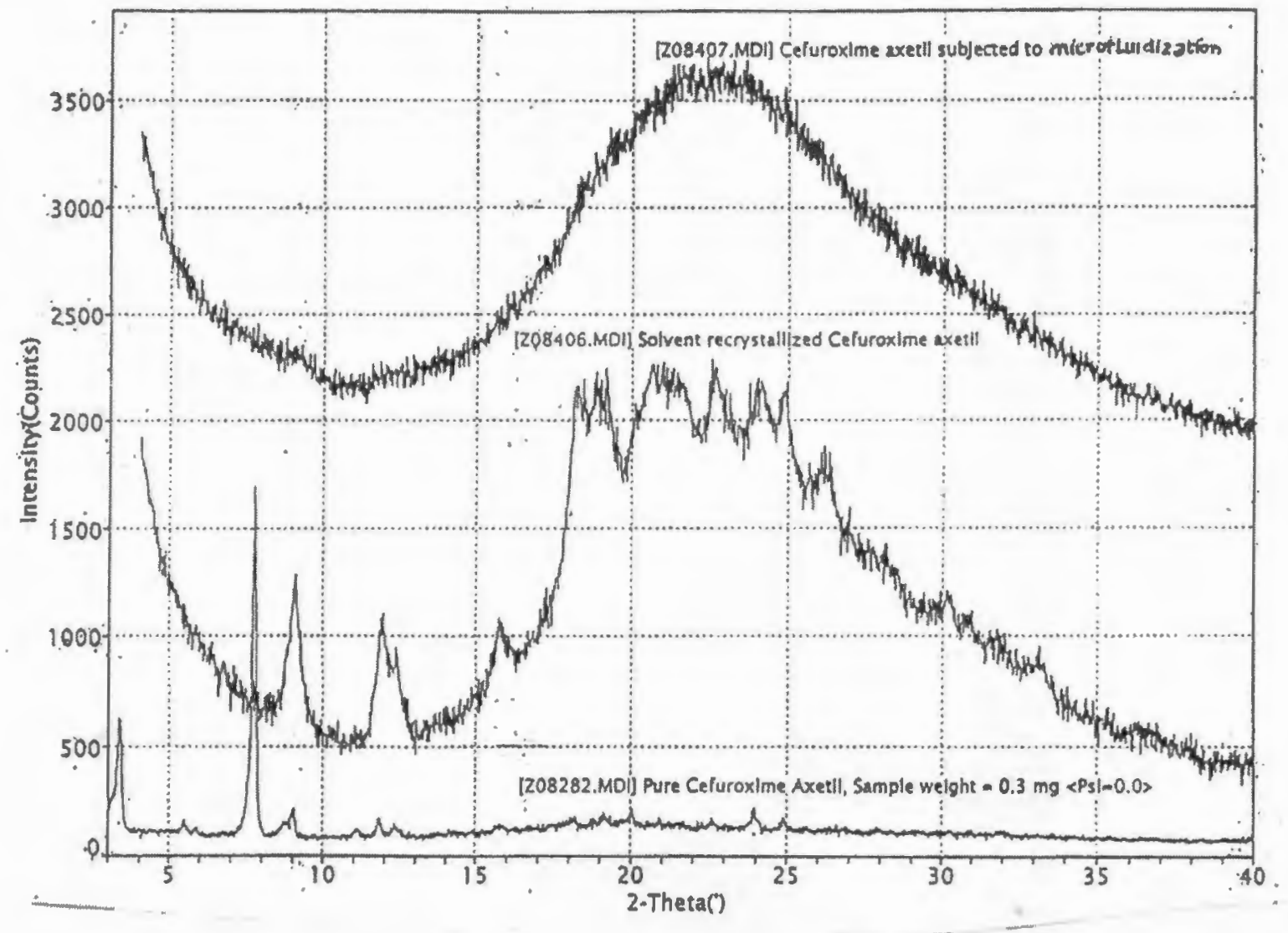

Figure 21: XRD scan of the untreated, microfluidized and recrystallized cefuroxime axetil (without polymers) 


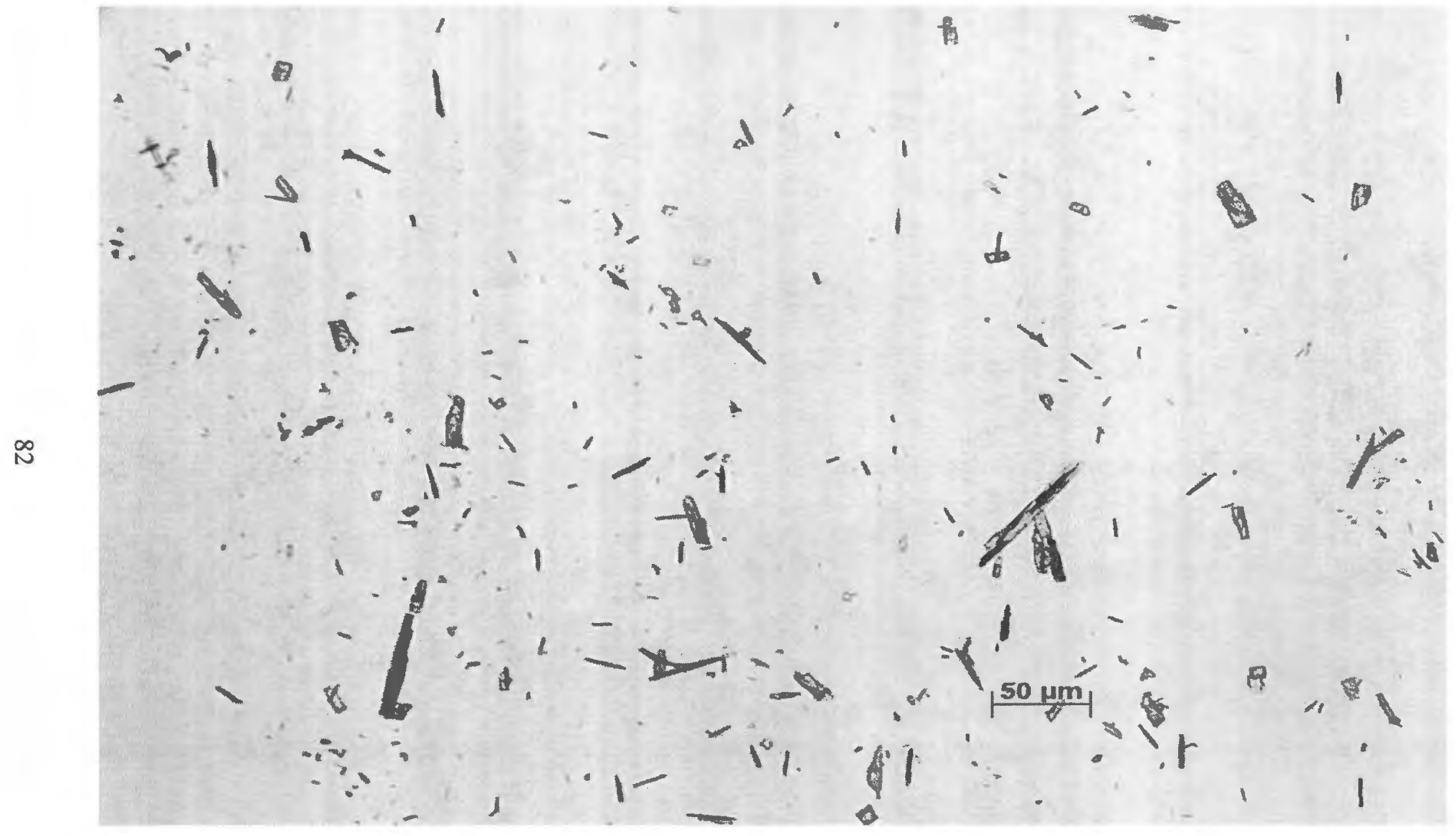

Figure 22: Optical microscopic image of cefuroxime axetil showing needle shaped crystals 


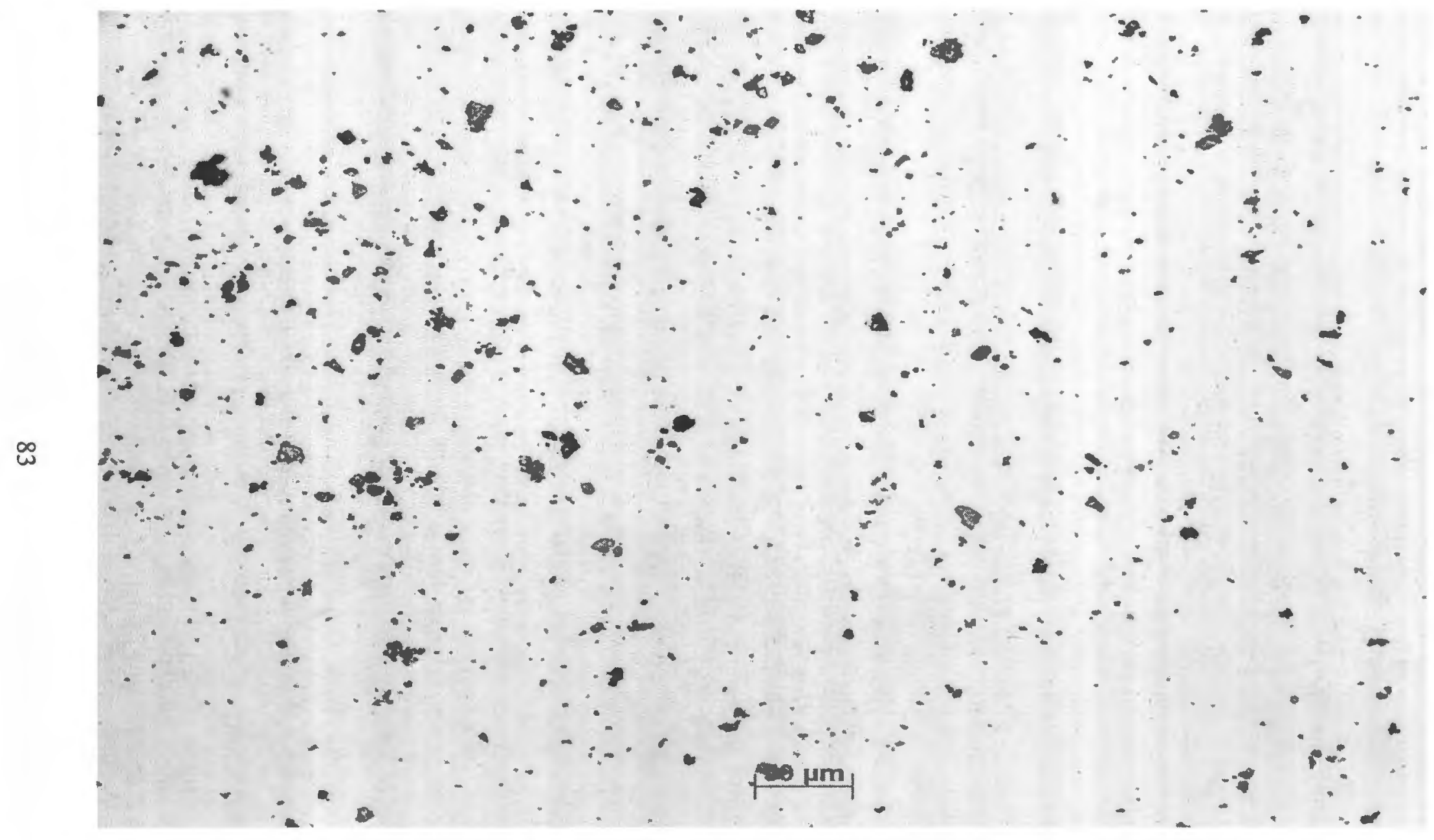

Figure 23: Optical microscopic image of treated cefuroxime axetil showing loss of needle shaped crystals 


\subsubsection{Effect of crystalline to amorphous conversion on solubility of the drug in}

the presence of polymers

The crystalline to amorphous conversion of the drug was also examined in the presence of several selected polymers. The physical mixtures of the drug and the three polymers were tested to rule out any positive effect on the solubility of the drug in the absence of the processes. The following section compares only the nine mixtures that involve the three polymers (Table 10 - Nos. 4-12).

Figures 24 and 25 show the solubility profile of the drug and its physical mixtures with PVP, Eudragit EPO and Eudragit RD100, determined in $0.07 \mathrm{~N}$ $\mathrm{HCl}$ and water, respectively. A look at the solubility profiles shows a 10-50 $\mu \mathrm{g} / \mathrm{ml}$ increase in solubility for all the physical mixtures at any given time point. The physical mixtures of all the three polymers show no significant increase in solubility and hence can be considered equivalent to the untreated drug for all practical purposes. The XRD (Figure 26) data does not show the presence of any additional peaks and is comparable to the XRD pattern of the untreated drug. The DSC data of the physical mixtures also does not show any changes in the melting endotherms of the isomers, from that of the untreated drug. Table 12 shows the purity of the physical mixtures that were found to be very close to or equal to (between $99-101 \%$ ) the pure drug. Thus, we can safely conclude that there is no form of chemical interaction between the drug and any of the three polymers in their physical mixtures. When the drug and polymer combinations are subjected to the process of microfluidization and recrystallization, solubility profiles are as shown in Figures 27 and 28. It is evident that PVP when 


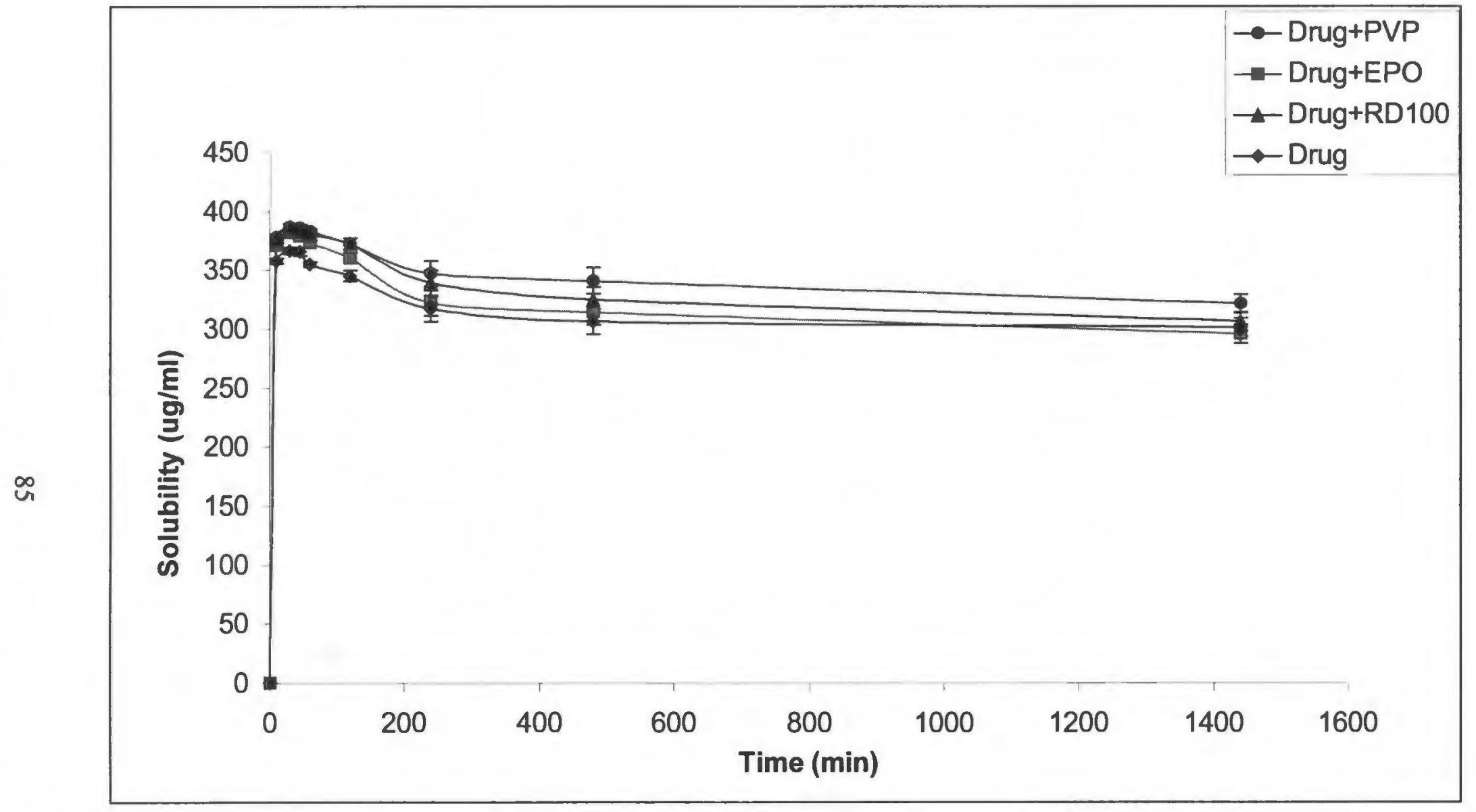

Figure 24: Solubility profile of cefuroxime axetil and its physical mixtures with PVP, Eudragit EPO and Eudragit RD100, in $0.07 \mathrm{~N} \mathrm{HCl}$ 


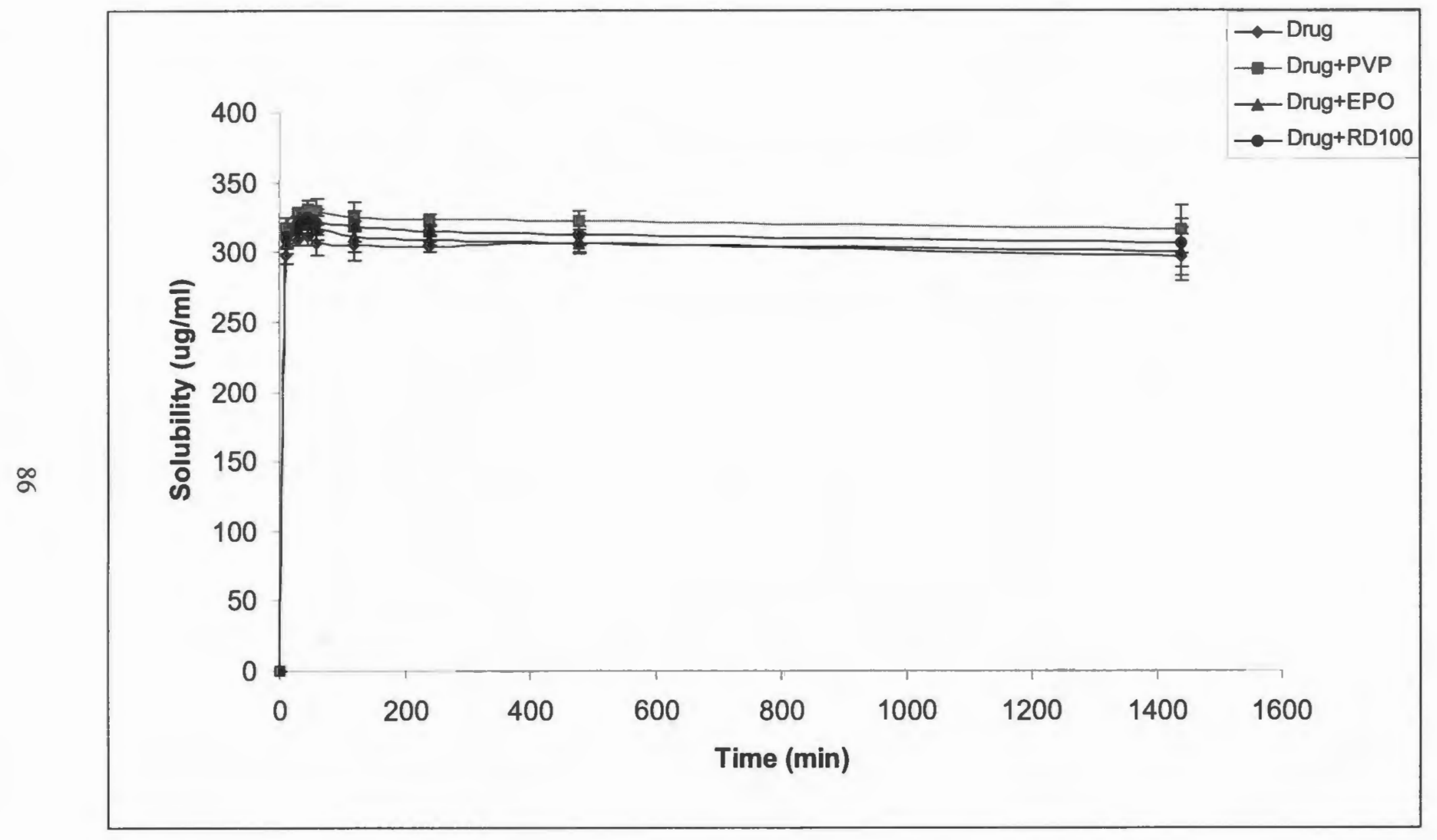

Figure 25: Solubility profile of cefuroxime axetil and its physical mixtures with PVP, Eudragit EPO and Eudragit RD100, in water 

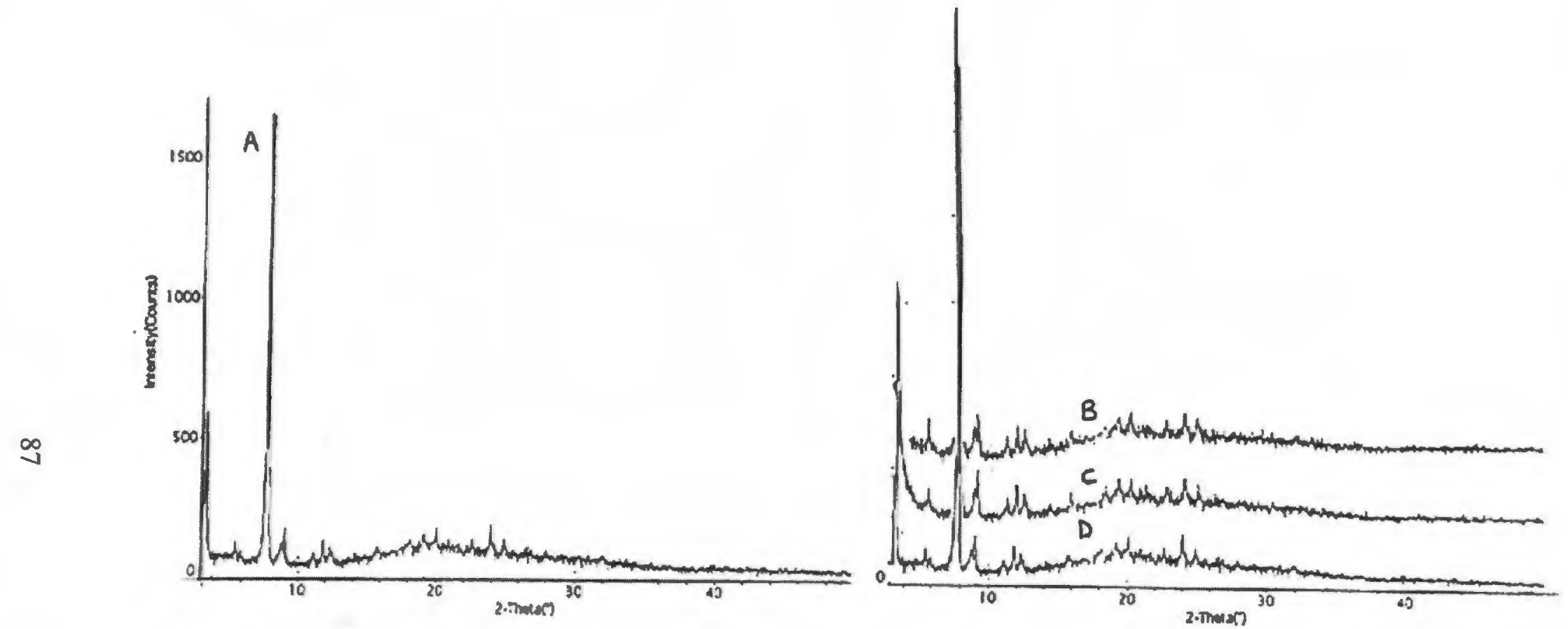

Figure 26: XRD scan of the untreated drug and physical mixtures of the drug with polymers (A: untreated, B: CA + PVP, C: CA + Eudragit RD100, D: CA + Eudragit EPO) 


\begin{tabular}{|c|c|c|c|c|c|c|}
\hline \multicolumn{2}{|c|}{ Cefuroxime Axetil } & \multicolumn{5}{|c|}{ Physical Mixtures of CA and Polymers } \\
\hline $\begin{array}{c}\text { Concentration } \\
(\mu \mathrm{g} / \mathrm{ml})\end{array}$ & Total AUC & $\mid \begin{array}{c}\text { Experimental } \\
\text { Concentration } \\
(\mu \mathrm{g} / \mathrm{ml})\end{array}$ & Total AUC & $\begin{array}{c}\text { Theoretical } \\
\text { Concentration } \\
(\mu \mathrm{g} / \mathrm{ml})\end{array}$ & $\%$ Purity & Average \\
\hline \multirow{12}{*}{$\begin{array}{c}20 \\
60 \\
100\end{array}$} & \multirow{12}{*}{$\begin{array}{c}654898 \\
2021660 \\
3318363\end{array}$} & \multicolumn{5}{|c|}{$C A+P V P$} \\
\hline & & 20 & 649876 & 19.85 & 99.23 & \multirow{3}{*}{99.74} \\
\hline & & 60 & 2034544 & 60.38 & 100.6 & \\
\hline & & 100 & 3296875 & 99.35 & 99.35 & \\
\hline & & \multicolumn{5}{|c|}{$C A+$ Eudragit RD 100} \\
\hline & & 20 & 651984 & 19.91 & 99.55 & \\
\hline & & 60 & 2010431 & 59.67 & 99.44 & 99.54 \\
\hline & & 100 & 3305816 & 99.62 & 99.62 & \\
\hline & & \multicolumn{5}{|c|}{$\mathrm{CA}+$ Eudragit EPO } \\
\hline & & 20 & 660124 & 20.16 & 100.8 & \\
\hline & & 60 & 2031254 & 60.29 & 100.5 & 100.54 \\
\hline & & 100 & 3330125 & 100.35 & 100.4 & \\
\hline
\end{tabular}

Table 12: Purity data of physical mixtures of cefuroxime axetil with polymers - PVP, Eudragit RD100 and Eudragit EPO 


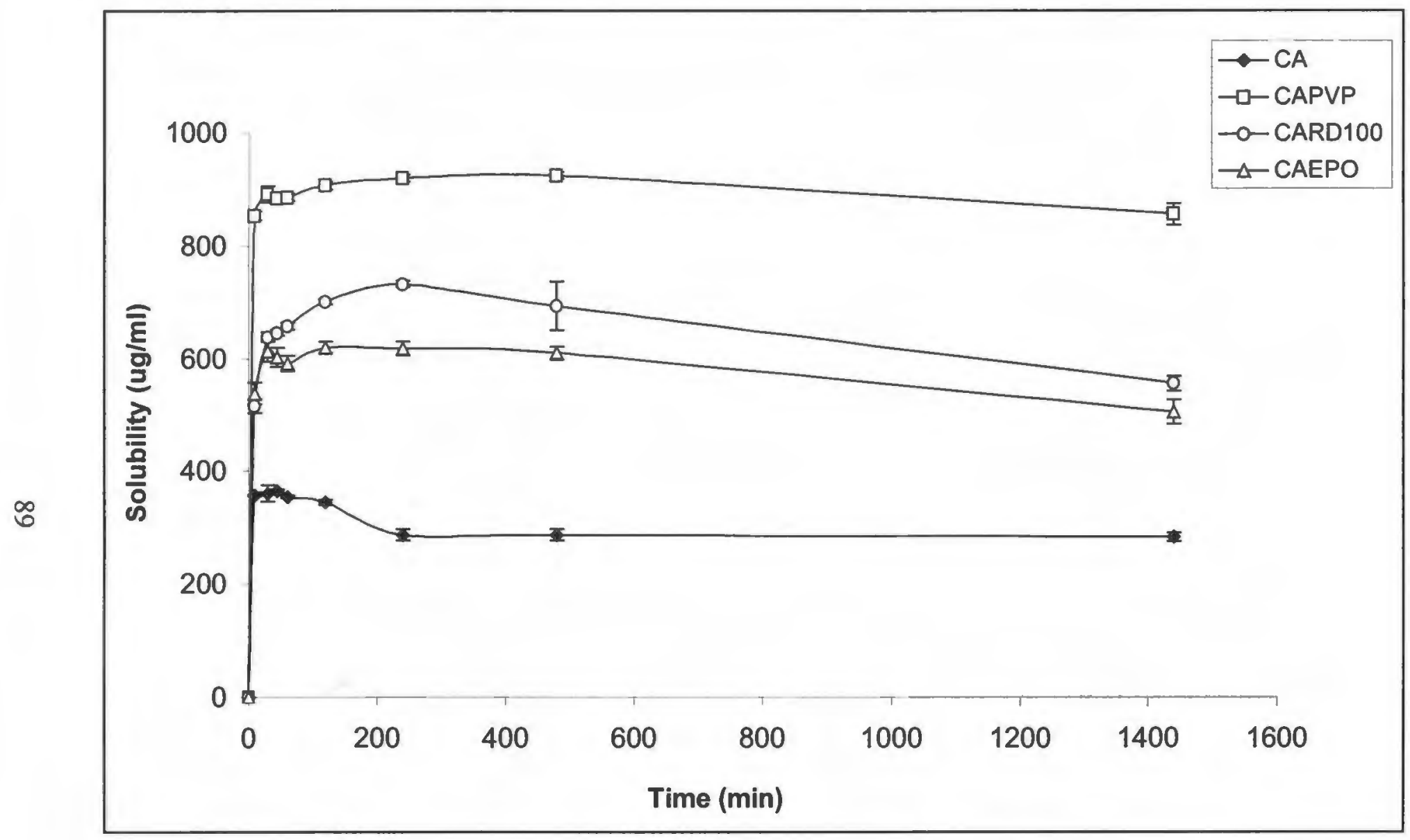

Figure 27: Solubility profile of untreated and microfluidized cefuroxime axetil - with PVP, Eudragit EPO and Eudragit RD100 (average of $n=3, \pm$ S.D.) 


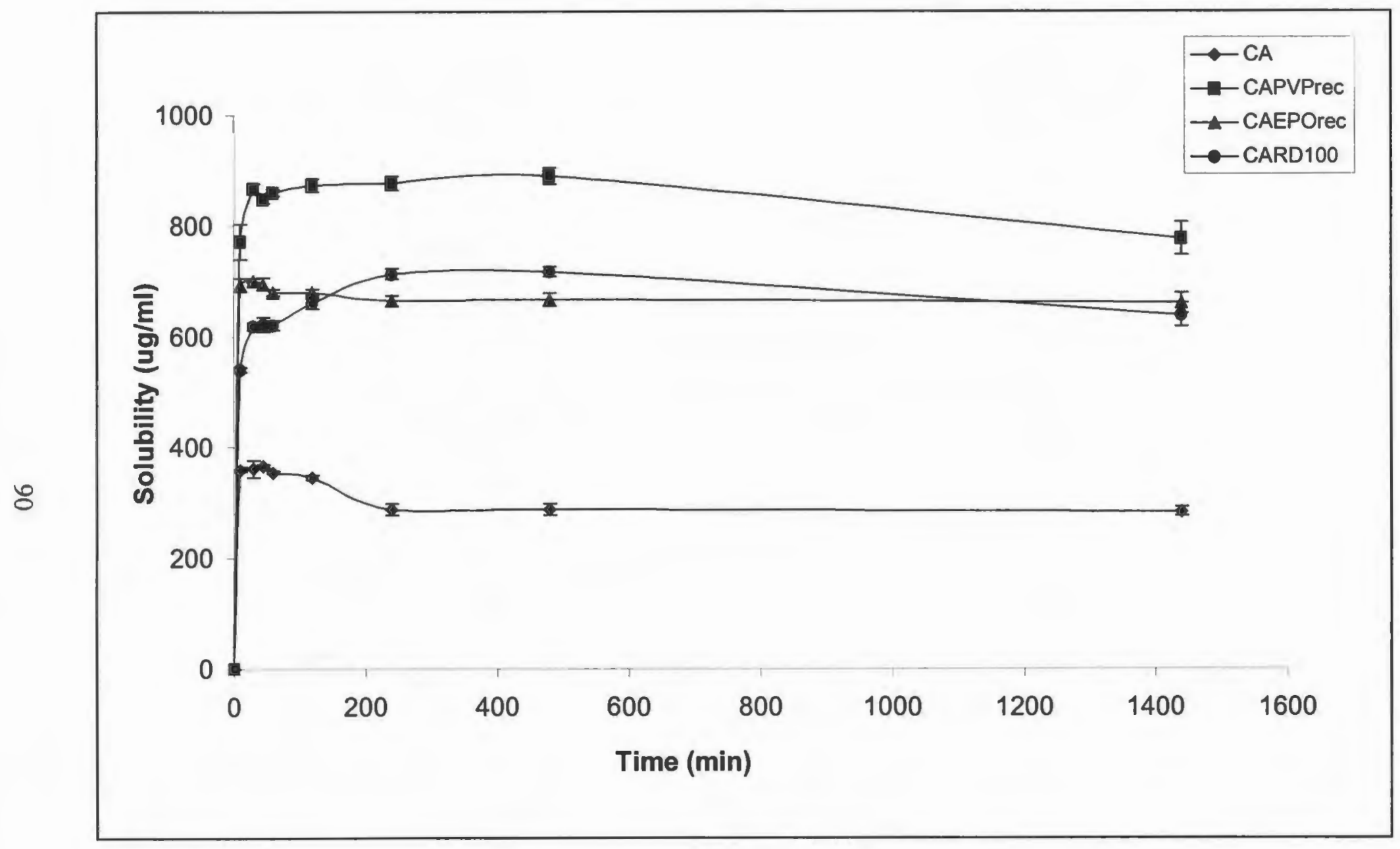

Figure 28: solubility profile of untreated and recrystallized cefuroxime axetil - with PVP, Eudragit EPO and Eudragit RD100 (average of $n=3, \pm S . D$.) 
subjected to the two aforementioned processes shows a greater increase in solubility as compared to that caused by the other two polymers. There is an approximate 3-fold increase in solubility with the use of PVP, and only a 2-fold increase with the use of the Eudragits. Both the Eudragits show an increase in solubility to approximately the same extent, with Eudragit RD100 showing a slightly greater increase. The purity of these samples was determined and the data has been tabulated in Table 13. The purity of drug in the presence of Eudragit EPO, after treatment with either of the processes, was found to be very low $(76.3 \%$ and $80.6 \%$ for the microfluidized and recrystallized drug respectively). The low purity of the drug can be attributed to the formation of a complex between the cationic polymer and the anionic drug. This complex is detected on the chromatogram (shown in Figure 29) as a third peak eluting at $12.5 \mathrm{~min}$ after those of the two isomers $\mathrm{A}$ and $\mathrm{B}$. When the solubilities of the microfluidized and recrystallized samples of drug are compared with respect to the individual polymers (Figures $30,31,32$ ), it was noticed that there is not much difference between the microfluidized and recrystallized samples. The differences in solubility range from $20-100 \mu \mathrm{g} / \mathrm{ml}$ with the greatest difference seen for the samples using Eudragit EPO. The microfluidized and recrystallized samples show an almost equivalent increase in solubility as seen in Figures 30 , 31,32 .

The X-ray diffraction data for the recrystallized - PVP, Eudragit EPO, and Eudragit RD100 samples are shown in Figure 33. The sample containing Eudragit EPO is totally amorphous, while those containing PVP and Eudragit 


\begin{tabular}{|c|c|c|c|c|c|c|c|c|c|c|c|}
\hline \multicolumn{2}{|c|}{ Cefuroxime Axetil } & \multicolumn{5}{|c|}{ Microfluidized Samples of CA and Polymers } & \multicolumn{5}{|c|}{ Recrystallized Samples of CA and Polymers } \\
\hline $\begin{array}{c}\text { Conc. } \\
(\mu \mathrm{g} / \mathrm{ml})\end{array}$ & $\begin{array}{l}\text { Total } \\
\text { AUC }\end{array}$ & $\begin{array}{c}\text { Experimental } \\
\text { Conc. } \\
(\mu \mathrm{g} / \mathrm{ml})\end{array}$ & $\begin{array}{l}\text { Total } \\
\text { AUC }\end{array}$ & $\begin{array}{c}\text { Theoretical } \\
\text { Conc. } \\
(\mu \mathrm{g} / \mathrm{ml})\end{array}$ & \begin{tabular}{|c} 
Purity \\
$(\%)$
\end{tabular} & Average & $\begin{array}{c}\text { Experimental } \\
\text { Conc. } \\
(\mu \mathrm{g} / \mathrm{ml})\end{array}$ & $\begin{array}{l}\text { Total } \\
\text { AUC }\end{array}$ & $\begin{array}{c}\text { Theoretical } \\
\text { Conc. } \\
(\mu \mathrm{g} / \mathrm{ml})\end{array}$ & $\begin{array}{c}\text { Purity } \\
(\%)\end{array}$ & Average \\
\hline \multirow{12}{*}{$\begin{array}{c}20 \\
60 \\
100\end{array}$} & \multirow{12}{*}{$\begin{array}{c}654898 \\
2021660 \\
3318363\end{array}$} & \multicolumn{5}{|c|}{ CA + PVP } & \multicolumn{5}{|c|}{$C A+P V P$} \\
\hline & & 20 & 645149 & 19.70 & 98.51 & \multirow{3}{*}{96.93} & 20 & 652168 & 19.92 & 99.58 & \multirow{3}{*}{99.55} \\
\hline & & 60 & 1945851 & 57.75 & 96.25 & & 60 & 2014763 & 59.79 & 99.66 & \\
\hline & & 100 & 3186489 & 96.03 & 96.03 & & 100 & 3298689 & 99.41 & 99.41 & \\
\hline & & \multicolumn{5}{|c|}{$C A+$ Eudragit RD 100} & \multicolumn{5}{|c|}{ CA + Eudragit RD 100} \\
\hline & & 20 & 635965 & 19.42 & 97.11 & \multirow{3}{*}{95.08} & 20 & 642781 & 19.63 & 98.15 & \multirow{3}{*}{97.77} \\
\hline & & 60 & 1915728 & 56.86 & 94.76 & & 60 & 1986573 & 58.96 & 98.26 & \\
\hline & & 100 & 3098787 & 93.38 & 93.38 & & 100 & 3214893 & 96.88 & 96.88 & \\
\hline & & \multicolumn{5}{|c|}{$C A+$ Eudragit EPO } & \multicolumn{5}{|c|}{ CA + Eudragit EPO } \\
\hline & & 20 & 498967 & 15.24 & 76.19 & \multirow{3}{*}{76.34} & 20 & 541789 & 16.55 & 82.73 & \multirow{3}{*}{80.61} \\
\hline & & 60 & 1567546 & 46.523 & 77.54 & & 60 & 1603494 & 47.59 & 79.32 & \\
\hline & & 100 & 2498723 & 75.299 & 75.3 & & 100 & 2647239 & 79.78 & 79.78 & \\
\hline
\end{tabular}

Table 13: Purity data of the microfluidized and recrystallized drug with the polymers - PVP, Eudragit EPO and Eudragit RD 100 


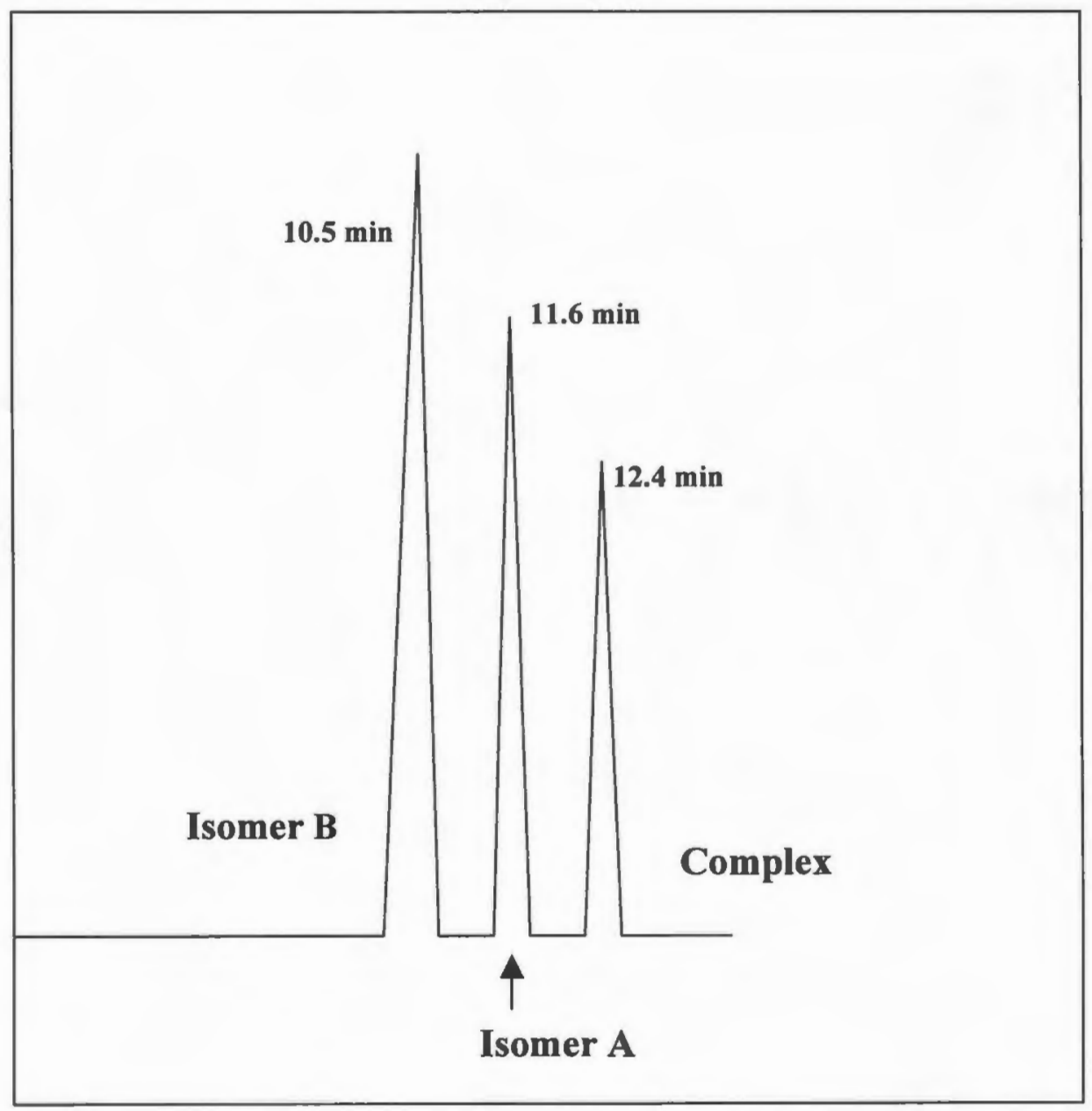

Figure 29: Chromatogram showing the peaks of isomers B and A, eluting at $10.5 \mathrm{~min}$ and $11.6 \mathrm{~min}$ and the complex at $12.4 \mathrm{~min}$ 


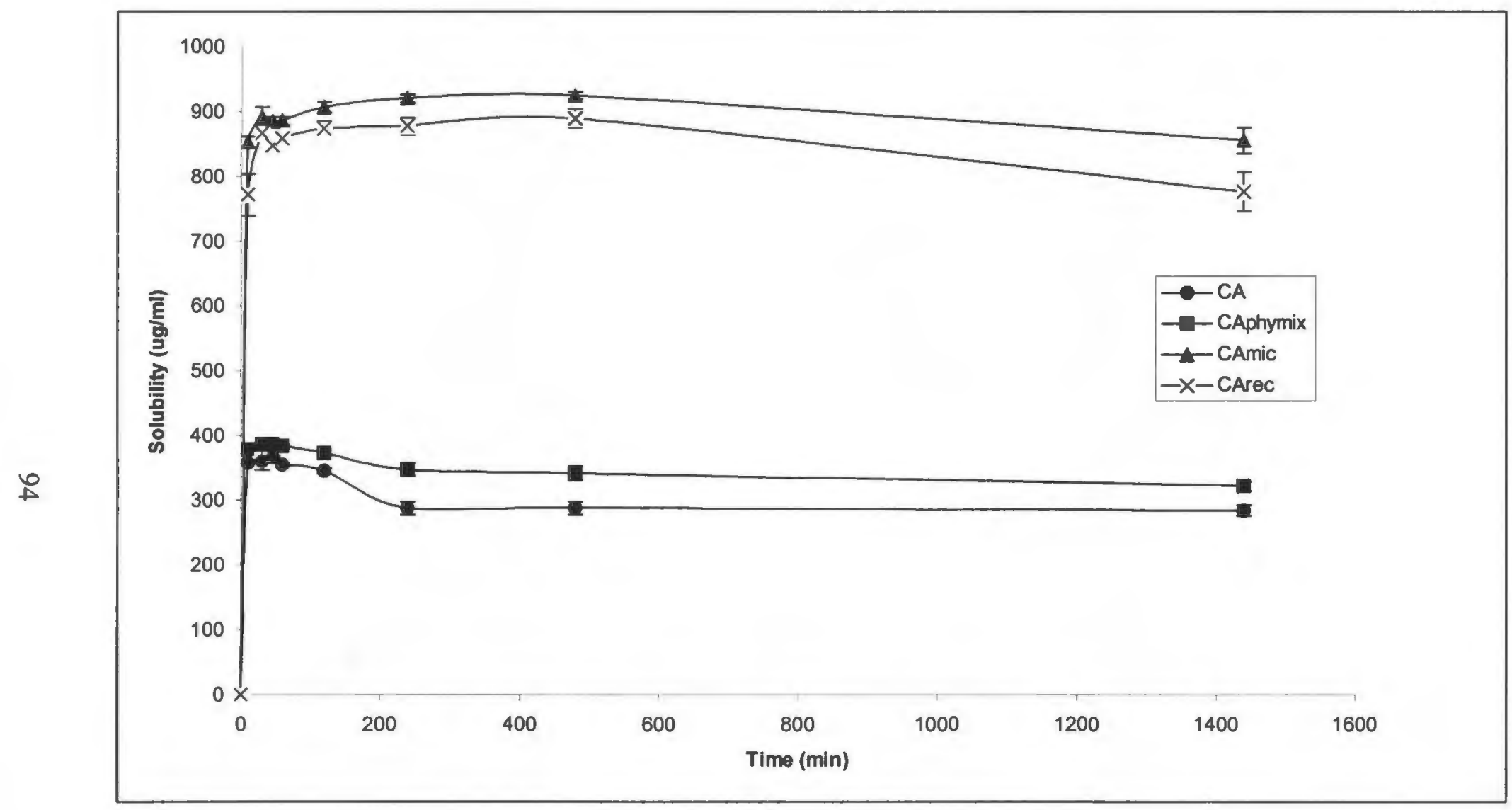

Figure 30: Solubility profile of the untreated drug and the physical mixture, microfluidized and recrystallized drug with PVP 


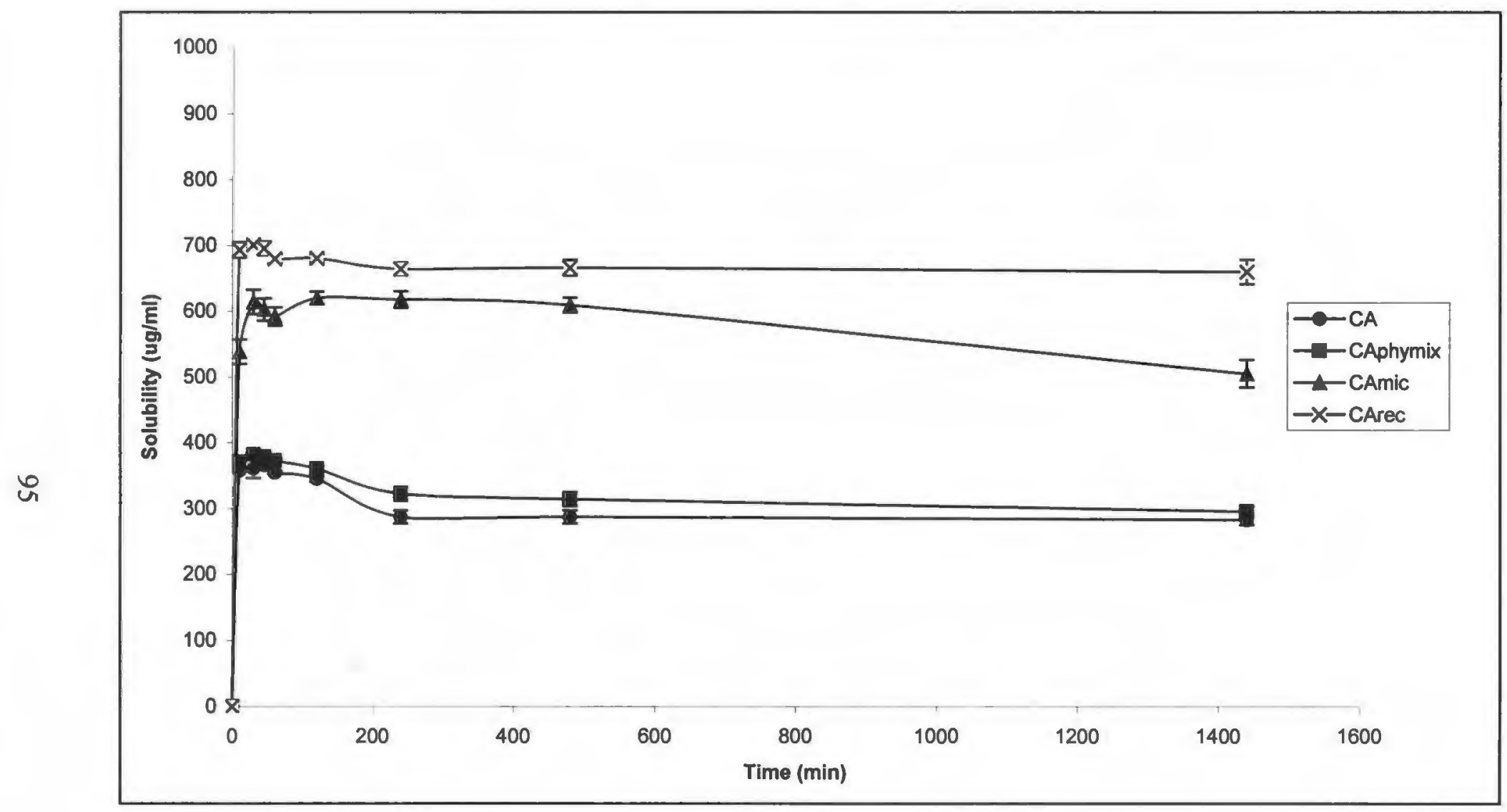

Figure 31: Solubility profile of the untreated drug and the physical mixture, microfluidized and recrystallized drug with Eudragit EPO 


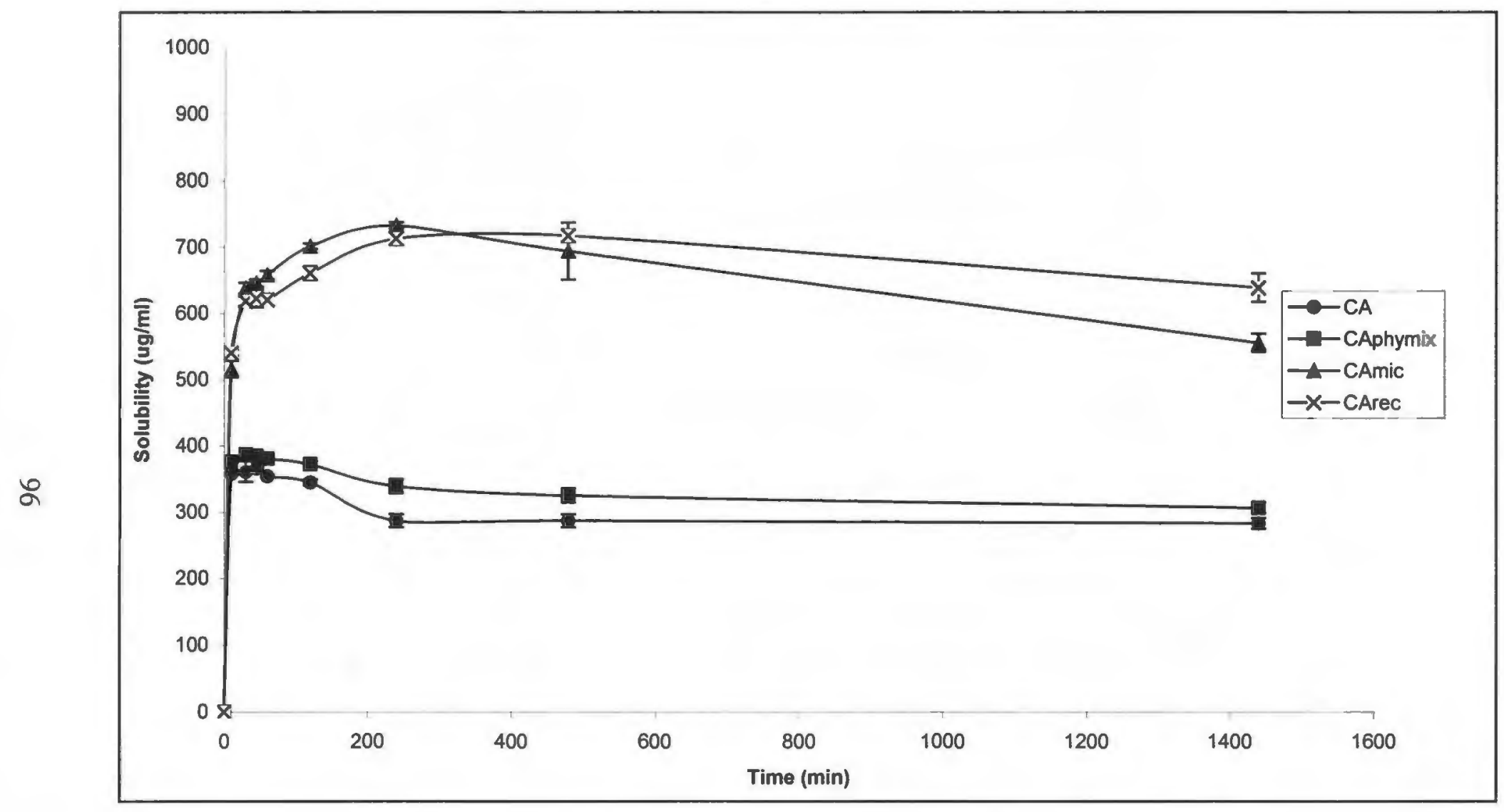

Figure 32: Solubility profile of the untreated drug and the physical mixture, microfluidized and recrystallized drug with Eudragit RD100 

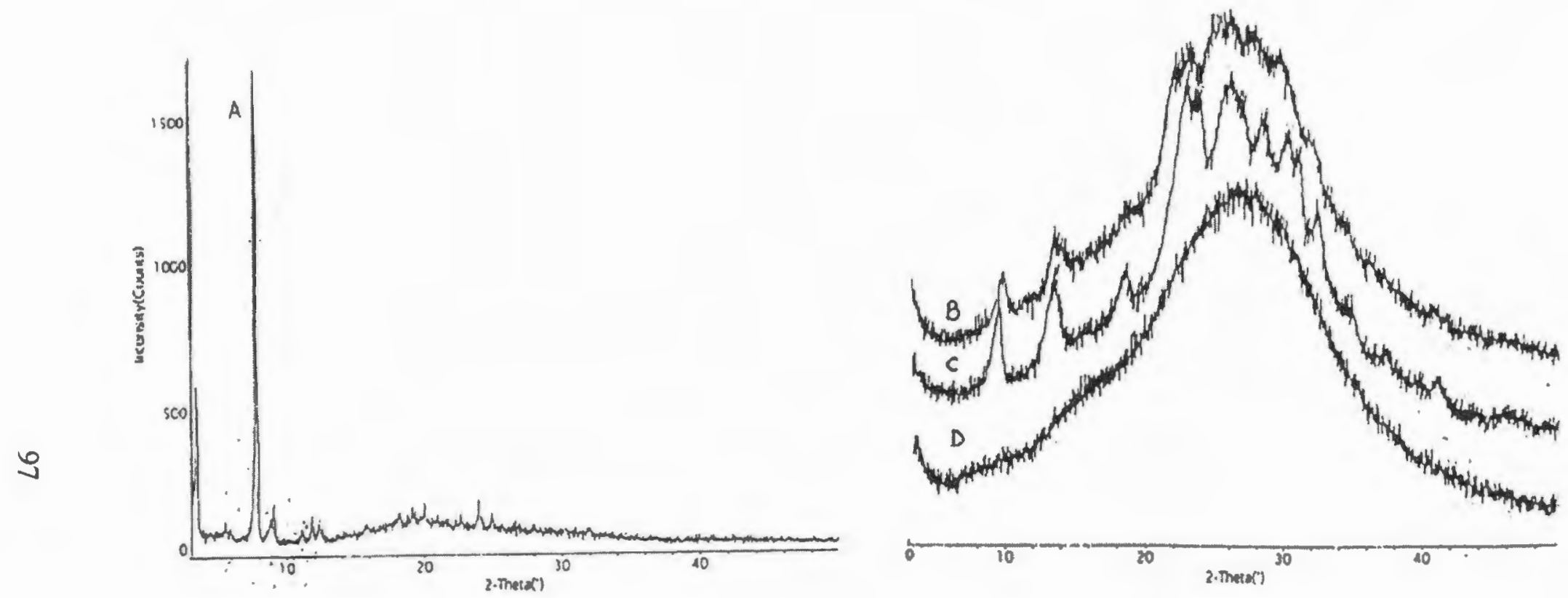

Figure 33: XRD scan of the untreated and recrystallized cefuroxime axetil with the polymers (A: untreated, B: CA + PVP, C: CA + Eudragit RD 100, D: CA + Eudragit EPO) 
RD100 are partially amorphous with varying degrees of crystallinity. The DSC scans show an absence of the endotherm at $123^{\circ} \mathrm{C}$ in all the samples, while the endotherm at $173{ }^{\circ} \mathrm{C}$ is absent in the sample containing Eudragit EPO. The other two samples show the presence of the higher melting endotherm but the heat of fusion is lower than that of the pure sample indicating disruption of the crystal structure of isomer $A$ (Table 11). Heat of fusion $\left(\Delta S^{f}=\Delta H^{f} / T_{m}\right)$ has been used as an indication of disruption or disorder induced by additives or impurities $^{16}$. The X-ray diffraction data for the microfluidized - PVP, Eudragit EPO, and Eudragit RD100 samples are shown in Figure 34. All the samples subjected to microfluidization are converted to the totally amorphous form as seen from the XRD scans and confirmed from the DSC data, indicating the absence of both the melting endotherms.

The samples prepared with Eudragit EPO show the lowest solubility, which could be attributed to the formation of the complex between the cationic polymer and the anionic drug, detected on the chromatogram as a third peak (at $\sim 12.5 \mathrm{~min}$ ). The recrystallization process and polymer combinations involving PVP and Eudragit RD100 do not render the drug amorphous, but a high degree of crystal disruption may be the cause of the enhanced solubility. We do notice, however, that one of the isomers is converted to the amorphous form while the other is in a partially crystalline state. The heat of fusion of the partially crystalline isomer (A) is also reduced, as seen in Table 11. 

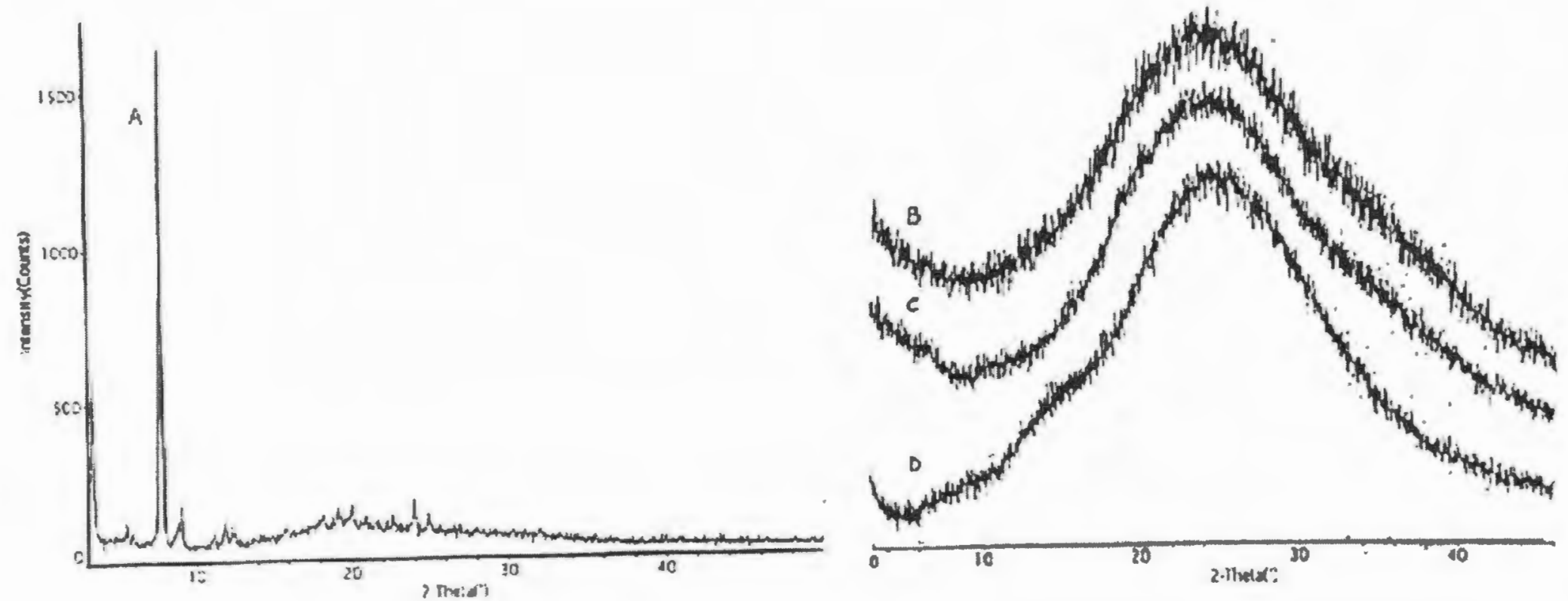

Figure 34: XRD scan of the untreated and microfluidized cefuroxime axetil with the polymers (A: untreated, B: CA + PVP, C: CA + Eudragit RD100, D: CA + Eudragit EPO) 
A microscopic analysis of all the processed mixtures shows a loss of the needle shaped crystalline structure of the samples, similar to the ones shown before (Figures 22 and 23).

Table 14 lists the yields for the two processes along with the polymers. It was noticed that the process of microfluidization yielded very low quantities of the sample $(\sim 70 \%)$, whereas the recrystallization process gave significantly higher yields. Based on the statistical analysis along with the process yields, the recrystallized CA-PVP combination was selected for the preparation of the tablets.

\subsection{Statistical Analysis}

A two-factor factorial design is used to study the effect of the different processes and polymers on the solubility of the drug. In this study, we have a $3 \times 4$ factorial design, that is, we have 2 factors, one with 3 levels and the other with 4 levels. The two factors are polymer $\left(C_{1}\right)$ and process $\left(C_{2}\right)$, with 4 and 3 levels, respectively. The two independent variables, their levels and their values are summarized in Table 15. Therefore the number of treatment groups we have is $3 \times 4=12$ groups (Table 16). Data for each representative group was generated in triplicates, hence we have 36 observations, as listed in Table 17. Solubility was the response parameter. All the statistical and regression analysis procedures on the response parameters were performed using Minitab® software package. Statistical analysis carried out included analysis of variance (ANOVA) to determine the significance of each independent variable (process, 


\begin{tabular}{|l|c|c|}
\hline \multicolumn{1}{|c|}{ Method } & $\begin{array}{c}\text { Yield } \\
(\mathrm{mg})\end{array}$ & $\%$ Yield \\
\hline \multirow{8}{*}{ Recrystallization } & & \\
CA - without polymer & $850 / 900$ & 94.44 \\
CA - with PVP & $962 / 1000$ & 96.2 \\
CA - with Eudragit EPO & $938 / 1000$ & 93.8 \\
CA - with Eudragit RD100 & $944 / 1000$ & 94.4 \\
& & \\
Microfluidization & & \\
CA - without polymer & $674 / 900$ & 74.8 \\
CA - with PVP & $703 / 1000$ & 70.3 \\
CA - with Eudragit EPO & $673 / 1000$ & 67.3 \\
CA - with Eudragit RD100 & $695 / 1000$ & 69.5 \\
\multicolumn{2}{|l}{} & \\
\hline
\end{tabular}

Table 14: Yields for the different process-polymer combinations are shown (reported values are the average of three replicates) 


\begin{tabular}{|llll|}
\hline Factor & Type & Levels & Values \\
& & & \\
Polymer & Fixed & 4 & 1234 \\
Process & Fixed & 3 & 123 \\
& & & \\
\hline
\end{tabular}

Polymer Process

$\begin{array}{llll}1 & \text { No polymer } & 1 & \text { No process } \\ 2 & \text { PVP } & 2 & \text { Microfluidization } \\ 3 & \text { Eudragit EPO } & 3 & \text { Recrystallization } \\ 4 & \text { Eudragit RD 100 } & & \end{array}$

Table 15: List of factors and levels used in ANOVA analysis of effects on solubility 


\begin{tabular}{|c|c|c|}
\hline No. & $\begin{array}{c}\text { C1 } \\
\text { Polymer }\end{array}$ & $\begin{array}{c}\text { C2 } \\
\text { Process }\end{array}$ \\
\hline 1 & 1 & 1 \\
2 & 1 & 2 \\
3 & 1 & 3 \\
4 & 2 & 1 \\
5 & 2 & 2 \\
6 & 2 & 3 \\
7 & 3 & 1 \\
8 & 3 & 2 \\
9 & 3 & 3 \\
10 & 4 & 1 \\
11 & 4 & 2 \\
12 & 4 & 3 \\
\hline
\end{tabular}

Table 16: $3 \times 4$ (2-factor) full factorial design 


\begin{tabular}{|c|c|c|}
\hline $\begin{array}{c}\text { C }_{1} \\
\text { Polymer }\end{array}$ & $\begin{array}{c}\mathrm{C}_{2} \\
\text { Process }\end{array}$ & $\begin{array}{c}\mathrm{C}_{3} \\
\text { Solubility } \\
(\mathrm{ug} / \mathrm{ml})\end{array}$ \\
\hline 1 & 1 & 353.97 \\
\hline 1 & 1 & 352.91 \\
\hline 1 & 1 & 357.02 \\
\hline 1 & 2 & 882.26 \\
\hline 1 & 2 & 859.85 \\
\hline 1 & 2 & 843.40 \\
\hline 1 & 3 & 900.14 \\
\hline 1 & 3 & 949.69 \\
\hline 1 & 3 & 918.86 \\
\hline 2 & 1 & 402.03 \\
\hline 2 & 1 & 398.57 \\
\hline 2 & 1 & 395.14 \\
\hline 2 & 2 & 887.52 \\
\hline 2 & 2 & 891.77 \\
\hline 2 & 2 & 877.80 \\
\hline 2 & 3 & 859.48 \\
\hline 2 & 3 & 858.90 \\
\hline 2 & 3 & 860.15 \\
\hline 3 & 1 & 380.15 \\
\hline 3 & 1 & 365.41 \\
\hline 3 & 1 & 373.81 \\
\hline 3 & 2 & 641.89 \\
\hline 3 & 2 & 632.44 \\
\hline 3 & 2 & 654.62 \\
\hline 3 & 3 & 672.85 \\
\hline 3 & 3 & 685.17 \\
\hline 3 & 3 & 681.95 \\
\hline 4 & 1 & 391.08 \\
\hline 4 & 1 & 359.43 \\
\hline 4 & 1 & 374.91 \\
\hline 4 & 2 & 652.35 \\
\hline 4 & 2 & 657.13 \\
\hline 4 & 2 & 664.86 \\
\hline 4 & 3 & 627.90 \\
\hline 4 & 3 & 620.82 \\
\hline 4 & 3 & 623.54 \\
\hline
\end{tabular}

Polymer

1 - No polymer

2 - PVP

3 - Eudragit EPO

4 - Eudragit RD 100

Process

1 - No process

2 - Microfluidization

3 - Recrystallization
Table 17: Data for each representative group of factors and response 
polymer), two-way interactions (process-polymer), main effect plots and interaction plots ${ }^{17}$. The general linear model used for the experimental design was:

$$
Y=\beta_{0}+\beta_{1} C_{1}+\beta_{2} C_{2}+\beta_{3} C_{1} C_{2}
$$

The ANOVA table (Table 18) summarizes the statistical analyses conducted. From the table we can see that the P-values for the polymer, process, and the polymer-process interactions are lower than the $\alpha$-value (0.05). Hence we can conclude that these three factors have a significant effect on the solubility of the drug. The main effects plot for process shown in Figure 35 indicates that both the processes (microfluidization or recrystallization) show an almost equivalent increase in solubility as seen from points 2 and 3 in the graph. From the interactions plot, Figure 36, it is observed that the combination of PVP with either of the processes (represented as line - - - - - $)$ would be a good choice for improving solubility. As seen from the graph, process 2 (microfluidization) and 3 (recrystallization) show a significantly higher solubility, thus making them a good choice for use in the preparation of tablets. The normal probability plot (Figure 37) follows an almost straight line, and hence the distribution is normal and the model used is adequate. 


\section{General Linear Model: Solubility versus Polymer, Process}

Factor Type Levels Values

Polymer fixed $4 \begin{array}{lllll}4 & 2 & 3 & 4\end{array}$

Process fixed 3123

Analysis of Variance for Solubility, using Adjusted ss for Tests

$\begin{array}{lrrrrrr}\text { Source } & \text { DF } & \text { Seq SS } & \text { Adj SS } & \text { Adj MS } & \text { F } & \text { P } \\ \text { Polymer } & 3 & 216859 & 216859 & 72286 & 543.12 & 0.000 \\ \text { Process } & 2 & 1226825 & 1226825 & 613412 & 4608.85 & 0.000 \\ \text { Polymer*Process } & 6 & 119052 & 119052 & 19842 & 149.08 & 0.000 \\ \text { Error } & 24 & 3194 & 3194 & 133 & & \end{array}$

$\begin{array}{ll}\text { Polymer: } 4 \text { levels } & \text { Process: } 3 \text { levels } \\ 1 \text { - no polymer } & 1 \text { - no process } \\ 2 \text { - PVP } & 2 \text { - microfluidization } \\ 3 \text { - Eud EPO } & 3 \text { - recrystallization } \\ 4 \text { - Eud RD100 } & \end{array}$

Table 18: ANOVA table summarizing the statistical analyses 
Main Effects Plot - LS Means for Solubility

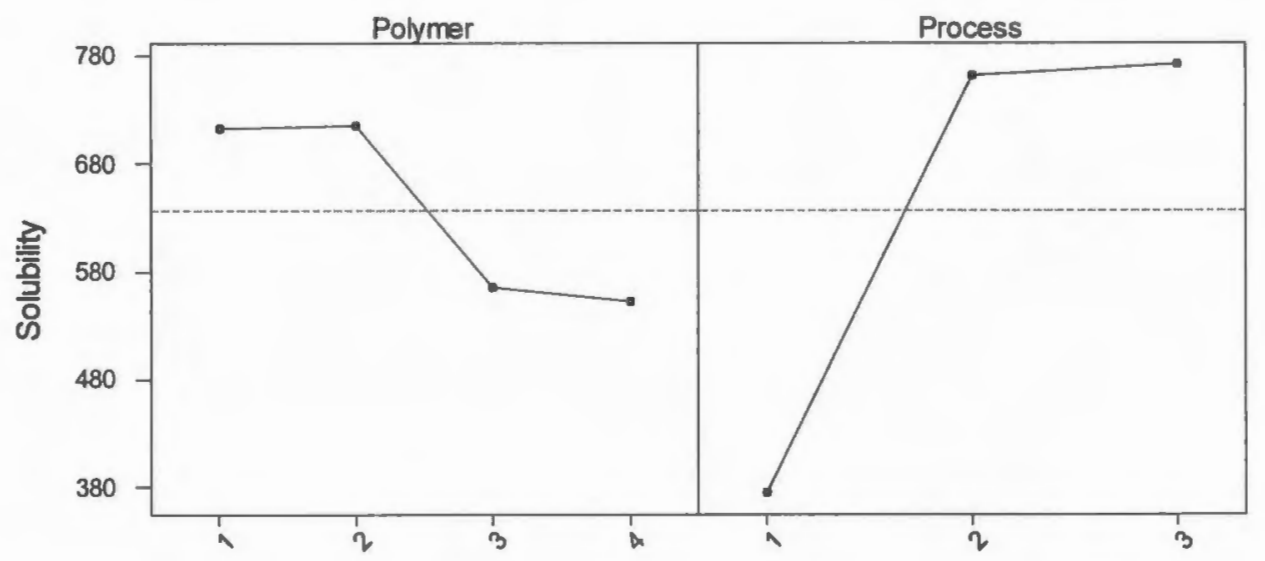

Figure 35: Main effects plot for polymer and process 


\section{Interaction Plot - LS Means for Solubility}

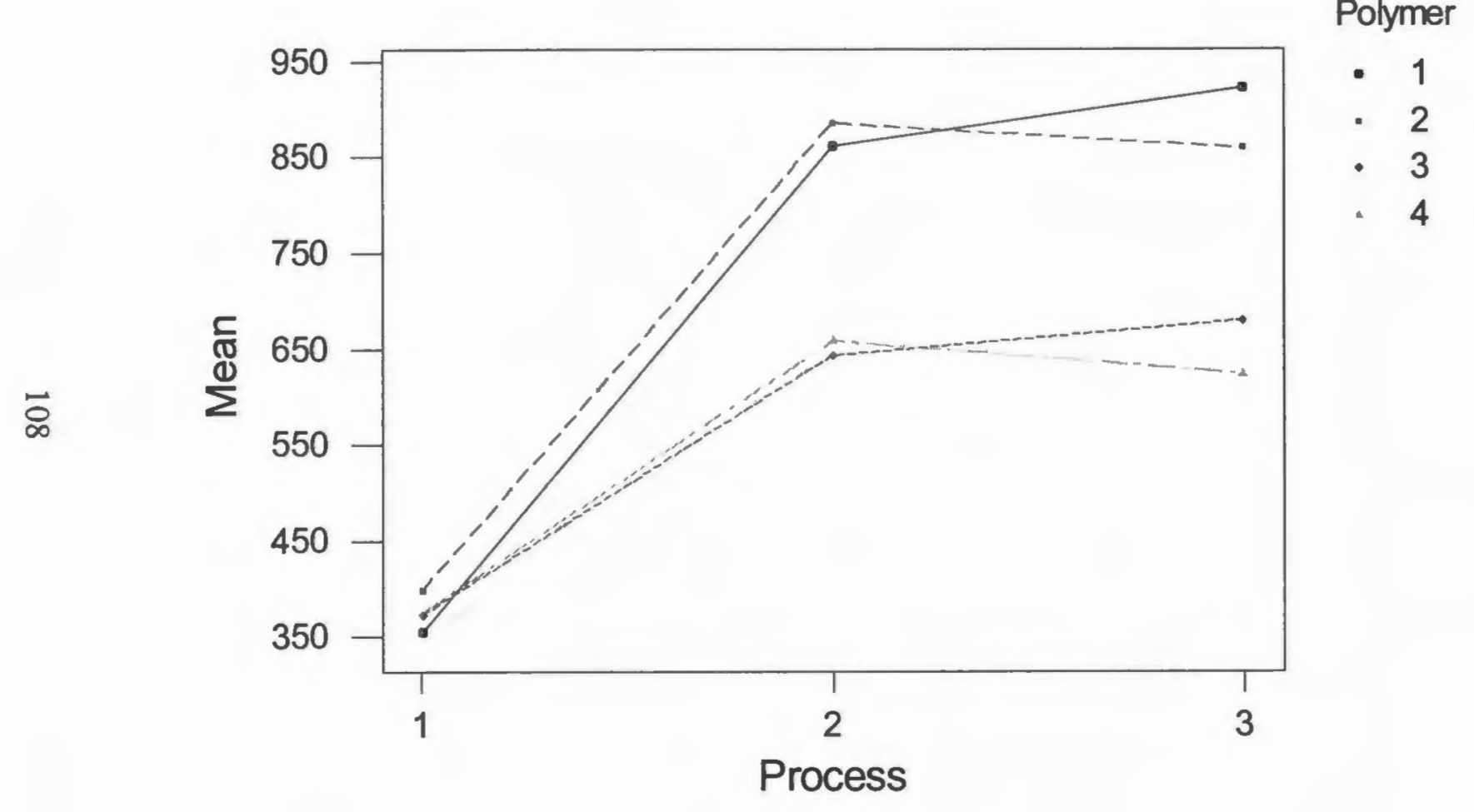

Figure 36: Interaction plot showing effect of various process-polymer combinations on solubility (polymer: 1-no polymer, 2-PVP, 3-Eudragit EPO, 4-Eudragit RD100) 


\section{Normal Probability Plot of the Residuals}

(response is solubility)

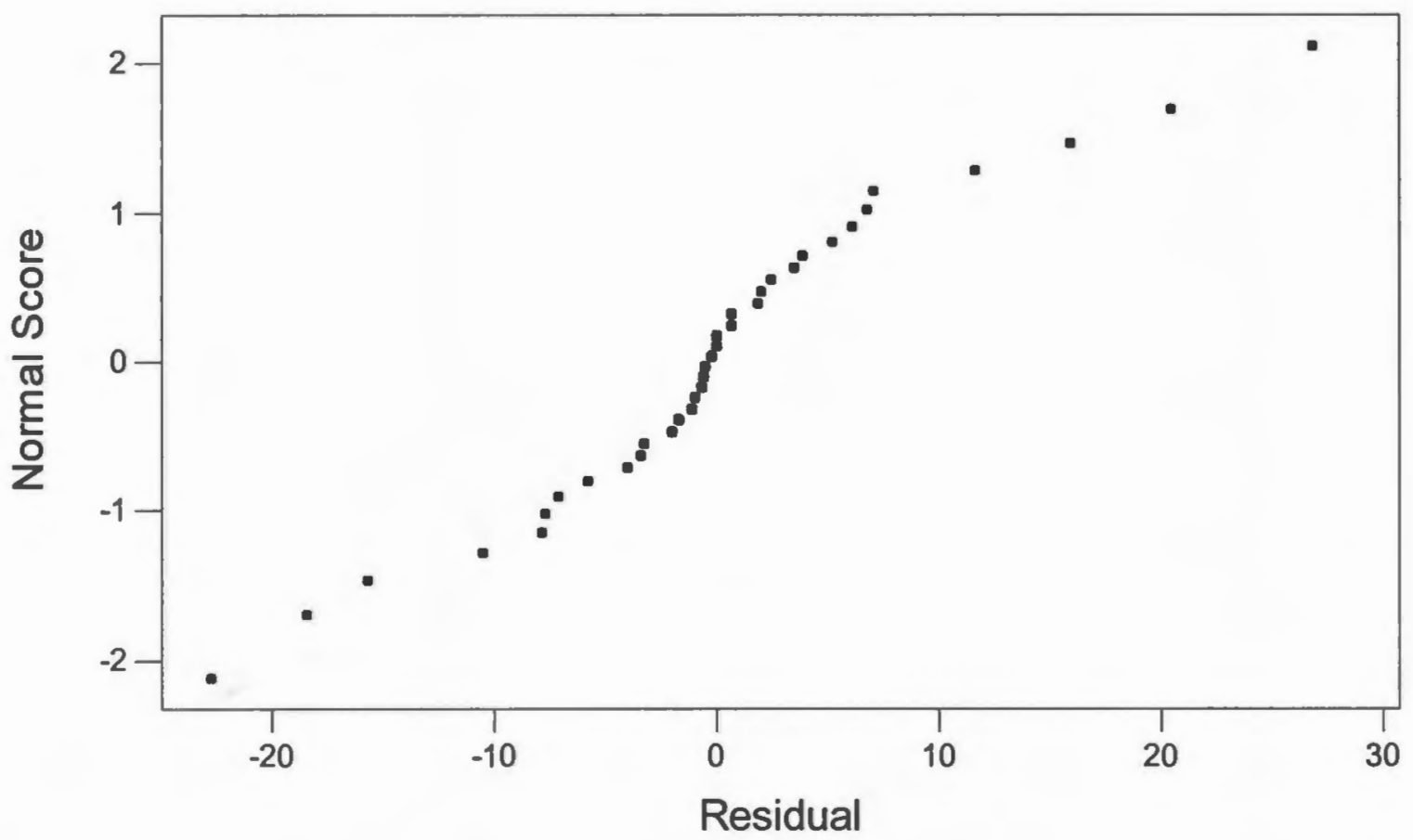

Figure 37: Normal probability plot following an almost normal or linear distribution 


\subsection{Tablet Preparation and Dissolution Studies}

Drug absorption from a solid dosage form after oral administration depends on the release of the drug substance from the drug product, the dissolution or solubilization of the drug under physiological conditions, and the permeability of the gastrointestinal tract. Because of the critical nature of the first two of these steps, in vitro dissolution may be relevant in the prediction of in vivo performance ${ }^{18}$. Based on the statistical analysis of the data obtained from the solubility studies of the microfluidized and recrystallized drug-polymer combinations, it was noticed that the drug in combination with PVP and either of the processes rendered the drug more soluble. However, due to the low yield of the microfluidization process, the recrystallized drug-PVP combination has been used in preparation of the tablets (or compacts) for dissolution studies. The dissolution studies have been performed to ensure that the dissolution profile of the treated drug, in its dosage form, follows USP requirements. The recrystallized drug-PVP combination is also a good choice for the tablet formulation as it not in a totally amorphous form and the stability issues related to the amorphous drug are minimized, when the drug used is in a partially crystalline state. Also the presence of a small amount of polymer acts as crystallization inhibitor, preventing the reconversion of the amorphous form of the drug to its crystalline form. This is evident from the solubility profiles of the treated drug in the absence and presence of polymers, as seen earlier. As the solubility profiles indicated, the stability of this form in the solution state is very high; and the drug would be expected to maintain a high level of solubility over 
the duration of the study. Tablets prepared with the untreated drug serve as a blank. The marketed formulation of cefuroxime axetil, Ceftin Tablets $\circledast$, manufactured by GlaxoSmithKline, was used as a reference for comparison purposes. The tablets prepared with the drug and the drug-PVP combinations contain similar excipients as the marketed formulation.

\subsubsection{Preparation of Tablets (or compacts):}

Tablets of cefuroxime axetil were prepared containing an equivalent of $250 \mathrm{mg}$ of cefuroxime. The total weight of the tablet was fixed at $470 \mathrm{mg}$ (based on the marketed formulation). In addition to the drug, the tablets contained the inactive ingredients colloidal silicon dioxide, croscarmellose sodium (Ac-Di-Sol), microcrystalline cellulose (Avicel), hydroxypropyl methylcellulose, and sodium lauryl sulfate. Tablets were prepared with the untreated drug as well as the recrystallized drug-PVP mixture. In the latter formulation HPMC was omitted due to the presence of PVP. All the powders were sieved through a sieve of mesh size 40. The components of the formulation were mixed according to the formulation (Table 19) for 15 minutes on the rotary shaker. Tablets were prepared by direct compaction on the Carver press at a compression pressure of 1000 lbs. A batch of 20 tablets was prepared for each of the formulations.

\subsubsection{Dissolution studies:}

USP apparatus 2 was used. The apparatus was set to $55 \mathrm{rpm}$. The temperature of the water bath was set to $37 \pm 0.5^{\circ} \mathrm{C}$. Dissolution medium used was $0.07 \mathrm{~N}$ $\mathrm{HCl}$. For the dissolution studies, $900 \mathrm{ml}$ of the dissolution medium was filled in the dissolution flasks and the system was allowed to equilibrate for 30 minutes. 


\begin{tabular}{|c|l|c|c|c|}
\hline Formulation & Ingredients & $\begin{array}{c}\text { Composition } \\
(\%)\end{array}$ & $\begin{array}{c}\text { Composition } \\
(\mathrm{mg} / \text { tablet })\end{array}$ & $\begin{array}{c}\text { Batch of 20 tablets } \\
(\mathrm{gm})\end{array}$ \\
\hline \multirow{2}{*}{$\begin{array}{c}\text { A } \\
\text { (untreated } \\
\text { CA) }\end{array}$} & Cefuroxime axetil & 64.255 & 302 & 6.04 \\
& HPMC & 0.25 & 1.175 & 0.0235 \\
& MCC & 20 & 94 & 1.88 \\
& Croscarmellose sodium & 8.995 & 42.275 & 0.8455 \\
& SLS & 6 & 28.2 & 0.564 \\
& Colloidal silica & 0.5 & 2.35 & 0.047 \\
& & & & \\
B & Cefuroxime axetil + PVP & 72.341 & 340 & 6.8 \\
& MCC & 13.617 & 64 & 1.28 \\
& Croscarmellose sodium & 8.569 & 40.275 & 0.8055 \\
& SLS & 5.149 & 24.2 & 0.484 \\
& Colloidal silica & 0.5 & 2.35 & 0.047 \\
& & & & \\
\hline
\end{tabular}

Table 19: Formulations $\mathrm{A}$ and $\mathrm{B}$ for tablet preparation 
Six tablets weighing approximately $470 \mathrm{mg}$ were selected and placed in each of the six dissolution flasks. Sampling was performed at predetermined time points, namely $5,15,30,45,60,90$ and 120 minutes. At each time interval, 1 $\mathrm{ml}$ of the sample was withdrawn from the dissolution flask and replaced by equivalent amount of fresh dissolution medium at the same temperature. The samples were filtered by centrifugation, $0.5 \mathrm{ml}$ of the filtrate was diluted with $0.5 \mathrm{ml}$ of the mobile phase and the samples were analyzed by HPLC.

\subsection{Results and Discussion:}

The tablets prepared were tested for their drug content and their dissolution profiles were determined based on the above method. The USP limits for content uniformity are as follows, "Cefuroxime axetil tablets should contain the equivalent of not less than 90.0 percent and not more 110.0 percent of the labeled amount of cefuroxime". Six (6) tablets were used to determine the amount of drug present in the tablets. The results for the drug content in the tablets are tabulated in Table 20. As the results indicate, Formulation A contains an average of $97 \%$ and Formulation B contains an average of $99 \%$ of cefuroxime. Hence, both the formulations lie within the USP limits for drug content. The limits for the USP content uniformity have been used as a basis for determining the amount of drug in both the formulations. The dissolution profiles of the tablets prepared from the untreated drug and the drug-PVP mixture are shown in Figure 38. For dissolution, the USP limits state that "not less than $60 \%$ of the labeled amount of cefuroxime is dissolved in 15 minutes, 


\begin{tabular}{|c|c|c|c|c|c|c|c|}
\hline \multirow[b]{2}{*}{ Formulation } & \multirow[b]{2}{*}{$\begin{array}{c}\text { AUC } \\
\text { Isomer B }\end{array}$} & \multirow[b]{2}{*}{$\begin{array}{c}\text { AUC } \\
\text { Isomer A }\end{array}$} & \multicolumn{3}{|c|}{ Cefuroxime Axetil } & \multicolumn{2}{|c|}{ Cefuroxime } \\
\hline & & & $\begin{array}{l}\text { Concentration } \\
\text { Isomer B } \\
(\mathrm{mg} / \mathrm{ml})\end{array}$ & $\begin{array}{c}\text { Concentration } \\
\text { Isomer A } \\
(\mathrm{mg} / \mathrm{ml})\end{array}$ & $\begin{array}{c}\text { Concentration } \\
\text { Total } \\
(\mathrm{mg} / \mathrm{ml}) \\
\text { X }\end{array}$ & $\begin{array}{c}\text { Concentration } \\
\text { Total } \\
(\mathrm{mg} / \mathrm{ml}) \\
X^{\star} 0.83=\mathrm{Y}\end{array}$ & $\begin{array}{c}\text { Percent } \\
(\%) \\
(Y / 250)^{\star} 100\end{array}$ \\
\hline \multirow{7}{*}{$\begin{array}{l}\text { Formulation } \\
\text { A } \\
\text { (untreated } \\
\text { CA) }\end{array}$} & \multirow{7}{*}{$\begin{array}{l}3162192 \\
3016117 \\
3063252 \\
3128591 \\
3045763 \\
3089162\end{array}$} & \multirow{7}{*}{$\begin{array}{c}599854 \\
767811 \\
1020631 \\
651743 \\
857881 \\
1015047\end{array}$} & \multirow{7}{*}{$\begin{array}{l}237.21 \\
226.26 \\
229.79 \\
234.69 \\
228.48 \\
231.74\end{array}$} & \multirow{7}{*}{$\begin{array}{l}45.19 \\
57.77 \\
76.72 \\
48.17 \\
64.52 \\
76.30\end{array}$} & \multirow{7}{*}{$\begin{array}{l}282.39 \\
284.03 \\
306.51 \\
282.86 \\
293.01 \\
308.04\end{array}$} & 234.37 & 93.75 \\
\hline & & & & & & 235.75 & 94.29 \\
\hline & & & & & & 254.41 & 101.76 \\
\hline & & & & & & 234.78 & 93.91 \\
\hline & & & & & & 243.19 & 97.28 \\
\hline & & & & & & 255.67 & 102.27 \\
\hline & & & & & & \multicolumn{2}{|l|}{ Average } \\
\hline \multirow{7}{*}{$\begin{array}{c}\text { Formulation } \\
\text { B } \\
(\mathrm{CA}+\mathrm{PVP})\end{array}$} & \multirow{7}{*}{$\begin{array}{l}2369873 \\
2675032 \\
2442159 \\
2514097 \\
2489156 \\
2513965\end{array}$} & \multirow{7}{*}{$\begin{array}{l}1519100 \\
1447847 \\
1529541 \\
1607521 \\
1439513 \\
1481834\end{array}$} & \multirow{7}{*}{$\begin{array}{l}177.83 \\
200.69 \\
183.25 \\
188.64 \\
186.77 \\
188.63\end{array}$} & \multirow{7}{*}{$\begin{array}{l}114.08 \\
108.74 \\
114.86 \\
120.71 \\
108.11 \\
111.29\end{array}$} & \multirow{7}{*}{$\begin{array}{l}291.91 \\
309.44 \\
298.11 \\
309.34 \\
294.88 \\
299.92\end{array}$} & 242.28 & 96.91 \\
\hline & & & & & & 256.83 & 102.73 \\
\hline & & & & & & 247.43 & 98.97 \\
\hline & & & & & & 256.76 & 102.70 \\
\hline & & & & & & 244.75 & 97.89 \\
\hline & & & & & & 248.93 & 99.57 \\
\hline & & & & & & Average & 99.79 \\
\hline
\end{tabular}

Table 20: Data for the drug content of the tablets for formulations A and B 


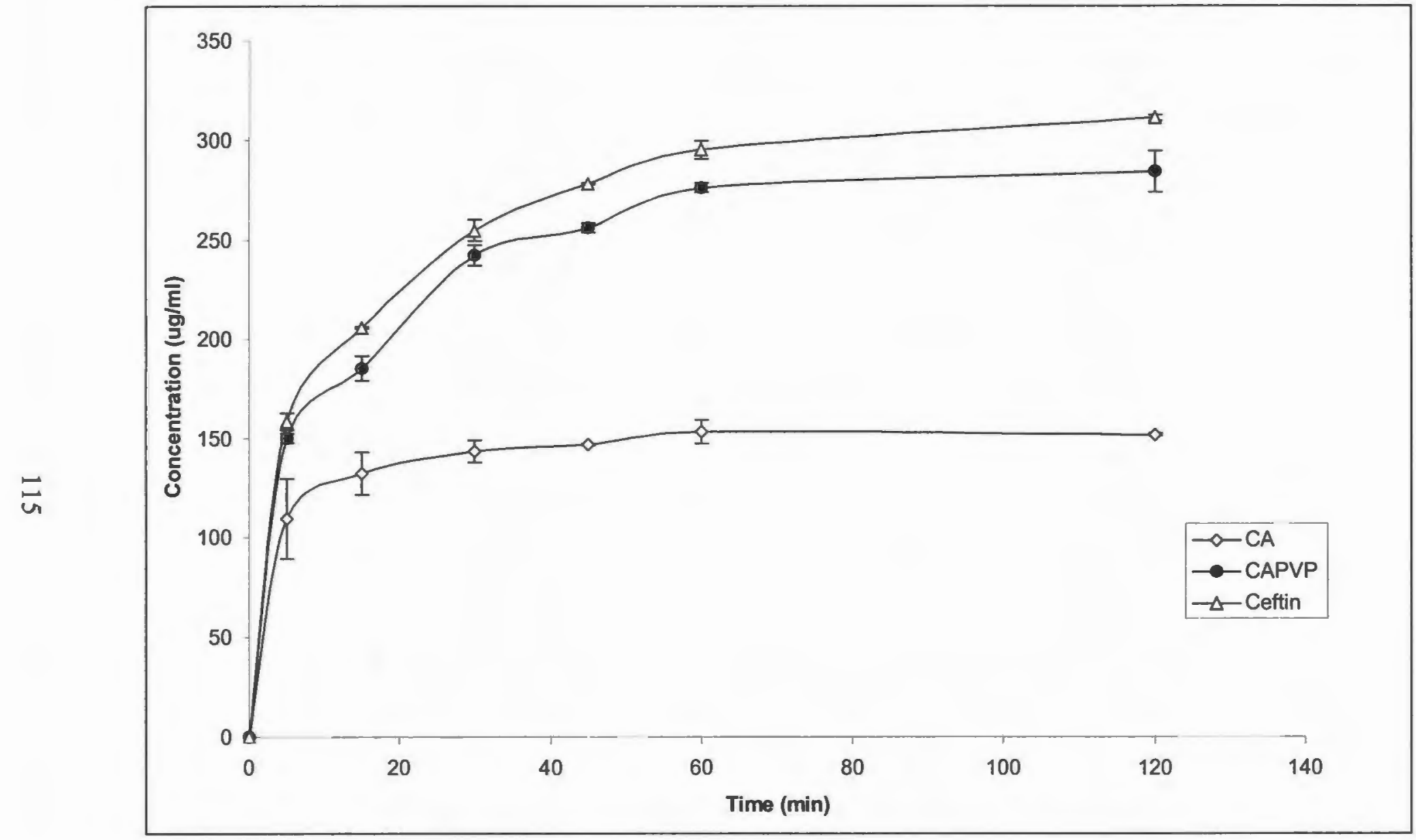

Figure 38: Dissolution profiles (in terms of concentration of cefuroxime axetil) of the tablets prepared from untreated drug (formulation A), drug-PVP mixture (formulation B) and the marketed formulation (Ceftin®) 
and not less than $75 \%$ is dissolved in 45 minutes". The tablets prepared from the drug-PVP mixture show a dissolution profile comparable to that of the marketed formulation (Figure 38). The dissolution profiles in Figure 38 are shown in terms of the concentration of cefuroxime axetil determined over time, whereas in Figure 39, the dissolution profiles are expressed in terms of the

percent cefuroxime dissolved over time. The data for the dissolution profiles of the two formulations (untreated drug and drug-PVP combination) are shown in Table 21. As seen from this data, tablets of formulation A show substantially lower concentrations of cefuroxime at 15 minutes $(109.619 \mu \mathrm{g} / \mathrm{ml})$ and 45 minutes $(121.876 \mu \mathrm{g} / \mathrm{ml}$ ). These concentrations correspond to $43.847 \%$ (at 15 minutes) and $48.75 \%$ (at 45 minutes), and are well below the USP requirements stated above. The tablets prepared from the drug-PVP mixture, on the other hand, show a remarkable increase in concentration at the 15 minute (153.746 $\mu \mathrm{g} / \mathrm{ml})$ and 45 minute $(212.582 \mu \mathrm{g} / \mathrm{ml})$ time points. These tablets conform to the USP dissolution requirements, in that, $61 \%$ dissolves in 15 minutes and $85 \%$ in 45 minutes.

\subsection{Summary:}

The modification of a crystalline drug to its amorphous or partially crystalline form has a significant effect on the solubility of the drug, as evident from this study. The new application of microfluidization, as a means of modifying the crystal structure, has been successfully evaluated. However, studies with other 


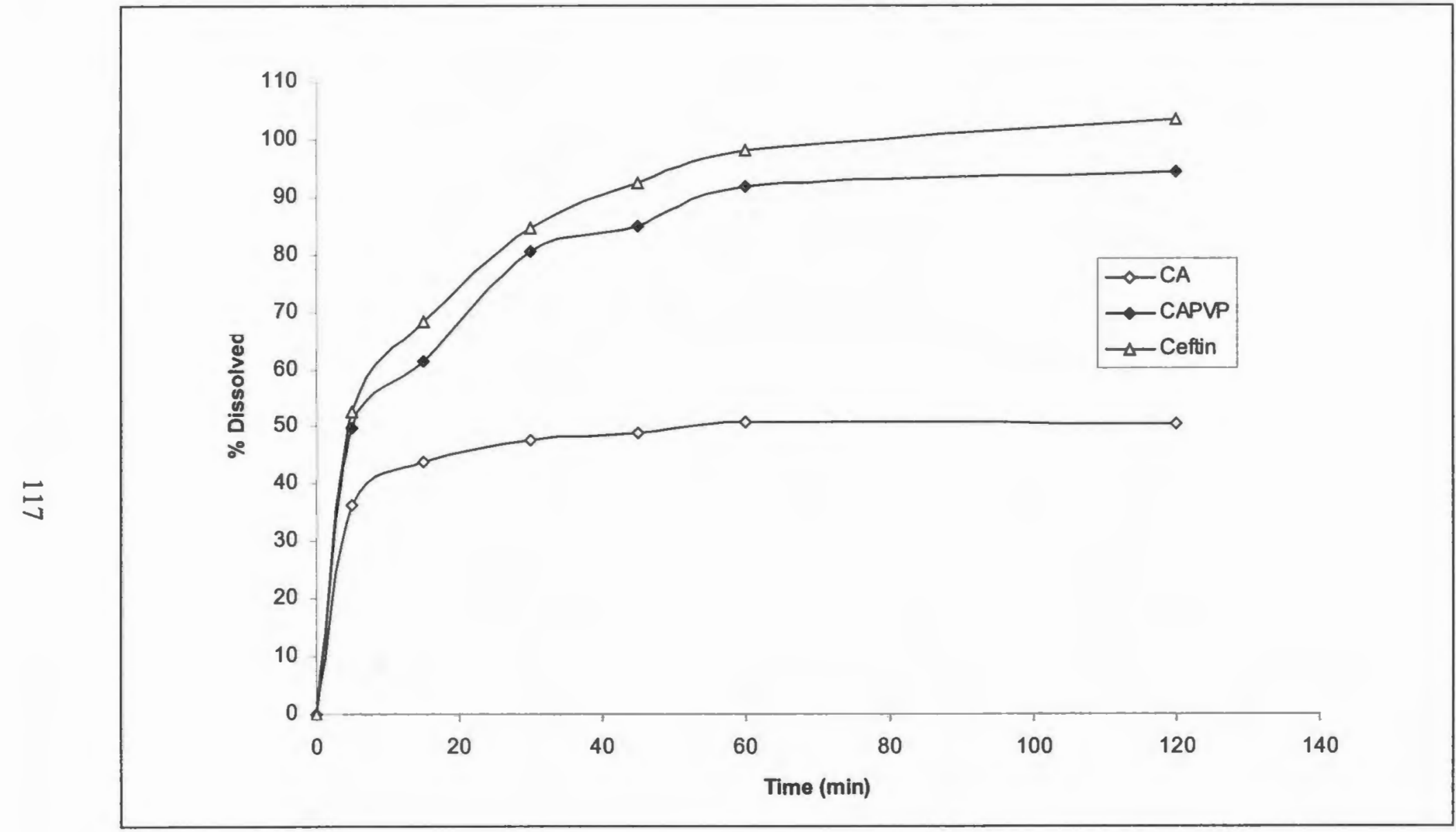

Figure 39: Dissolution profiles (in terms of \% dissolved of cefuroxime) of the tablets prepared from untreated drug (formulation A), drug-PVP mixture (formulation B) and the marketed formulation (Ceftin $®$ ) 


\begin{tabular}{|c|c|c|c|c|}
\hline Formulation & $\begin{array}{c}\text { Time } \\
\text { (min) }\end{array}$ & $\begin{array}{c}\text { Concentration } \\
\text { (Cefuroxime } \\
\text { axetil) X } \\
\text { (ug/ml) }\end{array}$ & $\begin{array}{c}\text { Concentration } \\
\text { (Cefuroxime) } \\
X^{\star} 0.83=Y \\
(\text { ug/ml) }\end{array}$ & $\begin{array}{c}\text { Percent } \\
\text { (Cefuroxime) } \\
(Y / 250)^{*} 100 \\
(\%)\end{array}$ \\
\hline Formulation & 0 & 0 & 0 & 0 \\
A & 5 & 109.53 & 90.91 & 36.37 \\
(untreated & 15 & 132.07 & 109.62 & 43.85 \\
CA) & 30 & 143.43 & 119.04 & 47.62 \\
& 45 & 146.84 & 121.88 & 48.75 \\
& 60 & 153.35 & 127.28 & 50.91 \\
& 120 & 151.72 & 125.93 & 50.37 \\
& & & & \\
\hline Formulation & 0 & 0 & 0 & 0 \\
B & 5 & 150.07 & 124.56 & 49.82 \\
CA + PVP) & 15 & 185.24 & 153.75 & 61.49 \\
& 30 & 242.19 & 201.02 & 80.41 \\
& 45 & 256.12 & 212.58 & 85.03 \\
& 60 & 276.31 & 229.34 & 91.74 \\
& 120 & 284.38 & 236.04 & 94.41 \\
& & & & \\
\hline
\end{tabular}

Table 21: Data for the dissolution of tablets for formulations A and B 
drugs need to be carried out to substantiate the results of this investigation and to emphasize the importance of this approach towards the development of a more stable amorphous form.

The results of this investigation can be summarized as follows:

1. Microfluidization can be effectively used as a means of converting a crystalline drug to its amorphous form.

2. Polymers used in this study efficiently serve the purposes they were employed for, namely, assisting in improving the solubility of the drug, acting as impurities to destabilize the rigid crystal structure, and as crystallization inhibitors, preventing reconversion of the amorphous drug to its crystalline form.

3. Different process-polymer combinations show different effects on the individual isomers of the drug.

4. PVP was the better polymer among the three polymers used in this study.

5. Tablets/compacts prepared from the drug-polymer mixture exhibit dissolution profiles in accordance to the USP limits. 


\section{References:}

1) Nguyen NAT. The relationship of diastereomer hydrolysis kinetics for shelf-life predictions for cefuroxime axetil. Pharmaceutical Research, $1991,8(7), 893-898$.

2) Al-Meshal M, York P, Grant DJW. Disruptant effects of surfactant molecules incorporated into phenylbutazone crystals. Journal of Pharmacy and Pharmacology, 1985, 37, 58P.

3) Kawashima Y, Handa T, Takeuchi H, Okumura M, Katou H, Nagata O. Crystal modification of phenytoin with polyethylene glycol for improving mechanical strength, dissolution rate and bioavailability by a spherical crystallization technique. Chemical and Pharmaceutical Bulletin, 1986, $34,3376-3383$.

4) Michaels AS, Tausch FWJ. Modification of growth rate and habit of adipic acid crystals with surfactants. Journal of Physical Chemistry, 1961, $65,1730-1737$.

5) Sato T, Okada A, Sekiguchi K, Tsuda Y. Difference in physicopharmaceutical properties between crystalline and non-crystalline 9,3 "diacetylmidecamycin. Chemical and Pharmaceutical Bulletin, 1981, 29, $2675-2682$.

6) Hancock BC, Parks M. What is the true solubility advantage for amorphous pharmaceuticals? Pharmaceutical Research, 2000, 17 (4), 397-404. 
7) Corrigan OI, Holohan EM, Sabra K. Amorphous forms of thiazide diuretics prepared by spray drying. International Journal of Pharmaceutics, 1984, 18, 195-200.

8) Eudragit@ versatile polymers for solid oral dosage formulations, Eudragit technical Bulletin, Rohm America.

9) Plasdone ${ }^{\circledR}$ povidone USP, Technical Profile, ISP (International Specialty Products) Technologies, Inc.

10) M-110S Microfluidizer processor, Equipment Information, Microfluidics $^{\mathrm{TM}}$.

11) Martin A. Physical Pharmacy, 1993, 6 ${ }^{\text {th }}$ Edition, Lea and Febiger, Malvern, PA.

12) Hancock BC, Zografi G. Characteristics and significance of the amorphous state in pharmaceutical systems. Journal of Pharmaceutical Sciences, 1997, 86 (1), 1-12.

13) Saleki-Gerhardt A. Role of water in the solid-state properties of crystalline and amorphous sugars. Ph.D. Thesis, University of WisconsinMadison, 1993.

14) Saleki-Gerhardt A, Ahlneck C, Zografi G. Assessment of disorder in crystalline solids. International Journal of Pharmaceutics, 1994, 101, $237-247$.

15) Saleki-Gerhardt A, Zografi G. Non-isothermal and isothermal crystallization of sucrose from the amorphous state. Pharmaceutical Research, 1194, 11 (8), 1166-1173. 
16) York P, Grant DJW. A disruption index for quantifying the solid state disorder induced by additives or impurities. I. Definition and evaluation from heat of fusion. International Journal of Pharmaceutics, 1985, 25, 57-72.

17) Montgomery DC. Design and Analysis of Experiments, $1997,5^{\text {th }}$ Edition, John Wiley and Sons, Inc.

18) Leuner C, Dressman J. Improving drug solubility for oral delivery using solid dispersions. European Journal of Pharmaceutics and Biopharmaceutics, 2000, 50, 47-60. 


\section{BIBILIOGRAPHY}

Aguiar AJ, Kro J, Kinkle AW, Samyn J. Effect of polymorphism on the absorption of chloramphenicol from chloramphenicol palmitate. Journal of Pharmaceutical Sciences, 56 (7): 847-53 (1967).

Al-Meshal M, York P, Grant DJW. Disruptant effects of surfactant molecules incorporated into phenylbutazone crystals. The Journal of Pharmacy and Pharmacology, 37: 58 (1985).

Black DB, Lovering EG. Estimation of the degree of crystallinity in digoxin by X-ray and infrared methods. Journal of Pharmacy and Pharmacology, 29 (11): 684-7 (1977).

Boldyrev VV, Bulens M, Delmon B. The Control of the Reactivity of Solids, Studies in Surface Science and Catalysis, Volume 2, Elsevier, Amsterdam (1979).

Borka L. Review on crystal polymorphism of substances in the European Pharmacopoeia. Pharmaceutica Acta Helvetia, 66: 16-22 (1991).

Borka L, Haleblian JK. Crystal polymorphism of pharmaceuticals. Acta Pharmaceutica Jugosl, 40: 71-94 (1990). 
Burt HM, Mitchell AG. Crystal defects and dissolution. International Journal of Pharmaceutics, 9: 137-152 (1981).

Byrn SR. Solid State Chemistry of Drugs. Academic Press, New York (1982).

Carpenter JF. Interactions of stabilizers with proteins during freezing and drying. Formulation and Delivery of Proteins and Peptides ACS, Washington DC, 134-147 (1994).

Cefuroxime axetil: a new oral cephalosporin. Drug and Therapeutics Bulletin, 27 (2): 5-7 (1989).

Chan HK, Grant DJW. Influence of compaction on the intrinsic dissolution rate of modified acetaminophen and adipic acid crystals. International Journal of Pharmaceutics, 57: 117-124 (1989).

Chiou WL, Kyle LE. Differential thermal, solubility, and aging studies on various sources of digoxin and digitoxin powder: biopharmaceutical implications. Journal of Pharmaceutical Sciences, 68(10): 1224-1229 (1979).

Chiou WL, Riegelman S. Pharmaceutical applications of solid dispersion systems. Journal of Pharmaceutical Sciences, 60 (9): 1281-1302 (1971). 
Chow AHL, Chow PKK, Zhongshan W, Grant DJW. Modification of acetaminophen crystals: influence of growth in aqueous solutions containing p-acetoxyacetanilide on crystal properties. International Journal of Pharmaceutics, 24: 239-258 (1985).

Chow AHL, Gordon JD, Szeitz A, Young JWM. Modification of phenytoin crystals. III. Influence of 3-butanoyloxymethyl-5,5-diphenylhydantoin on solution-phase crystallization and related crystal properties. International Journal of Pharmaceutics, 126: 11-19 (1995).

Chow AHL, Grant DJW. Modification of acetaminophen crystals. II. Influence of stirring rate during solution-phase growth on crystal properties in the presence and absence of p-acetoxyacetanilide. International Journal of Pharmaceutics, 41: 29-39 (1988).

Chow AHL, Grant DJW. Modification of acetaminophen crystals. III. Influence of initial supersaturation during solution-phase growth on crystal properties in the presence and absence of p-acetoxyacetanilide. International Journal of Pharmaceutics, 42: 123-133 (1988).

Chow AHL, Grant DJW. Influence of crystallization conditions on the physical properties of acetaminophen crystals: evaluation by multiple linear regression. International Journal of Pharmaceutics, 51: 115-127 (1989). 
Chow AHL, Grant DJW. Physical factors influencing the aqueous dissolution rate of acetaminophen crystals doped with p-acetoxyacetanilide: evaluation by multiple linear regression. International Journal of Pharmaceutics, 51: 129135 (1989).

Chow AHL, Hsia CK. Modification of phenytoin crystals: influence of 3acetoxymethyl-5,5-diphenylhydantoin on solution-phase crystallization and related crystal properties. International Journal of Pharmaceutics, 75: 219230 (1991).

Chow AHL, Hsia CK, Gordon JD, Young JWM, Vargha-Butler EI. Assessment of wettability and its relationship to the intrinsic dissolution rate of doped phenytoin crystals. International Journal of Pharmaceutics, 126: 21-28 (1995).

Chow KY, Go J, Mehdizadeh M, Grant DJW. Modification of adipic acid crystals: influence of growth in the presence of fatty acid additives on crystal properties. International Journal of Pharmaceutics, 20: 3-24 (1984).

Corrigan OI, Holohan EM, Sabra K. Amorphous forms of thiazide diuretics prepared by spray-drying. International Journal of Pharmaceutics, 18: 195200 (1984). 
Crowe JH, Carpenter JF, Crowe LM. The role of vitrification in anhydrobiosis. Annual Review of Physiology, 60: 73-103 (1998).

Donn KH, James NC, Powell JR. Bioavailability of cefuroxime axetil formulations. Journal of Pharmaceutical Sciences, 83 (6): 842-844 (1994).

Duddu SP, Fung FKY, Grant DJW. Effect of the opposite enantiomer on the physicochemical properties of (-)-ephedrinium 2-naphthalenesulfonate crystals. International Journal of Pharmaceutics, 94: 171-179 (1993).

Duddu SP, Fung FKY, Grant DJW. Effect of crystallization in the presence of the opposite enantiomer on the crystal properties of (SS)-(+)pseudoephedrinium salicylate. International Journal of Pharmaceutics, 127: 53-63 (1996).

Duddu SP, Grant DJW. The use of thermal analysis in the assessment of crystal disruption. Thermochimica Acta, 248: 131-145 (1995).

Duncan-Hewitt WC, Grant DJW. True density and thermal expansivity of pharmaceutical solids: comparison of methods and assessment of crystallinity. International Journal of Pharmaceutics, 28: 75-84 (1986). 
Egawa H, Maeda S, Yonemochi E, Oguchi T, Yamamoto K, Nakai Y.

Solubility parameter and dissolution behaviour of cefalexin powders with different crystallinity. Chemical and Pharmaceutical Bulletin, 40: 819-820 (1992).

El-Said Y. Effect of cosolvents on water content and physical properties of acetaminophen crystallized from aqueous solutions. Journal of Pharmaceutical Sciences, 5: 232-237 (1995).

Fabre H, lbork H, Lerner DA. Photoisomerization kinetics of cefuroxime axetil and related compounds. Journal of Pharmaceutical Sciences, 83 (4): 553-558 (1994).

Fairbrother JE, Grant DJW. Crystal engineering studies with and excipient material (adipic acid). Journal of Pharmacy and Pharmacology, 31: 27P (1979).

Findlay A. The Phase Rule, $5^{\text {th }}$ Edition, Dover, New York (1951).

Finn A, Straughn A, Meyer M, Chubb J. Effect of dose and food on the bioavailability of cefuroxime axetil. Biopharmaceutics and Drug Disposition, 8: 519-526 (1987). 
Ford JL. The current status of solid dispersions. Pharmaceutica Acta Helvetiae, 61 (3): 69-88 (1986).

Garraffo R, Drugeon HB, Chiche D. Pharmacokinetics and pharmacodynamics of two oral forms of cefuroxime axetil. Fundamentals of Clinical Pharmacology, 11: 90-95 (1997).

Gennaro AR. Remington's Pharmaceutical Sciences. Mack Publishing Company, Pennsylvania (1990).

Giron D. Thermal analysis and calorimetric methods in the characterization of polymorphs and solvates. Thermochimica Acta, 248: 1-59 (1995).

Glaxo Wellcome Inc. Cefuroxime axetil. Product information data sheet, Research Triangle Park, North Carolina, USA (2000).

Go J, Grant DJW. Locating the impurity in doped crystals using the isotopic double labeling and a column "flow-through" dissolution cell: adipic acid doped with oleic acid. International Journal of Pharmaceutics, 36: 17-28 (1987).

Goldberg AH, Gibaldi M, Kanig JL. Increasing dissolution rates and gastrointestinal absorption of drugs via solid solutions and eutectic mixtures I 
- theoretical considerations and discussion of the literature. Journal of Pharmaceutical Sciences, 54: 1145-1148 (1965).

Goldberg AH, Gibaldi M, Kanig JL. Increasing dissolution rates and gastrointestinal absorption of drugs via solid solutions and eutectic mixtures II - experimental evaluation of a eutectic mixture: urea-acetaminophen system. Journal of Pharmaceutical Sciences, 55: 482-487 (1966).

Goldberg AH, Gibaldi M, Kanig JL, Mayersohn M. Increasing dissolution rates and gastrointestinal absorption of drugs via solid solutions and eutectic mixtures. IV. Chloramphenicol--urea system. Journal of Pharmaceutical Sciences, 55 (6): 581-583 (1966).

Gordon JD, Chow AHL. Modification on phenytoin crystals. II. Influence of 3-propanoyloxymethyl-5,5-diphenylhydantoin on solution-phase crystallization and related crystal properties. International Journal of Pharmaceutics, 79: 171-181 (1992).

Grant DJW. Theory and origin of polymorphism, in: Brittain HG. Polymorphism in Pharmaceutical Solids, Vol. 95, Marcel Dekker, New York (1999). 
Haleblian JK, McCrone WC. Pharmaceutical applications of polymorphism. Journal of Pharmaceutical Sciences, 58: 911-929 (1969).

Hancock BC, Parks M. What is the true solubility advantage for amorphous pharmaceuticals? Pharmaceutical Research, 17 (4): 397-404 (2000).

Hancock BC, Zografi G. Characteristics and significance of the amorphous state in pharmaceutical systems. Journal of Pharmaceutical Sciences, 86 (1): 1-12 (1997).

Hatley RHM. Glass fragility and the stability of pharmaceutical preparations - excipients selection. Pharmaceutical Development and Technology, 2: 257264 (1997).

Higuchi WI, Lau PK, Higuchi T, Shell JW. Polymorphism and drug availability. Solubility relations in the methylprednisolone system. Journal of Pharmaceutical Sciences, 52: 150-153 (1963).

Hoerter D, Dressman JB. Influence of physicochemical properties on dissolution of drugs in the gastrointestinal tract. Advanced Drug Delivery Reviews, 25: 3-14 (1997). 
Huttenrauch R. Molecular pharmaceutics as a basis for modern drug formulation. Acta Pharmaceutica Technology Supplement, 6, 55-127 (1978).

Izutsu $\mathrm{K}$, Yoshioka S, Terao T. Effect of mannitol crystallinity on the stabilization of enzymes during freeze-drying. Chemical and Pharmaceutical Bulletin, 42: 5-8 (1994).

Kawashima Y, Handa Teturou, Takeuchi H, Okumura M, Katou H, Nagata O. Crystal modification of phenytoin with polyethylene glycol for improving mechanical strength, dissolution rate and bioavailability by a spherical crystallization technique. Chemical and Pharmaceutical Bulletin, 34 (8): $3376-3383$ (1986).

Kim AI, Akers MJ, Nail SL. The physical state of mannitol after freezedrying: effects of mannitol concentration, freezing rate, and a non-crystalline cosolute. Journal of Pharmaceutical Sciences, 87: $931-935$ (1998).

Kopp S, Beyer C, Graf E, Kubel F, Doelker E. Methodology for a better evaluation of the relation between mechanical strength of solids and polymorphic form. Journal of Pharmacy and Pharmacology, 41: 79-82 (1989). 
Kuhnert-Brandstatter M. Thermomicroscopy in the Analysis of Pharmaceuticals, Pergamon, Oxford (1971).

Law D, El-Said Y, Grant DJW. Influence of the crystallization medium on liquid inclusions in adipic acid crystals. Agglomeration and size enlargement: a symposium in the First International Particle Technology Forum of the AIChE, Denver, CO. American Institute of Chemical Engineers, 389-399 (1994).

Leuner C, Dressman J. Improving drug solubility for oral delivery using solid dispersions. European Journal of Pharmaceutics and Biopharmaceutics, 50: $47-60(2000)$.

Li ZJ, Grant DJW. Effects of excess enantiomer on the crystal properties of a racemic compound: ephedrinium 2-naphthalenesulfonate. International Journal of Pharmaceutics, 137: 21-31 (1996).

Loftsson T, Brewster ME. Pharmaceutical application of cyclodextrins. I. Drug solubilization and stabilization. Journal of Pharmaceutical Sciences, 85: 1017-1025 (1996). 
Longuemard P, Jbilou M, Guyot-Hermann AM, Guyot JC. Ground and native crystals: comparison of compression capacity and dissolution rate. International Journal of Pharmaceutics, 170: 51-61 (1998).

Lorenzo-Lamosa M. L., Cuna M., Vila-Jato J. L., Torres D., Alonso M. J. Development of a microencapsulated form of cefuroxime axetil using $\mathrm{pH}$ sensitive acrylic polymers. Journal of Microencapsulation, 14: 607-616 (1997).

Martin A. Physical Pharmacy, $4^{\text {th }}$ Edition, Lea and Febiger (1993).

Motyl MS, Wisniewska I, Gumulka W, Oszczapowicz I, Szelachowska M, Interewicz B. Esters of cephalosporins. Part I. Permeability of cefuroxime liberated from its 1-acetoxyethyl ester through biological membranes; influence of the form and size of the ester particles. Acta Poloniae Pharmaceutica - Drug Research, 52 (5): 391-395 (1995).

Mullin JW. Crystallization, $3^{\text {rd }}$ Edition, Butterworth Heinemann, Oxford (1993)

Nguyen NAT. The relationship of diastereomer hydrolysis kinetics to shelflife predictions for cefuroxime axetil. Pharmaceutical Research, 8 (7): 893898 (1991). 
Noyes AA, Whitney WR. The rate of solution of solid substances in their own solutions. Journal of the American Chemical Society, 19: 930-934 (1897).

Nozawa Y, Mizumoto T, Higashide F. Increases in dissolution rate of nifedipine by roll mixing with polyvinylpyrrolidone. Pharmaceutica Acta Helvetiae, 61: 337-341 (1986)

Oszczapowicz I, Malafiej E, Malafiej AH, Szelachowska M, Kuklewicz C, Sieranska E. Esters of cephalosporins. Part III. Separation and properties of the $\mathrm{R}$ and $\mathrm{S}$ isomers of the 1-acetoxyethyl ester of cefuroxime. Acta Poloniae Pharmaceutica - Drug Research, 52 (6): 471-476 (1995).

Oszczapowicz I, Malafiej E, Szelachowska M, Malafiej AH, Kuklewicz C, Sieranska E, Denys A, Niedworok J. Esters of cephalosporins. Part II. Differences in the properties of various forms of the 1-acetoxyethyl ester of cefuroxime. Acta Poloniae Pharmaceutica - Drug Research, 52 (5): 397-401 (1995).

Oszczapowicz I, Tejchman B, Zimniak A, Oszczapowicz J. Esters of cephalosporins. Part VI. Properties of the $\beta$-form of 1 -acetoxyethyl ester of cefuroxime. Acta Poloniae Pharmaceutica - Drug Research, 55 (3): 197-204 (1998). 
Perry CM, Brogden RN. Cefuroxime axetil $-\mathrm{A}$ review of its antibacterial activity, pharmacokinetic properties and therapeutic efficacy. Drug Evaluation, 52 (1): 125-158 (1996).

Perry CM, Brogden RN. Cefuroxime axetil. A review of its antibacterial activity, pharmacokinetic properties and therapeutic efficacy. Drugs, 52: 125$158(1996)$.

Pikal M. Freeze drying of proteins: process, formulation and stability. Formulation and Delivery of Proteins and Peptides, American Chemical Society, Washington DC, 20-133 (1994).

Pikal MJ, Grant DJW. A theoretical treatment of changes in energy and entropy of solids caused by additives or impurities in solid solution. International Journal of Pharmaceutics, 39: 243-253 (1987).

Pramar Y, Das Gupta V, Bethea C, Zeria T. Stability of cefuroxime axetil in suspensions. Journal of Clinical Pharmacy and Therapeutics, 16: 341-344 (1991).

Prasad KVR, Ristic RI, Sheen DB, Sherwood JN. Crystallization of paracetamol from solution in the presence and absence of impurity. International Journal of Pharmaceutics, 215: 29-44 (2001). 
Read WT. Dislocations in Crystals, McGraw Hill, New York (1953).

Robson HJ, Craig DQM, Deutsch D. An investigation into the release of cefuroxime axetil from taste-masked stearic acid microspheres. Part I. The influence of the dissolution medium on the drug release profile and the physical integrity of the microspheres. International Journal of Pharmaceutics, 190: 183-192 (1999).

Robson HJ, Craig DQM, Deutsch D. An investigation into the release of cefuroxime axetil from taste-masked stearic acid microspheres. Part II. The effects of buffer composition on drug release. International Journal of Pharmaceutics, 195: 137-145 (2000).

Robson HJ, Craig DQM, Deutsch D. An investigation into the release of cefuroxime axetil from taste-masked stearic acid microspheres. Part III. The use of DSC and HSDSC as means of characterizing the interaction of the microspheres with buffered media. International Journal of Pharmaceutics, 201: 211-219 (2000).

Roy RJ. Non Crystalline Solids, 3: 33-40 (1970). 
Ruiz-Balaguer N, Nacher A, Casabo VG, Merino M. Nonlinear intestinal absorption kinetics of cefuroxime axetil in rats. Antimicrobial Agents and Chemotherapy, 41 (2): 445-448 (1997).

Ruiz-Carretero P., Nacher A., Merino-Sanjuan M., Casabo V. G. Pharmacokinetics and absolute bioavailability of oral cefuroxime axetil in the rat. International Journal of Pharmaceutics, 202: 89-96 (2000).

Sato T, Okada A, Sekiguchi K, Tsuda $\mathrm{Y}$. Difference in physicopharmaceutical properties between crystalline and non-crystalline 9,3"diacetylmidecamycin. Chemical and Pharmaceutical Bulletin, 29: 2675-2682 (1981).

Sekiguchi K, Obi N. Studies on absorption of eutectic mixture. I. A comparison of the behavior of eutectic mixture of sulfathiazole and that of ordinary sulfathiazole in man. Chemical and Pharmaceutical Bulletin, 9: 866872 (1961).

Serajuddin ATM. Solid dispersion of poorly water-soluble drugs: early promises, subsequent problems, and recent breakthroughs. Journal of Pharmaceutical Sciences, 88: 1058-1066 (1999). 
Shah JC, Chen JR, Chow D. Metastable polymorph of etoposide with higher dissolution rate. Drug Development and Industrial Pharmacy, 25 (1): 63-67 (1999).

Shalaev EY, Lu Q, Shalaeva M, Zografi G. Acid-catalyzed inversion of sucrose in the amorphous state at very low levels of residual water. Pharmaceutical Research, 17: 366-370 (2000).

Stoeckel K, Hofheinz W, Laneury JP, Duchene P, Shedlofsky S, Blouin RA. Stability of cephalosporin prodrug esters in human intestinal juice: implications for oral bioavailability. Antimicrobial Agents and Chemotherapy, 42 (10): 2602-2606 (1998).

Sullivan M. Cefuroxime axetil (Drug information update: Hartford Hospital). Connecticut Medicine, 52 (11): 667-669 (1988).

Sun WQ, Davidson P, Chan HSO. Protein stability in the amorphous carbohydrate matrix: relevance to anhydrobiosis. Biochimica et Biophysica Acta, 1425: 245-254 (1998).

Tejchman B., Jarominska M., Horodecka M., Oszczapowicz I. Esters of cephalosporins. Part IV. Hydrolysis of 1-acetoxyethyl ester of cefuroxime in 
vitro and in vivo. Acta Poloniae Pharmaceutica - Drug Research, 52 (6): 477-482 (1995).

Verma AR, Krisha P. Polymorphism and Polytypism in Crystals, Wiley, New York (1966).

Vippagunta SR, Brittain HG, Grant DJW. Crystalline solids. Advanced Drug Delivery Reviews 2001, 48: 3-26 (2001).

Wang D, Notari RE. Cefuroxime hydrolysis kinetics and stability prediction in aqueous solution. Journal of Pharmaceutical Sciences, 83 (4): 577-581 (1994).

Ward GH, Schultz RK. Process-induced crystallinity changes in albuterol sulfate and its effect on powder physical stability. Pharmaceutical Research, 12 (5): $773-779$ (1995).

Weisinger-Lewin Y, Frolow F, McMullan RK, Koetzle TF, Lahav M, Leiserowitz L. Reduction in crystal symmetry of a solid solution: A neutron diffraction study at $15 \mathrm{~K}$ of the host/guest system asparagines/aspartic acid. Journal of the American Chemical Society, 111: 1035-1040 (1989). 
Weissbuch I, Addadi L, Berkovitch-Yellin Z, Gati E, Weinstein S, Lahav M, Leiserowitz L. Centrosymmetric crystals for the direct assignment of the absolute configuration of chiral molecules. Application to the $\alpha$-amino acids by their effect on glycine crystals. Journal of the American Chemical Society, 105, 6615-6621 (1983).

Wright JD. Molecular Crystals, Cambridge University Press, Cambridge (1987).

Yalkowsky SH. Techniques of Solubilization of Drugs (Drugs and the Pharmaceutical Sciences), Volume 12: Marcel Dekker Inc (1981).

York P, Grant DJW. A disruption index for quantifying the solid state disorder induced by additives or impurities. I. Definition and evaluation from heat of fusion. International Journal of Pharmaceutics, 25: 57-72 (1985).

Yoshioka M, Hancock BC, Zografi G. Crystallization of indomethacin from the amorphous state below and above its glass transition temperature. Journal of Pharmaceutical Sciences, 83(12): 1700-5 (1994).

Yu L. Amorphous pharmaceutical solids: preparation, characterization and stabilization. Advanced Drug Delivery Reviews, 48: 27-42 (2001). 
Zhang GGZ, Grant DJW. Incorporation mechanism of guest molecules in crystals: solid solution or inclusion? International Journal of Pharmaceutics, 181: $61-70(1999)$. 